

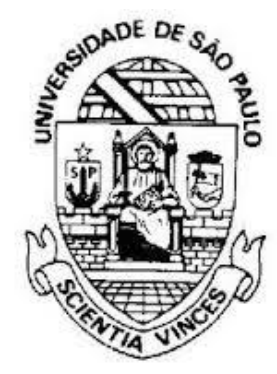

UNIVERSIDADE DE SÃO PAULO

INSTITUTO DE PSICOLOGIA

PROGRAMA DE PÓS-GRADUAÇÃO EM PSICOLOGIA EXPERIMENTAL

EFEITO DE CONTRASTE NA RESPOSTA OCULAR:

AVALIAÇÃO DE UM PROCEDIMENTO.

SÃO PAULO - SP

JULIO de 2017 


\section{EFEITO DE CONTRASTE NA RESPOSTA OCULAR: AVALIAÇÃO DE UM PROCEDIMENTO.}

Dissertação de mestrado apresentada ao Programa de Pós-Graduação em Psicologia Experimental da Universidade de São Paulo como parte dos requisitos necessários à obtenção do título de Mestre em Psicologia Experimental.

Área de concentração:

Psicologia Experimental

Orientadora:

Profa. Dra. Jaroslava Varella Valentova

São Paulo

JULIO 2017 
AUTORIZO A REPRODUÇÃO E DIVULGAÇÃO TOTAL OU PARCIAL DESTE TRABALHO POR QUALQUER MEIO CONVENCIONAL OU ELETRÔNICO, PARA FINS DE ESTUDO E PESQUISA, DESDE QUE CITADA A FONTE.

Catalogação na Publicação

Biblioteca Dante Moreira Leite

Instituto de Psicologia da Universidade de São Paulo

Saavedra Moreno, Adriana.

Efeito de contraste na resposta ocular: avaliação de um procedimento.

/Adriana Saavedra Moreno; orientadora Jaroslava Varella Valentova.

- São Paulo, 2017

XXf.

Dissertação (Mestrado - Programa de Pós-Graduação em Psicologia. Área de Concentração: Psicologia Experimental) - Instituto de Psicologia da Universidade de São Paulo.

1. Contraste Sucessivo 2. Aprendizagem por discriminação. 3. Eyetracking. 4. Rastreamento Ocular. 5. Humanos I. Título 
Dissertação financiada pela Coordenação de Aperfeiçoamento de Pessoal de Nível Superior com bolsa de Mestrado concedida a Adriana Saavedra Moreno (processo $\mathrm{N}^{\mathrm{o}}$ XXXXXX/2010-0). A pesquisa foi desenvolvida no Instituto de Psicologia da Universidade de São Paulo, com recursos da CAPES (Processo $N^{\circ}$ xxxxxx/2008-7). 
Nome: Adriana Saavedra Moreno.

Título: Efeito de contraste na resposta ocular: avaliação de um procedimento.

Dissertação apresentada ao Instituto de Psicologia da Universidade de São Paulo como parte do requisito para obtenção do título de Mestre em Psicologia.

Aprovado em:

Banca Examinadora.

$\operatorname{Prof}(a)$.

$\operatorname{Dr}(\mathrm{a})$

Instituição:

Assinatura:

$\operatorname{Prof}(a)$.

Dr(a)

Instituição:

Assinatura:

Prof(a).

Dr(a)

Instituição: Assinatura: 
A mis papás, María Edith y Eduardo, y a mi hermano. 


\section{Agradecimentos}

Meus agradecimentos vão para minha família, pelo apoio, por ser o amor que não termina... e por tudo.

Para meus colegas na Colombia. Saudades de ustedes.

Para o Instituto de Psicologia e seus funcionários, por ser o lugar de trabalho dos últimos anos.

Para os colegas brasileiros com quem me descobri menos behaviorista do que eu achava, e por aguentar meus papos cognitivistas e de cachorros salivando.

Para os colegas estrangeiros que conheci no Brasil: Estamos together ici, galera!

Para os amigos da Física, por me fazer sentir uma Penny-Amy da vida.

Para GV, o programador que materializou minhas ideias, em tempo record e com baixo orçamento. Não esquecerei o momento em que testamos o programa e descobrimos que funcionou! NASA feelings.

Para a participante, CS, por ser um bom sujeito experimental

Para as pessoas que conheci no CRUSP, por andar na vereda de SP e pelo convívio tipo OITNB mais ameno.

Para o pessoal do Remo, Corinthians de Futebol e regatas. Para o pessoal da Ioga do CEPE. Porque "Mens sana in corpore sano". Agora posso correr $10 \mathrm{~km} / \mathrm{hr}$ numa boa.

Para CAPES e as políticas de educação, pesquisa e desenvolvimento brasileiras. Latino américa está aparecendo no mapa da Ciência com vocês... por enquanto \#ForaTemer

Para ANPG (Associação Nacional de Pós-graduandos), por me fazerem sentir menos sozinha no longo caminho que andamos na vida acadêmica não reconhecida.

Para Jaroslava, porque agora estou na sua sala, terminando de escrever um documento que parecia impossível. Teve várias oportunidades para desistir. No meio de um naufrágio, pedi para não me deixar afogar, e ela respondeu... desculpa pela água que respingou, você não tinha porque oferecer sua ajuda.... Por sua companhia neste Processo Kafkiano de monstruosos moinhos de vento quixotescos, agradeço!. Espero que a vida me deixe fazer por alguém mais o que você fez por mim. 
Vou te contar Os olhos já não podem ver Coisas que só o coração pode entender Fundamental é mesmo o amor É impossível ser feliz sozinho

(Tom Jobim) 


\section{Resumo}

O Contraste Sucessivo é um dos paradigmas experimentais que modelam a experiencia de perda. Nele, os organismos deixam de estarem expostos à eventos reforçadores, apetitivos e/ou preferidos para entrarem em contato com outros de menor qualidade ou valor. Isto resulta numa série de estratégias comportamentais caracterizadas por um importante componente emocional, uma diminuição na execução da resposta (consumatória ou operante) que não está mais correlacionada com a consequência, um aumento na execução de respostas que eram menos prováveis, e uma conservação da estrutura do comportamento exibido antes da perda ou deterioro. A função dos estímulos antecedentes e/ou discriminativos envolvidos, que constituem a parte vigente da contingência que foi quebrada, também tem se mostrado comprometida. Contudo, a interação entre essas características tem sido estudada de modo separado, seja por complicações técnicas ou por isolamento teórico entre os paradigmas. Neste experimento se apresenta uma proposta que tenta obter uma caracterização mais abrangente das estratégias comportamentais que emergem numa situação de perda, aproveitando a versatilidade topológica e funcional da resposta ocular, e a disponibilidade de recursos técnicos que permitem obter medidas precisas dela. Para isso, no procedimento utilizado foram disponibilizadas alternativas de resposta com diferentes valores de reforçamento em cada. 192 fotografias do IAPS foram categorizadas segundo seu valor emotivo e seu conteúdo em seis categorias: Eróticas, Filhotes (Agradáveis), Paisagens naturais, Paisagens artificiais (Neutrais), Doenças e Violência (Desagradáveis). Pares dessas fotografias foram apresentadas num arranjo de quatro quadrantes na tela do computador, antecedidas de forma consistente por Figuras geométricas específicas para cada categoria, enquanto os tempos de fixação eram registrados com um rastreador ocular. Uma sétima figura geométrica foi pareada aleatoriamente com fotografias de todas as categorias. Após atingir um critério de estabilidade baseado no ranqueamento e correspondência entre os tempos de fixação das Figuras geométricas e das Fotografias, as Fotografias da categoria mais observada foram substituídas por Fotografias daquela correspondente ao terceiro lugar, mas continuaram sendo antecedidas pela mesma Figura geométrica.

Os resultados mostraram que o procedimento foi sensível às condições e a manipulação experimental. Foi possível estabelecer um ranqueamento entre as categorias a partir das respostas oculares e caracterizar um padrão de observação após a incongruência introduzida. No caso, as preferências exibidas pela participante foram reorganizadas, com um aumento nos tempos de fixação das categorias agradáveis, evitação das fotografias da categoria Doença enquanto a Figura geométrica que à antecedia começou a ser mais observada, e um aumento no tempo de fixação da categoria de imagens aleatórias. No caso das Categorias alteradas, as fotografias de Filhotes (terceira categoria no ranqueamento) que começaram a ser antecedidas pela Figura geométrica correspondente à categoria Violência (a mais observada), foram menos observadas do que àquelas antecedidas pela figura geométrica treinada na fase anterior. São discutidas as melhoras que o procedimento poderia ter assim como o uso das medidas mais apropriadas na exploração de diversos fenômenos comportamentais. Se analisa se os resultados podem ser entendidos dentro do paradigma de contraste e por último se apresentam comentários sobre a necessidade de aproveitar os desenvolvimentos técnicos que permitem executar experimentos mais complexos.

Palavras chave: Expectativa, Perda, Contraste Sucessivo, Respostas oculares, Condicionamento, Aprendizagem por discriminação, Eyetracking, Rastreamento Ocular. 


\begin{abstract}
Successive Contrast is one of the experimental paradigms that models the experience of loss. On it, organisms are no longer exposed to reinforcing, appetitive and/or preferred events, but to some others with less quality or value. This results in different behavioral strategies characterized by an important emotional component, a decrement in the response not any longer associated with the consequence (consummatory or operant), an increment in less likely responses, and a preservation of behavioral structure from before the impairment. The role of the antecedent and / or discriminative stimuli involved, which constitute the current part of the contingency that has been broken, has also shown to be compromised. However, the interaction between these characteristics has been studied separately, either by technical complications or by theoretical isolation between paradigms. In this study, we propose a procedure to obtain a more comprehensive characterization of the behavioral strategies that emerge in a situation of loss, taking advantage of the topological and functional versatility of the ocular response, and the availability of technical resources that allow to obtain precise measurements of it. To solve this, alternatives for responding with different values of reinforcement were available. 192 photographs from the IAPS were categorized into six categories according to their emotional value and their content: Erotic, Puppies (Pleasant), Natural Landscapes, Artificial Landscapes (Neutral), Diseases and Violence (Unpleasant). Pairs of these photographs were presented in a four-quadrant arrangement on the computer screen, consistently preceded by specific geometric figures for each category, while fixation times were recorded with an eye tracker. A seventh geometric figure was randomly paired with photographs of all categories. After reaching a stability criterion based on the ranking and correspondence between the fixation times of the Geometric Figures and the Photographs, the Photographs of the most observed category were replaced by Photographs of the one corresponding to the third place, but continued to be preceded by the same Geometric Figure.

The results showed that the procedure worked well within our experimental conditions and manipulation. It was possible to establish a ranking from the ocular responses among the categories and to characterize a pattern of observation after the introduced incongruity. The preferences exhibited by the participant were reorganized, with an increase in the fixation time of the pleasant categories, avoidance of photographs of the category Disease while its geometric Figure became more observed, and an increase in the fixation time of the category of random images. On the changed Categories, the photographs of Pups (third category in the ranking) that began to be preceded by the geometric Figure corresponding to the category Violence (the most observed category), were less observed than those preceded by the geometric figure trained in the previous phase. The improvements that the procedure could have as well as the use of the most appropriate measures in the exploration of several behavioral phenomena are discussed. It is analyzed if the results can be understood within the contrast paradigm and finally comments are made on the need to take advantage of the technical developments that allow to execute more complex experiments.
\end{abstract}

Key words: Expectation, Loss, Successive Contrast, Ocular Responses, Conditioning, Discrimination Learning, Eyetracking, Eye Tracking. 


\section{Sumário}

Resumo

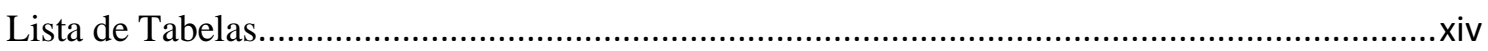

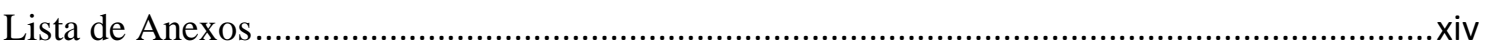

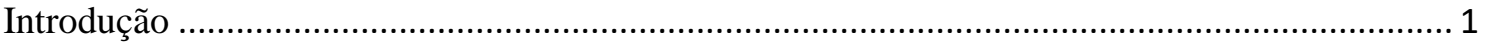

Ordem no meio do caos: Conservação de comportamentos após a Extinção. ..................... 2

Outras mudanças além da Extinção: Contraste Sucessivo ........................................ 6

Os olhos e a observação como modelo ............................................................ 10

Contraste Sucessivo e respostas oculares: Um labirinto para os olhos. ............................ 14

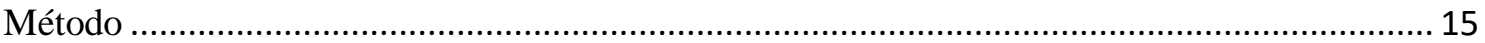

Participante ....................................................................................................... 15

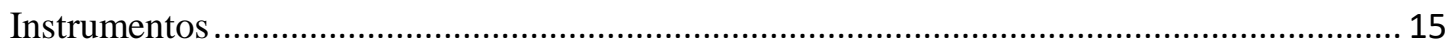

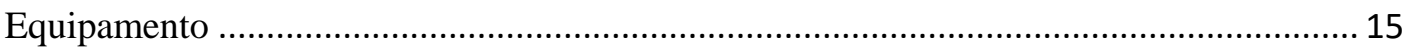

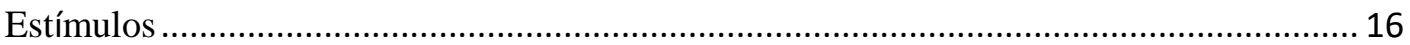

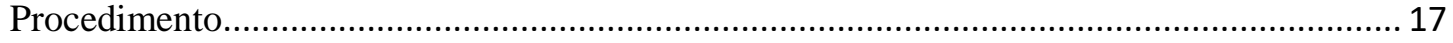

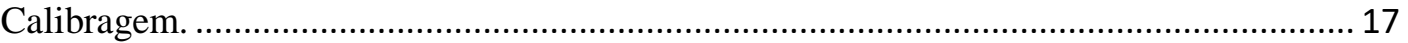

Instrução......................................................................................................... 18

Fase I: Pareamento dos estímulos arbitrários com as fotografias de cada categoria.......... 18

Fase II: Irregularidade no pareamento mais observado............................................ 22

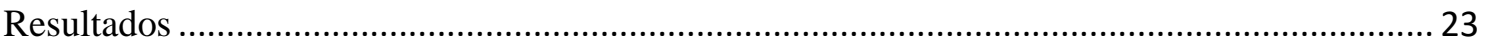

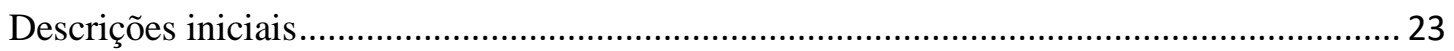

Durações e frequências...................................................................................... 25

Rejeição e Exclusividade .............................................................................. 33

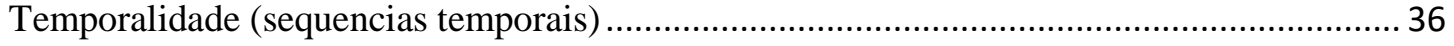

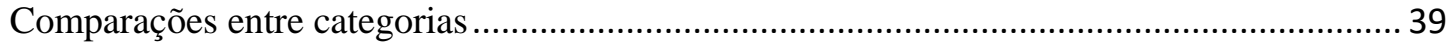

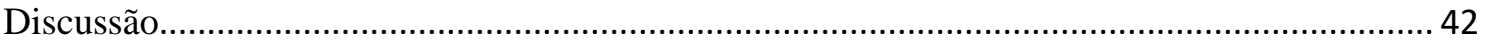

Avaliação Técnica e Metodológica. ...................................................................... 42

Avaliação Teórica e Conceitual. ............................................................................... 47

Considerações Finais..................................................................................... 57

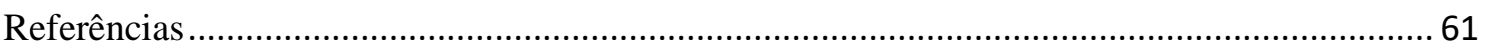

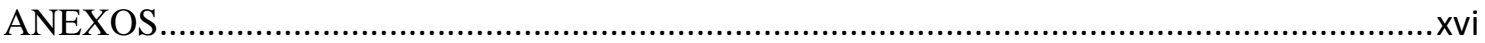




\section{Lista de Figuras}

Figura 1. Percurso geral e características da extinção depois do período de reforçamento nos quatro programas simples (tomada de Catania, 1999). ............................................................. 3

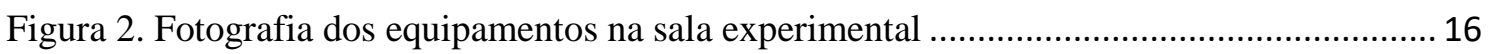

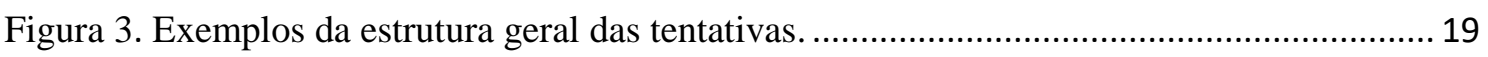

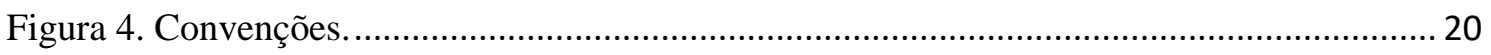

Figura 5. Características do estímulo arbitrário aleatório. ........................................................ 21

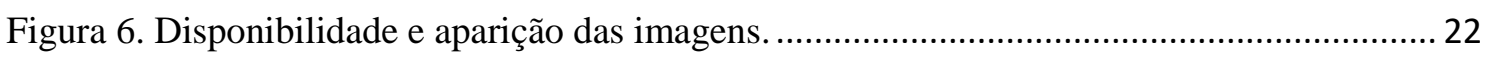

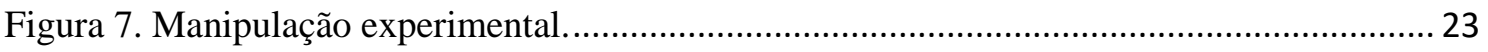

Figura 8. Tempo de observação dos quadrantes em diferentes momentos. ................................ 24

Figura 9. Frequência relativa de preferência Figuras geometricas e Fotografias ........................ 26

Figura 10. Frequência relativa de preferência das Figuras geometricas que atingem o criterio de

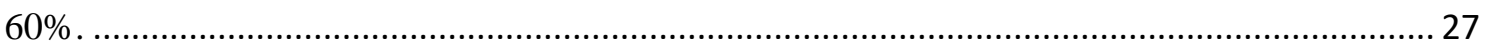

Figura 11. Frequência relativa de preferência das Fotografias que atingem o critério de $60 \%$.. 28

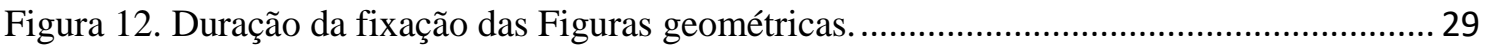

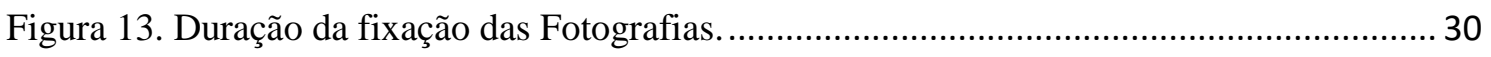

Figura 14. Tempo efetivo de observação das Figuras geométricas............................................ 31

Figura 15. Tempo efetivo de observação das Fotografias ............................................................. 31

Figura 16. Tempo meio de fixação das Figuras geométricas preferidas ..................................... 32

Figura 17. Tempo meio de fixação das Fotografias preferidas ................................................ 32

Figura 18. Tempo meio de fixação das Figuras geométricas preferidas com o critério de $60 \% .33$

Figura 19. Tempo meio de fixação das Fotografias preferidas com o critério de $60 \%$................ 33

Figura 20. Distribuição dos tempos de fixação em relação ao tempo efetivo de observação das

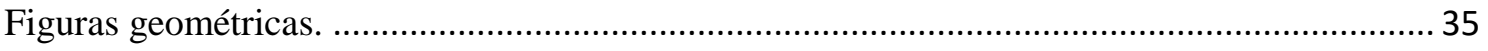

Figura 21. Distribuição dos tempos de fixação em relação ao tempo efetivo de observação. .... 36

Figura 22. Tempo de observação das Figuras geométricas e das Fotografias de cada categoria ao

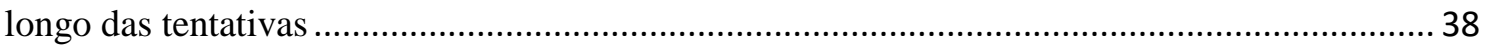

Figura 23. Observação das Figuras geométricas ao longo das tentativas................................... 40

Figura 24. Observação das Fotografias ao longo das tentativas............................................... 41 


\section{Lista de Tabelas}

Tabela 1. Descrição e exemplos das categorias de estímulos utilizados ........................................... 17

Tabela 2 . Ranqueamento obtido no momento de atingir o critério de aprendizagem ...................... 24

Tabela 3 Frequência de tentativas que atingiram os critérios de preferência.................................... 28

\section{Lista de Anexos}

Anexo 1 Número das imagens do IAPS utilizadas no experimento...............................................

Anexo 2 Termo De Consentimento Livre E Esclarecido ..........................................................

Anexo 3. Combinatória e controle das Tentativas de Treino........................................................ vvi 


\title{
Introdução
}

\begin{abstract}
Se o olho fosse um animal, sua alma seria a visão. Esta é, desde logo, a entidade definidora do olho. O olho, por sua vez, é a matéria da visão, de maneira que, removida esta, aquele não seria em absoluto um olho a não ser na palavra, como é o caso de um olho esculpido em pedra ou pintado. Procede também aplicar à totalidade do corpo vivente o que se aplica às partes. (Aristóteles, De Anima)
\end{abstract}

Além de ser um tópico fundamental nos tratados de filosofia universal, e amplamente discutido fora do entorno acadêmico nas conversações cotidianas, entender cientificamente o sofrimento e mal-estar que acontece quando objetos, atividades ou pessoas que amamos e disfrutamos não estão mais disponíveis tem sido um desafio para a pesquisa psicológica. Várias situações que envolvem algum tipo de perda, como por exemplo, a morte do parceiro, divorcio, separação, morte de algum parente, perder um emprego, um investimento, ou se aposentar, aparecem na lista dos eventos reportados como os mais estressantes (Scully, Tosi e Banning, 2000). Adicionalmente, a pesquisa clínica também tem apontado que ditas experiências podem resultar em diversas desordens afetivas, perturbações da função autonômica e dos padrões de sono, e numa deterioração geral da saúde, da atividade imune, e até num aumento da mortalidade (ver Hall e Irwin, 2001).

A compreensão de quais são e como estão relacionadas as variáveis envolvidas nessas correlações apontadas na pesquisa clínica tem se beneficiado do desenvolvimento de toda uma serie de modelos laboratoriais que tentam homologar as características essenciais das situações de perda. Desde um ponto de vista evolutivo e comparativo, qualquer organismo sensível ao ambiente, independentemente de sua capacidade cognitiva, corre o risco de perder ou ver desvalorizados recursos importantes para a supervivência, seja alimento, abrigo, ou aqueles de caráter social (parceiros sexuais, aliados ou posição na hierarquia do grupo), entre outros. Se "o que chamamos comportamento evoluiu como um conjunto de funções que promovem o intercâmbio entre organismo e ambiente" (Skinner, 1987, p.51) então, é de esperar que estruturas e mecanismos dedicados ao problema da perda tenham sido desenvolvidos durante a filogênese (Papini, 2002; 2006), e que as estratégias comportamentais diante dessa situação estejam organizadas ao longo da ontogênese satisfazendo algum critério. 
Ao respeito dos fatores filogenéticos, pode ser comentado brevemente que áreas afins ao estudo do comportamento têm achado vantajoso o uso de análises que consideram alguns dos conceitos relacionados à expectativa. É o caso da pesquisa neurofisiológica que a partir da predição de eventos e do fato dessas predições serem violadas ou verificadas tem identificado, por exemplo, estruturas e mecanismos envolvidos na extinção de comportamentos (p.e. Abler, Walter e Erk, 2005; Salamone, 2012) assim como a circuitaria subjacente às respostas diante de estressores ambientais (como a perda de recursos) entre diferentes táxones (p.e. LeDoux, 2012). Do lado da ontogênese, reconhecer que a expectativa é referencial resulta conveniente porque coloca ênfase na história particular de cada indivíduo mais do que no valor objetivo daquilo que é perdido. Os $\$ 2000$ que um investidor perde na bolsa de valores todo dia não tem o mesmo valor psicológico do que os \$2000 mensais que perde um pósgraduando quando a bolsa de estudos termina.

\section{Ordem no meio do caos: Conservação de comportamentos após a Extinção.}

As estratégias metodológicas que modelam situações de perda variam dentro das diversas áreas da literatura psicológica. Já nos estudos de Pavlov (1927) foram identificados vários fenômenos na quebra da contingência clássica quando o Estímulo Condicionado (CS) não é mais seguido pelo Estímulo Incondicionado (US). Dentre os fenômenos post-extinção se encontram a recuperação espontânea ${ }^{1}$, a renovação ${ }^{2}$, o reestabelecimento $^{3}$ e a rápida reaquisição ${ }^{4}$. Nesse momento, tais achados foram entendidos como evidência de que a extinção não destruía o aprendizado CS-US, e a partir disso foram geradas elaborações teóricas ao redor do conceito de associação inibitória em contraposição à associação excitatória (p.e. Konorski, 1948).

A conservação das respostas que 'sobrevivem' à extinção tem sido também um tópico na literatura operante. As curvas de desempenho nos esquemas de reforçamento

\footnotetext{
${ }^{1}$ Recuperação espontânea: após a extinção, a passagem do tempo é suficiente para recuperar a CR.

${ }^{2}$ Renovação: a apresentação do CS num contexto diferente daquele em que aconteceu a extinção dá lugar a aparição da CR

${ }^{3}$ Reestabelecimento: A apresentação do US depois da extinção leva a reaparição da CR diante do CS

${ }^{4}$ Rápida reaquisição: depois da extinção, um menor número de pareamentos US-CS é necessário para atingir níveis máximos da $\mathrm{CR}$, quando comparado com o número de pareamentos necessários da primeira vez.
} 
mantêm algumas das suas características ainda durante algum tempo depois do esquema de extinção entrar em vigor (ver Figura 1). Para Skinner (1953), o comportamento observado durante a extinção é função da história particular de reforçamento. Assim, ao quebrar as contingências se faz com que a taxa de respostas diminua, mas algumas partes do ambiente ainda funcionariam como discriminativos para executar a resposta, o que daria conta dos comportamentos que 'reaparecem'. Assim, tanto mais estiver exposto o organismo a nova condição sem reforçamento, menos probabilidade de executar a resposta operante e mais achatadas serão as curvas de desempenho.

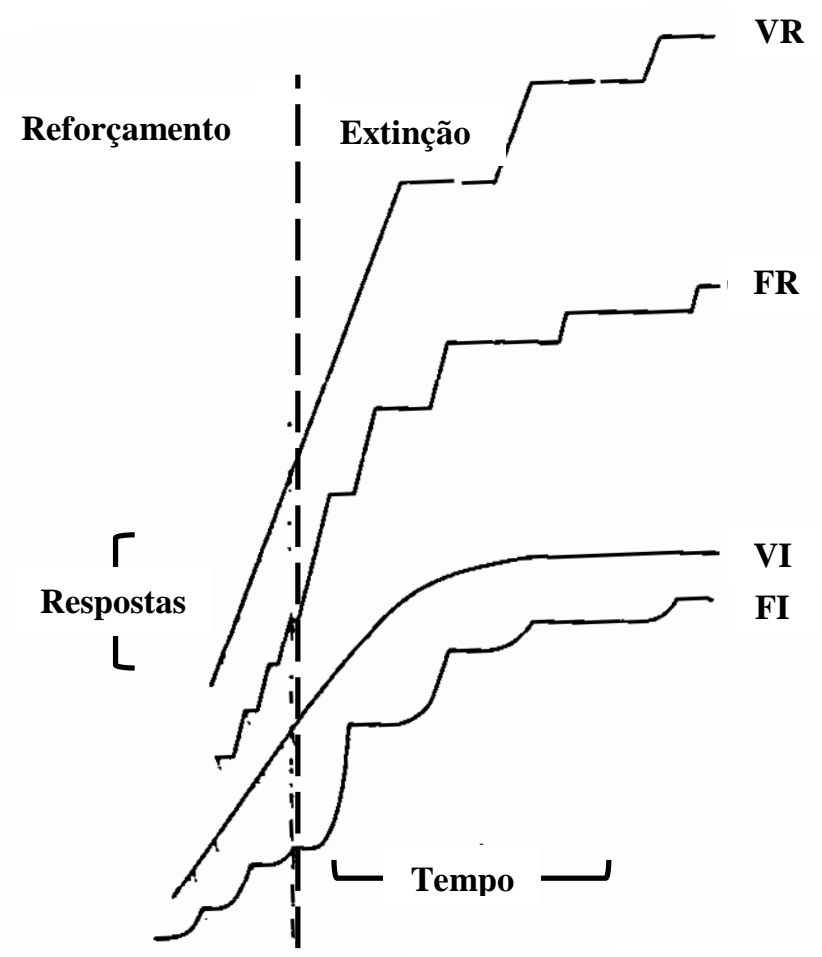

Figura 1. Percurso geral e características da extinção depois do período de reforçamento nos quatro programas simples (tomada de Catania, 1999).

Para Skinner (1957), nesse processo gradual que seria a adaptação as novas condições de reforçamento, as respostas emocionais são consideradas um tipo de interferência que dificulta tal adaptação, pois algumas partes do ambiente ainda funcionariam como discriminativos para executar a resposta que funcionou em situações anteriores. 
Sob algumas circunstâncias a curva é perturbada por um efeito emocional. $O$ não reforçamento de uma resposta leva não apenas à extinção operante, mas também a uma reação comumente chamada de frustração ou raiva. Um pombo que não recebeu reforço afasta-se da chave, arrulha, bate suas asas... o pombo voltará novamente para a chave quando as respostas emocionais desaparecerem. Na medida em que outras respostas [...] ocorrerem sem reforço, outros episódios emocionais podem acontecer. Sob tais circunstâncias, as curvas de extinção mostram uma oscilação cíclica à medida que as respostas emocionais surgem, desaparecem e surgem novamente. [...] O comportamento durante a extinção é resultado do condicionamento que a precedeu e, nesse sentido, a curva da extinção fornece uma medida adicional do efeito do reforçamento. (p. 69-70).

São diversos os termos emocionais usados para caracterizar as estratégias desenvolvidas durante a perda, incluindo ansiedade (Flaherty, Greenwood, Martin, Leszczuk, 1998), raiva (Tinklepaugh, 1928), depressão (Crespi, 1942), desapontamento (Spence, 1956), frustração (Amsel, 1992) e dor psicológica (Papini, Wood, Daniel, Norris, 2006). Contudo, o fato das respostas emocionais serem uma característica persistente nessa situação, sua existência resulta insuficiente, ou pelo menos incompleto, na tentativa de entender a nova distribuição de comportamentos. Reconhecer o componente emocional nas curvas de extinção não dá conta da conservação das características próprias do esquema de reforçamento utilizado. A aleatoriedade atribuída às respostas emocionais pode dar conta das mudanças abruptas observadas durante a perda ou desvalorização de um recurso, mas a partir dela, nada pode ser inferido sobre a direção dessas mudanças.

Estudos posteriores sugerem que os fenômenos post-extinção poderiam ser parte de um conjunto de adaptações comportamentais mais gerais. Bouton e Peck (1992), por exemplo, num primeiro experimento parearam consistentemente um som seguido por um choque, analisando o congelamento como Resposta Condicionada. Num segundo experimento do mesmo conjunto de estudos, o som foi seguido por comida e foi registrado o movimento da cabeça dirigido ao comedouro. Após atingirem respostas estáveis frente ao som, este começou a ser seguido pelo outro estímulo incondicionado: os animais que recebiam comida começaram a receber um choque, e vice-versa. As 
respostas condicionadas diante do som se adaptaram conforme o novo pareamento, enquanto as respostas da fase anterior foram diminuindo. $\mathrm{O}$ som foi testado novamente após um período de vinte e oito dias durante o qual os animais não foram expostos nem ao contexto experimental, nem aos estímulos condicionados ou incondicionados. Uma das análises pretendia esclarecer se era a ordem dos pareamentos CS-US o que iria controlar a resposta (i.e. se em ambos os experimentos a resposta apresentada seria aquela treinada na primeira ou na última fase), ou se a variável relevante seria a natureza apetitiva ou aversiva do estímulo incondicionado (i.e. se a resposta emitida seria aquela correspondente à comida ou ao choque, independentemente da ordem de apresentação). Os resultados mostraram que a resposta condicionada diante do som depois de vinte e oito dias foi aquela aprendida durante o primeiro pareamento em ambos os experimentos.

Os resultados permitiram aos autores considerar que a extinção funcionava do mesmo modo, só que ao invés de ser CS-US1 seguido por CS-US2, a contingência CSUS inicial é seguida por CS-'nada'. O restabelecimento (Bouton, 1995) e a renovação (Bouton, 2002, 2004) seguem o padrão descrito anteriormente no sentido de ser a primeira resposta condicionada a que é exibida durante os testes. No entanto, também têm sido observadas algumas particularidades quando manipulados parâmetros sobre o intervalo entre o primeiro e o segundo treino, ou quando usados pareamentos inibitórios (i.e. CS-'nada') na primeira fase e seguida por um pareamento com 'conteúdo' (CSUS), o que mantem discussões ao respeito do que é aprendido durante a extinção (ver Rescorla, 2004).

Ainda quando aparece que a principal característica do comportamento durante a extinção seja a diminuição de uma das respostas exibidas pelo organismo, se trata de uma descrição incompleta se não incluídos os aspectos estruturais e topográficos que se conservam e que constituem uma nova distribuição do comportamento. Nevin (1967), por exemplo, reportou que mesmo quando a taxa de respostas cai drasticamente durante a extinção, o critério vigente durante o treino discriminativo (no caso, a chave mais brilhante entre duas disponíveis) continua sendo atingido mesmo sem reforçamento. De outro lado, é observado um aumento da variabilidade comportamental quando o reforçador não está mais disponível, é o caso do estudo de Antonitis (1951) que observou ratos focinhando num comedouro de $50 \mathrm{~cm}$ de comprimento, o local 
específico foi estável durante o reforçamento, mas as respostas ao longo dos diferentes pontos do comedouro aumentaram durante a extinção. A distribuição do comportamento após uma mudança como a extinção, seja clássica ou operante, está caracterizada então por uma conservação daquilo que é experimentado antes dela acontecer, e por um aumento na variabilidade de respostas exibidas.

Neuringer, Kornell e Olufs (2001) desenharam um experimento tentando entender melhor essa relação entre a variabilidade e a conservação de comportamentos durante a extinção. Para isso, ratos que deviam fazer uma sequência de três respostas em qualquer combinação dos três operandos disponíveis. A sequência era reforçada só se fosse diferente do $95 \%$ das combinações executadas durante as tentativas anteriores. No experimento dois do estudo, sujeitos de um grupo controle recebiam comida sempre que o grupo experimental recebesse, independentemente de atingir o critério ou não. Durante a extinção, os animais não recebiam comida mesmo que atingissem o critério de variabilidade. Os resultados mostraram que, durante o treino, o grupo experimental realizou um maior número de combinações do que o grupo controle (i.e. reforçamento da variabilidade), e mesmo que sequências pouco prováveis foram mais frequentes durante a extinção para ambos os grupos (i.e. variabilidade induzida), aquelas que eram mais prováveis durante o treino continuaram sendo as mais prováveis durante a extinção (i.e. conservação). Os autores assinalam que fazer aquilo que funcionou antes e, ocasionalmente, fazer algo muito diferente, maximiza a possibilidade de obter reforçamento em uma situação de recursos esgotados ao mesmo tempo que proporciona condições para o surgimento da variação comportamental necessária na aprendizagem.

\section{Outras mudanças além da Extinção: Contraste Sucessivo}

A extinção é só uma das possíveis mudanças à que um organismo está exposto. Ainda que metodologicamente se fala de extinção quando o reforçador, consequência ou estímulo incondicionado é retirado completamente, uma definição mais precisa implica falar da quebra da contingência entre os estímulos: tanto a campainha quanto a comida podem estar presentes durante a extinção, só que não estão sendo mais apresentadas de forma contingente (ver Domjam, 2009). Quando a mudança não consiste em perder totalmente acesso as consequências reforçadoras, mas sim em receber menos 
reforçamento, ou reforçamento de menor qualidade, estamos falando de uma situação de Contraste.

Os antecedentes deste procedimento podem ser traçados desde Spencer e Hull quando apareceram as discussões sobre a aprendizagem e sua relação com a magnitude da recompensa. No entanto, de forma específica para o caso do Contraste são reconhecidos três experimentos fundacionais. $\mathrm{O}$ primeiro, desenvolvido por Tinklepaugh (1928), em que um grupo de macacos observava um troço de comida localizado dentro de um de dois recipientes que eram cobertos por uma tela antes de ficar acessíveis para os sujeitos. Tanto no caso de ser apresentado um pedaço de banana quanto de ser apresentado um pedaço de alface, os animais consumiam o alimento. Numa segunda fase, e sem o macaco perceber, durante o intervalo em que a tela cobria os recipientes, o experimentador trocava o pedaço de banana por um pedaço da menos preferida alface. Os resultados dessa manipulação são descritos como rejeição ao alimento apresentado, exploração do segundo recipiente e claras respostas emocionais. $\mathrm{O}$ autor discute suas observações em termos da antecipação que o macaco teria da comida apresentada no primeiro momento, e expectativas insatisfeitas.

No mesmo ano, Elliot (1928) elaborou um experimento com ratos num labirinto. Ele observou que o desempenho após a diminuição da qualidade da recompensa estava caracterizado por um maior número de entradas aos pontos cegos do instrumento quando comparado com um grupo de animais que continuaram recebendo a recompensa de maior valor. $\mathrm{O}$ autor considerou que os resultados não podiam ser entendidos a partir de um conceito emocional pois as respostas exploratórias (como chamou aos "erros" no labirinto) se mantiveram durante vários dias. Questionando as teorias da época, Elliot sugeriu que além de aprender uma tarefa, os animais aprendiam algo sobre a recompensa.

Por último, usando uma tarefa de corredor, Crespi (1942) observou que a mesma "magnitude do incentivo" não tinha o mesmo efeito comportamental se os animais tinham experiencia com magnitudes diferentes. Uma determinada quantidade de alimento resultaria num pior desempenho caso o rato tivesse experimentado quantidades maiores no passado (chamado de efeito de "depressão" por ele), enquanto seriam observados melhores tempos se o animal tivesse experimentado quantidades menores 
antes (efeito de "elação"). Foi Zeaman (1949) quem após replicar os resultados de Crespi se referiu às observações como "efeito de contraste", utilizando a terminologia própria da psicologia da percepção da época.

Atualmente, na literatura aparece o termo Contraste Sucessivo Negativo (Flaherty, 1996; Papini, 2003, 2013). No procedimento básico, uma solução açucarada a $32 \%$ está disponível para os ratos durante cinco minutos diariamente. Após atingir estabilidade no consumo, a solução é trocada por uma de concentração ao $4 \%$. O efeito observado é uma diminuição abrupta do volume consumido que resulta menor inclusive daquele atingido por animais do grupo controle que sempre tiveram acesso à solução de menor concentração. Depois de algumas tentativas adicionais com a solução a 4\%, os animais que experimentam a desvalorização consomem um volume semelhante ao do grupo controle. Trata-se de um fenômeno robusto, avaliado com diversos parâmetros experimentais e diversas espécies. Igualmente, são vários os aspectos fisiológicos identificados com ajuda desse paradigma, dentre eles se destacam o aumento nos níveis de corticosterona, sensibilidade a dor, e o efeito amortecedor dos ansiolíticos, o que sustenta a importância dos aspectos emocionais nesse tipo de situações (ver Papini, 2006; Bentosela, Ruetti, Muzio, Mustaca, e Papini, 2007; Jimenez-Garcia, Ruiz-Leyva, Cendan, Torres, Papini,e Moron, 2016).

Ainda com a ênfase nos componentes emocionais do fenômeno de contraste, existem destaques experimentais que tentam descreve-lo de forma mais abrangente. Pecoraro, Timberlake e Tinsley (1999) modificaram o procedimento de contraste colocando os ratos num labirinto em cruz elevado. Três grupos foram comparados: o primeiro deles foi treinado com uma solução a 32\% no mesmo braço todo dia (grupo 32 fixo), o segundo grupo tinha disponível a mesma solução em um dos braços a cada dia (grupo 32 variável) e o grupo controle tinha uma solução a $4 \%$ no mesmo braço todo dia (grupo 4 Fixo). Os locais não utilizados contavam com bebedouros vazios. Depois de 14 dias de treino, a solução de $4 \%$ foi oferecida em todos os braços do labirinto durante quatro dias mais. Quando comparados com os animais que sempre receberam a solução de baixa concentração, os animais dos grupos que experimentaram a solução a $32 \%$ mostraram uma diminuição significativa no consumo quando esta foi substituída pela solução a $4 \%$ (Contraste consumatório). Os autores observaram também diferenças nos tempos de locomoção e no número de entradas aos braços do labirinto depois da 
mudança, pois só os animais do grupo 32 fixo aumentaram esses valores em relação à fase anterior e em comparação com os animais das outras condições (aumento da variabilidade). Do mesmo modo, o local mais visitado por esse grupo durante a primeira fase foi o local mais visitado durante a segunda (conservação do comportamento).

As interpretações usualmente elaboradas ao redor do fenômeno de contraste foram questionadas, pois se o comportamento do animal fosse aleatório em virtude das respostas emocionais eliciadas no evento do alimento acabar ou diminuir, a exploração seria indiferente, sem preferências entre os locais disponíveis. Se o braço do labirinto tivesse adquirido propriedades aversivas condicionadas em virtude da desvalorização da solução açucarada, não deveria ter sido o braço mais visitado. Os autores sugerem uma análise funcional a partir da história evolutiva e do contexto ecológico de cada espécie para entender melhor as estratégias observadas em situações de escassez ou perda de um recurso. Nesse sentido, deve ser considerado que o padrão de exploração do rato está inserido no fato de, por exemplo, ser um animal predado, que corre grandes riscos se não escolher cuidadosamente os locais nos quais se movimenta, e que pode perder calorias valiosas com deslocamentos desnecessários. Animais localizados em outro ponto da cadeia alimentar, com metabolismo e estratégias de forrageio diferentes, talvez assumam a situação de perda (alimentar) com outra estratégia. A relevância desse estudo consiste na possibilidade de analisar respostas adicionais às consumatórias colocando os animais numa situação com várias opções de exploração, o que serviu para entender melhor as limitações das explicações baseadas em respostas emocionais, e propondo um novo conjunto de hipóteses a serem testadas.

Existe uma aproximação ao problema da relatividade do reforçador também na literatura do condicionamento operante. Além do esquema de reforçamento, existem outras variáveis envolvidas na distribuição de respostas em situações concorrentes. Guttman (1977) utilizou um esquema múltiplo de dois componentes VI 30-s cada, um deles associado a uma luz e o outro a um som. Depois dos animais atingirem taxas de resposta semelhantes em ambos os componentes, um deles entrou em extinção. Como esperado, o responder diminuiu quando apresentado o estímulo associado a esse componente. No entanto, foi observado um aumento na taxa de respostas do segundo componente mesmo sem ter mudanças na contingência vigente para ele. Esse tipo de achados sugere que o valor de um esquema é relativo aos outros esquemas 
experimentados pelo indivíduo, e se faz necessário pensar em arranjos experimentais que consigam lidar com a complexidade que isso implica.

A mudança nos componentes concorrentes não tem que ser total (como no caso da extinção) para ter efeitos nos outros componentes vigentes. Belke (1992) propôs um procedimento de concorrentes múltiplo, no qual um dos componentes apresentava esquemas VI 20-s, VI 40-s, e o outro VI 40-s, VI 80-s. Após atingir estabilidade, os pombos respondiam igualando a taxa de reforçamento em cada um dos componentes (i.e. à razão de dois para um). Posteriormente, em tentativas ocasionais, foram apresentados ao mesmo tempo os estímulos de cada VI 40-s. Os animais responderam à razão de quatro para um naquele que foi apresentado junto com o esquema VI 80-s, isto é, no componente no qual VI 40-s era relativamente mais rico. O experimento de Belke (1992) é importante porque mostra que determinada distribuição de repostas não depende só do valor absoluto das consequências (pois no caso, a taxa de reforçamento era a mesma em ambas as opções) senão que a perda é relativa tanto à experiência anterior (i.e. menos do que antes), quanto às opções disponíveis (i.e. menos do que nas outras opções). Este estudo é importante também porque demonstra que essa relativização acontece diante dos estímulos discriminativos (i.e. a luz da chave) e que não é exclusivo dos estímulos primários (reforçadores).

\section{Os olhos e a observação como modelo}

Para caracterizar a estratégia comportamental desenvolvida em alguma circunstância particular, dispor várias alternativas de resposta tem sido o método explorado no uso de esquemas concorrentes. Dentro dos parâmetros mais importantes a serem considerados está a estabilidade e confiabilidade dos estímulos discriminativos, pois não só os estímulos correlacionados com as consequências afetam a dinâmica do comportamento conforme acontece uma perda. Quando analisado, o comportamento diante de estímulos irrelevantes, ambíguos ou redundantes, têm também um papel na redistribuição dos comportamentos que decorrem da mudança nos eventos ambientais. Num dos experimentos clássicos de resposta de observação com pombos (Wyckoff, 1969) foi comparada a aquisição e manutenção dessas respostas por contingências discriminativas e não discriminativas. O procedimento empregado foi uma 
discriminação simples sucessiva com tentativas de 30s de duração, durante as quais respostas de bicar na chave foram reforçadas com $4 \mathrm{~s}$ de acesso à comida em um esquema misto FI30- EXT. Os componentes alternavam de acordo com uma sequência previamente programada. Uma segunda contingência fazia com que a chave de respostas que permanecia iluminada com luz branca aparecesse com as cores verde ou vermelha quando pressionado um pedal disponível na caixa experimental. O reforçador "principal" (alimento) foi entregue de forma independente às cores da chave, que também dependiam do comportamento do sujeito por via dessa contingencia de observação aninhada do pedal.

Analisando as respostas do pedal, foi comparado o comportamento exibido por um grupo para o qual as cores da chave não estavam correlacionadas com as consequências da resposta de bicar (contingências não discriminativas), e um segundo grupo para o qual as cores da chave estavam correlacionadas com as consequências (uma das cores assinalava o esquema FI 30-s e a outra o não-reforçamento). Os resultados dessa fase mostraram que o primeiro grupo pressionou o pedal numa taxa menor do que o grupo com contingenciais discriminativas e de forma independente do esquema vigente para as bicadas, enquanto as contingências discriminativas controlaram a taxa de respostas diante de cada componente para o segundo grupo.

$\mathrm{Na}$ fase seguinte, o grupo que passou pelo treino discriminativo foi dividido entre aqueles que manteriam as cores discriminativas da fase anterior, aqueles que seriam sometidos a uma reversão das contingências (i.e. a cor associada aos componentes de extinção assinalaria nessa fase os componentes de reforçamento, e vice-versa); e finalmente, um grupo para o qual as contingencias passariam a ser não discriminativas, pois as cores deixaram de estar correlacionadas com as consequências de bicar (i.e. os componentes seriam antecedido por uma ou outra cor quando pressionado o pedal independentemente do esquema em vigor). Os resultados mostraram que o primeiro desses grupos continuou respondendo de forma discriminada no pedal, o segundo grupo demorou duas sessões para atingir o novo critério, e por fim, o terceiro grupo diminuiu a resposta ao pedal nessa fase. A pesquisa desenvolvida ao redor desse estudo mostra que organismos avaliados em diversas condições experimentais preferem observar estímulos que exercem funções discriminativas, e além do mais, preferem observar os estímulos que estão associados a maiores probabilidades 
de reforço (ver Tomanari, 2009, para uma revisão). Nesse sentido, junto ao valor de cada esquema e sua relação com outras opções disponíveis, a previsibilidade oferecida pelos estímulos discriminativos poderia ser considerada como uma variável adicional que afeta o valor relativo dos eventos.

Mesmo que escassos, alguns estudos tentaram aplicar o paradigma do Contraste sucessivo com humanos. Halpern, Schwartz e Chapman (1968), por exemplo, adaptaram uma tarefa em que, numa primeira fase, os participantes deviam adivinhar se no avesso de cada uma das cartas que lhe eram apresentadas tinha um ponto ou uma linha (250 tentativas), sendo que um dos desenhos tinha menor probabilidade de aparecer do que o outro. Do lado visível da carta aparecia um valor monetário que ganhariam caso acertassem ou perderiam caso contrário. Alguns grupos tiveram acesso sempre a um único valor $(1 \varnothing$ ou $5 \varnothing)$, enquanto outros foram treinados com os dois valores. Durante a segunda fase, o experimentador trouxe um novo maço de cartas para o participante, os grupos controle permaneceram nas mesmas contingências, enquanto os grupos experimentais começaram a receber só um dos dois valores. Aqueles que sofreram uma diminuição no valor das cartas (de $5 \& 1 \notin$ e $5 \notin$ para $1 \notin$ ) sofreram maiores desajustes nas predições que faziam, enquanto os grupos que experimentaram um valor só não se diferenciaram entre si. De outro lado, o grupo que experimentou um aumento nos valores apresentados (de $1 \not$ para $5 \not$ ), melhorou seu desempenho (ver também Weinstein, 1972, para um exemplo de contraste usando pontos como reforçador).

Recentemente, Cuenya, Kamenetzky, Fosacheca e Mustaca (2013) utilizaram imagens emotivas da bateria do IAPS ${ }^{5}$ para estudar o fenômeno de contraste. Durante a primeira fase do experimento, um grupo de participantes foi exposto a dez imagens avaliadas como altamente emotivas pelo $\mathrm{SAM}^{6}$ e posteriormente foram expostas mais dez imagens consideradas pouco emotivas (i.e. neutras). Os comportamentos registrados foram o tempo que cada participante deixou a imagem na tela de apresentação (que

\footnotetext{
${ }^{5}$ International Afecttive Picture System. O objetivo do IAPS é conformar um amplo banco de fotografias coloridas, de diversos conteúdos, padronizadas, emocionalmente evocativas e acessíveis internacionalmente para a pesquisa experimental da emoção e da atenção. Atualmente está sendo desenvolvido e distribuído pelo Centro para o Estudo da Emoção e da Atenção (CSEA - pela sua sigla em inglês) da Universidade de Flórida.

${ }^{6}$ Self-Assessment Manikin ê uma escala de nove pontos em formato likert, uma a uma das imagens que compõem o banco de dados do IAPS foi valorada em três dimensões: 1) Valência afetiva (de agradável a desagradável), 2) Nível de ativação (de calmo a excitado) e 3) Controle percebido (de dominado a dominante) (IAPS; Lang, Bradley e Cuthbert, 2008).
} 
ficava disponível sem restrição) e as pontuações numa escala likert de cinco pontos sobre a emotividade gerada pela imagem. Quando comparados com os resultados do grupo controle que o tempo todo teve acesso a imagens pouco emotivas, não houve diferenças nos tempos de observação inferidos a partir da latência para mudar de imagem. No entanto, o grupo que teve acesso às fotografias altamente emotivas no começo deu pontuações menores do que o outro grupo a cada imagem da segunda fase. Esses resultados sugerem que em alguma medida o uso de imagens é sensível à avaliação em função do conteúdo e da experiência dos participantes com diferentes valores dessa variável, isto é, experiência com imagens mais emotivas faz com que as imagens neutras fiquem menos emotivas do que avaliado por aqueles que só tiveram contato com imagens neutras. Talvez um delineamento intrasujeito e medidas mais sensíveis possam dar informações adicionais sobre a relatividade do valor das imagens, e apresentações concorrentes delas poderiam caracterizar melhor as respostas exibidas durante a desvalorização.

No caso dos humanos, as respostas oculares se constituem num modelo versátil, pois fazem parte de comportamentos tão diversos como se alimentar, flertar e se proteger. O conteúdo das imagens utilizadas nos estudos de rastreamento ocular tem sido um dos parâmetros avaliados, que incluem avaliação de imagens aversivas (p.e. Wangelin, Löw, McTeague, Bradley, e Lang,2011), sexuais (p.e. Rupp e Wallen, 2007), sociais (p.e. reconhecimento de emoções Schmid, Mast, Bombari, Mast, e Lobmaier, 2011), usando imagens "neutrais" como condição controle e/ou de comparação.

Wyckoff (1969) ressaltou que a resposta de observação natural para estímulos visuais é fixar os olhos, mas dificuldades técnicas podem atrapalhar a sua medição. Quase 50 anos depois, a tecnologia de rastreamento ocular tem desenvolvido equipamentos de alta sensibilidade e complexidade. O EyeLink 1000®, por exemplo, além de medir o movimento dos olhos, permite utilizar essa resposta como entrada (input) de processamento, substituindo o clicar do mouse e/ou a pressão da tecla como resposta efetiva. No geral, quando entramos numa sala ou outro ambiente, a primeira exploração é visual (não manual ou de outro tipo). Se for considerado que para ter acesso a determinadas porções do ambiente o funcionamento do olhar faz com que seja preciso pousar os olhos nelas, a possibilidade oferecida pelo equipamento constituiria 
um controle que favorece a validade externa e que se soma ao registro das respostas dos participantes.

\section{Contraste Sucessivo e respostas oculares: Um labirinto para os olhos.}

Temos então que as estratégias exibidas no momento da perda total ou parcial de um recurso podem ser descritas em termos de uma redistribuição do comportamento na qual 1) diminui a execução da resposta (consumatória ou operante) que não está mais correlacionada com uma consequência de maior valor, 2) aumenta a execução de respostas que eram menos prováveis, 3) se conserva a estrutura das respostas executadas antes da perda ou deterioro, 4) a execução das respostas é relativa aos valores das consequências experimentadas e não só respeito do seu valor absoluto, 5) os estímulos antecedentes ou discriminativos também funcionam de maneira relativa, 6) existem preferências nas respostas aos estímulos discriminativos e não discriminativos, 7) os movimentos oculares têm a particularidade de ser ao mesmo tempo resposta de observação ("procura") e resposta efetiva ("consumo"). No entanto, a interação entre as características numeradas tem sido estudada de modo isolado em paradigmas que, como no caso do Contraste, colocam a ênfase nos componentes emocionais das respostas diante da perda, ou em situações experimentais que não oferecem alternativas suficientes para conseguir descrever a dinâmica do comportamento em momentos de mudança.

Para entender as relações custo-benefício que acontecem durante as situações de perda, isto é, a experiência de um organismo sensível à diferentes valores de reforçamento, se faz necessário criar uma situação experimental que ofereça possibilidades de variação comportamental controlada. Os labirintos tem sido uma das opções metodológicas utilizadas para solucionar esse tipo de problema.

O objetivo do presente projeto foi testar um procedimento que empregasse a resposta ocular em humanos de forma análoga àqueles utilizados tradicionalmente no fenômeno de Contraste Sucessivo (com outras respostas e outras espécies) e que levasse em consideração várias das características já conhecidas das estratégias 
comportamentais observadas durante uma situação de perda. Se espera com isso obter uma caracterização da redistribuição de respostas oculares entre opções com diversos valores (dados pela alocação de fixações nos estímulos apresentados) e funções (discriminativas, consumatórias e operantes), após uma mudança parcial que quebre a regularidade dos eventos experimentados.

\section{Método}

\section{Participante}

O procedimento foi testado com uma participante com conhecimento formal (teórico) do experimento, mas sem experiencia (direta) com ele. Procedimentos semelhantes com o uso de rastreadores oculares contam com a participação dos autores como sujeitos dos seus próprios experimentos (p.e. Madelain, Champrenaut e Chauvin, 2007, 2007; Madelain, Harwood, Herman, e Wallman, 2010; Madelain, Paeye e Wallman, 2011) e não são observadas diferencias quando comparados com sujeitos ingênuos. A visão da participante não apresentava problemas. $\mathrm{O}$ procedimento experimental foi revisado e aprovado pelo Comité de Pesquisa em Seres Humanos do Instituto de Psicologia da Universidade de São Paulo, com o parecer número 1.747.728. A participante leu e assinou o Consentimento Informado.

\section{Instrumentos}

\section{Equipamento}

A sessão experimental foi realizada no Laboratório F. S. Keller de Estudos do Comportamento Operante no Instituto de Psicologia da USP, em uma sala de 2,5m x $5 \mathrm{~m}$, iluminada exclusivamente por luz artificial. Dois computadores foram utilizados, um deles equipado com um processador Intel Core 2 Quad $2.83 \mathrm{GHz}$, uma placa de vídeo NVIDIA GeForce GT440 e um monitor LCD de 22 polegadas de $120 \mathrm{~Hz}$ que rodou um programa de desenvolvimento próprio em Phyton para apresentar os estímulos à participante, registrar as respostas e fazer a interação com o software de rastreamento ocular. 
O segundo computador registrou o movimento ocular com o EyeLink 1000® Desktop Mount, e não ficou accessível à participante. O equipamento está conformado por (a) uma câmara configurada para gravar o olho esquerdo do participante a uma taxa de $1000 \mathrm{~Hz}$, a qual está conectada a um computador Intel Core 2 Duo 2.6GHz que, por sua vez, inclui o software EyeLink 1000® Version 4.56.

Uma fonte de iluminação infravermelha (b) e a câmara estão acopladas e colocadas logo abaixo do monitor (c) em que foram apresentados os estímulos. A luz infravermelha passa através da pupila e é refletida pela córnea registrando a posição e o tamanho da pupila enquanto o participante mantém a cabeça fixa num suporte (d) localizado a $75 \mathrm{~cm}$ da tela e a $62 \mathrm{~cm}$ da câmara. O software EyeLink 1000® DataViewer versão 1.11.1 é utilizado para processar os registros e gerar as planilhas com os dados das fixações e dos movimentos do olho. Figura 2 apresenta uma fotografia dos equipamentos acessíveis ao participante.

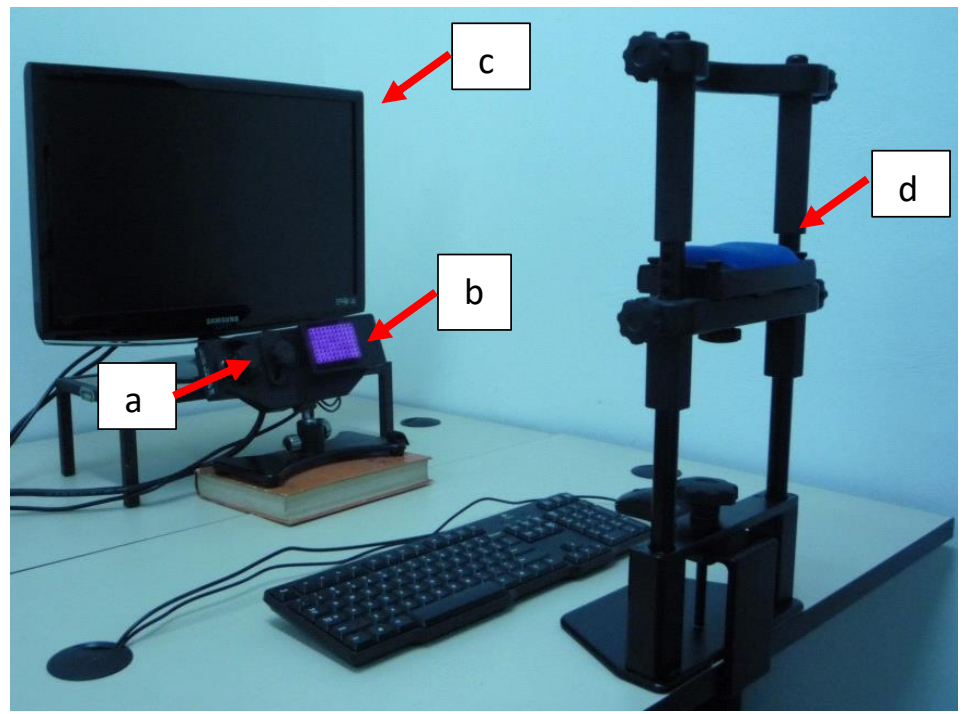

Figura 2. Fotografia dos equipamentos na sala experimental

A calibragem do EyeLink $1000 \circledR$ é feita com o software Popup Calibration versão 2.0, com um procedimento de nove pontos e validação posterior. Os dados gerados pelo movimento ocular foram analisados com SPSS $®$ e MAtematiKa ${ }^{\circledR}$.

\section{Estímulos}


Foram selecionadas 192 fotografias do IAPS que foram divididas em seis grupos com 32 cada. As categorias propostas foram: A) EROS: imagens eróticas (que incluem mulheres seminuas, nuas ou casais), B) BB: filhotes humanos e de outras espécies, C) PA: paisagens naturais (p.e. montanhas, praias, flores), D) PF: locais fechados e objetos cotidianos (p. e. um escritório, uma toalha), E) V: cenas que representam algum tipo de violência (p.e. guerras, assaltos, espancamentos), e F) Sick: imagens com pessoas feridas ou doentes (p.e. queimaduras, infecções). A partir dos valores reportados no relatório técnico de Lang, Bradley e Cuthbert (2008), a média da escala de valência afetiva das imagens utilizadas em cada categoria é apresentada no Anexo 1. Adicionalmente, foram usadas seis figuras geométricas de 250 × 250 pixels $(7 \times 7 \mathrm{~cm}$ aprox.) como estímulos antecedentes, cada uma correspondendo a uma das categorias propostas. Uma sétima figura foi pareada aleatoriamente com elementos de todas as categorias (estímulo aleatório).

Tabela 1. Descrição e exemplos das categorias de estímulos utilizados

\begin{tabular}{|c|c|c|c|}
\hline $\begin{array}{l}\text { Valencia } \\
\text { emotiva }\end{array}$ & Código & Categoria & Descrição/Exemplos \\
\hline \multirow{2}{*}{ Positiva } & EROS & Eróticas & $\begin{array}{l}\text { Mulheres seminuas, nuas ou casais envolvidos } \\
\text { em atividades eróticas. }\end{array}$ \\
\hline & $\mathrm{BB}$ & Filhotes & Filhotes humanos e de outras espécies \\
\hline \multirow{2}{*}{ Neutra } & PA & $\begin{array}{l}\text { Paisagem } \\
\text { Aberta }\end{array}$ & Paisagens naturais: montanhas, praias, flores. \\
\hline & $\mathrm{PF}$ & $\begin{array}{l}\text { Paisagem } \\
\text { Fechada }\end{array}$ & $\begin{array}{l}\text { Locais fechados e objetos cotidianos produzidos } \\
\text { pelo homem: prédios, uma xicara. }\end{array}$ \\
\hline \multirow{3}{*}{ Negativa } & V & Violência & Guerras, assaltos, espancamentos. \\
\hline & Sick & Doenças & $\begin{array}{l}\text { Imagens com pessoas feridas ou doentes (p.e. } \\
\text { queimaduras, infecções). }\end{array}$ \\
\hline & Random & Aleatória & $\begin{array}{l}\text { Inclui fotografias de todas as categorias } \\
\text { anteriores }\end{array}$ \\
\hline
\end{tabular}

\section{Procedimento}

\section{Calibragem.}

Após assinar o termo de consentimento, a participante foi levada à sala de coleta, sentou na frente da tela do computador que mostrava os diferentes estímulos enquanto o queixo descasava no suporte. Logo depois, foi realizado o procedimento de calibragem automatizado pelo software Popup Calibration 2.0. Nele, a participante devia seguir um ponto de $0,5 \times 0,5 \mathrm{~cm}$ apresentado de modo intermitente em nove diferentes pontos da 
tela, e a partir das coordenadas obtidas, o programa acha as correspondências entre as coordenadas do olho e sua distância com o centro do estímulo.

\section{Instrução.}

Após a calibragem do equipamento, uma tela cinza (utilizada ao longo de todo o experimento) foi apresentada contendo uma caixa de texto em sua parte central. Nela aparecia a seguinte instrução:

"Por favor, ao longo da sua participação, mantenha a cabeça acomodada sobre o suporte.

A seguir, será apresentada uma série de imagens. Cada apresentação conterá duas imagens de diverso conteúdo.

Antes da apresentação, olhe para o ponto de fixação no centro da tela para que as imagens sejam apresentadas.

Quando estiver pronto, clique no botão 'Começar'”.

Logo depois da participante clicar no botão, as instruções foram retiradas e a tela permaneceu completamente cinza durante $1000 \mathrm{~ms}$. A primeira tentativa foi apresentada em seguida.

Fase I: Pareamento dos estímulos arbitrários com as fotografias de cada categoria

O objetivo dessa fase era obter respostas oculares previsíveis e estáveis a partir do pareamento das fotografias de cada categoria com um estímulo arbitrário que antecedia consistentemente sua aparição.

A estrutura geral de cada tentativa consistiu em cinco momentos:

I) Apresentação do ponto de fixação no centro da tela até o participante fixar nele durante $500 \mathrm{~ms}$ consecutivos. O ponto de fixação aparece antes de cada uma das telas com quadrantes.

II) Apresentação de dois dos estímulos arbitrários, em diferentes quadrantes da tela, durante 1000 ms. As Figuras permanecem "apagadas" (cor cinza 
escuro) enquanto o participante não fixa nelas, e são "iluminadas" (cor branco) se isso acontece.

III) Apresentação dos quadrantes sem nenhuma imagem durante 1000 ms;

IV) Disponibilidade das fotografias correspondentes aos estímulos arbitrários (pois só apareciam quando fixadas) durante $3000 \mathrm{~ms}$, conservando a mesma posição do que seus respetivos estímulos antecedentes quando apresentados, e

V) Apresentação da tela vazia durante $500 \mathrm{~ms}$.

Assim, a forma do estímulo arbitrário está pareada com a categoria de imagens correspondente, e a posição dele nos quadrantes indica a posição na qual aparecerá essa imagem (ver Figura 3).

O ponto de fixação estabelece um local de partida e aparece entre as diferentes telas para garantir que o tempo de fixação não dependa de o olho já estar em determinada posição na tela, ou das diferentes distâncias entre os pontos de interesse.

I II III IV

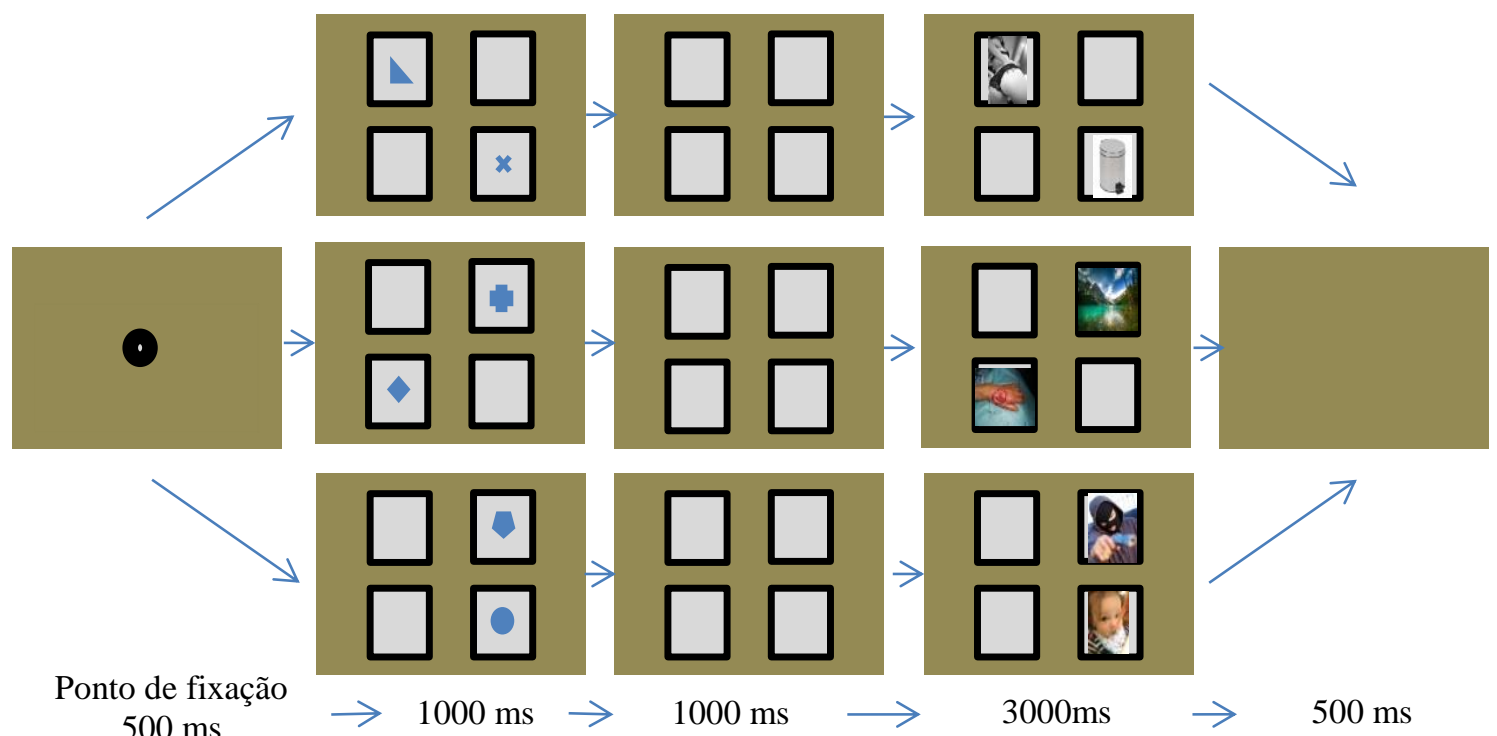

Figura 3. Exemplos da estrutura geral das tentativas. Depois da apresentação do Ponto de fixação (I), são apresentadas as figuras geométricas (II). As fotografias correspondentes aparecerem na mesma posição (IV) após um intervalo de 1000ms (III) em que só os quadrantes sem conteúdo são apresentados. A tentativa termina com a apresentação da tela vazia (V). O Ponto de fixação aparece entre as diferentes telas para garantir que o olho tenha sempre o mesmo ponto de partida. As fotografias apresentadas só representam exemplos dos conteúdos das categorias propostas e não pertencem à bateria do IAPS (detalhes no texto). 
A apresentação das diversas configurações entre Categorias e Localizações de maneira aleatória, de forma em que nenhum viés de posição ou frequência de aparição fosse favorecido, teve que atingir várias restrições e cumprir algumas condições. As imagens disponíveis em cada tentativa (tanto as figuras geométricas quanto as fotografias) pertenciam a duas categorias distintas. Cada um dos pares possíveis de imagens (15 no total $)^{7}$ foram apresentados seis vezes cada, uma a cada configuração possível de pares de quadrantes ${ }^{8}$. No caso dos pares de imagens A-B (imagens agradáveis), C-D (imagens neutras) e E-F (imagens desagradáveis) foram acrescentadas mais duas tentativas em cada para conservar o máximo de simetria no arranjo experimental em cada parâmetro. Em total, cada configuração de pares de quadrantes alojou 17 pares de imagens. A ordem das tentativas foi aleatorizada de modo que a mesma categoria não fosse apresentada mais de duas vezes consecutivas (detalhes da ordem das tentativas podem ser encontrados no Anexo 3). Na Figura 4 por exemplo, se mostram as figuras geométricas no par de quadrantes 1,4, que é o mesmo par que aloja as fotografias da combinação de categorias "AC". Nenhuma das fotografias foi apresentada mais do que uma vez durante esta fase.

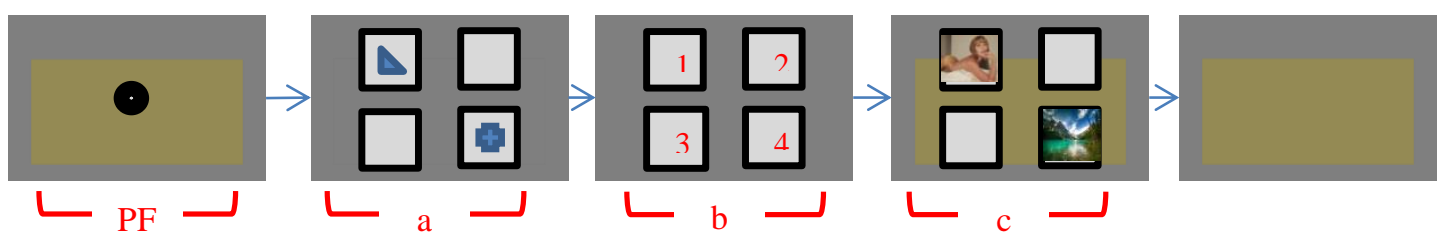

Figura 4. Convenções. A depender do momento do procedimento, os objetos na tela vão cumprindo distintas funções e são nomeados diferencialmente. PF: Ponto de Fixação. a: figuras geométricas, estímulos arbitrários, estímulos antecedentes, estímulos discriminativos. b: quadrantes $(1,2,3,4)$. c: fotografias, estímulos incondicionados, estímulos subsequentes, consequências. O termo "imagens" se usa tanto para a quanto para c quando estão juntos. Uma "categoria" se refere às imagens que compartilham um conteúdo e função. A categoria "A" - fotografias eróticas - inclui também a figura geométrica que antecede consistentemente sua aparição na tela.

Adicional as figuras geométricas correspondentes a cada uma das seis categorias de imagens, uma sétima figura antecedeu a localização de 24 fotografias (quatro de cada uma das categorias), conformando a categoria "Random" que pretendia servir como grupo de comparação com os pareamentos consistentes (ver Figura 5). A localização de este tipo de pareamento considerou o conteúdo das tentativas "consistentes" para manter uma distribuição homogênea e aleatória dentro do arranjo geral.

7 Um par de imagens está definido pelas categorias às quais pertencem as fotografias apresentadas em cada tentativa. Por exemplo, uma imagem erótica (A) apresentada junto a uma imagem de paisagem $(\mathrm{C})$ conformaria o par "AC". Os pares de imagens possíveis são: $\mathrm{AB}-\mathrm{AC}-\mathrm{AD}-\mathrm{AE}-\mathrm{AF}-\mathrm{BC}-\mathrm{BD}-\mathrm{BE}$ $-\mathrm{BF}-\mathrm{CD}-\mathrm{CE}-\mathrm{CF}-\mathrm{DE}-\mathrm{DF}-\mathrm{EF}$.

8 Um par de quadrantes está definido pela posição da imagem na tela, com as posições 1-2-3-4. Os pares de quadrantes possíveis seriam $1,2-1,3-1,4-2,3-2,4-3,4$. 


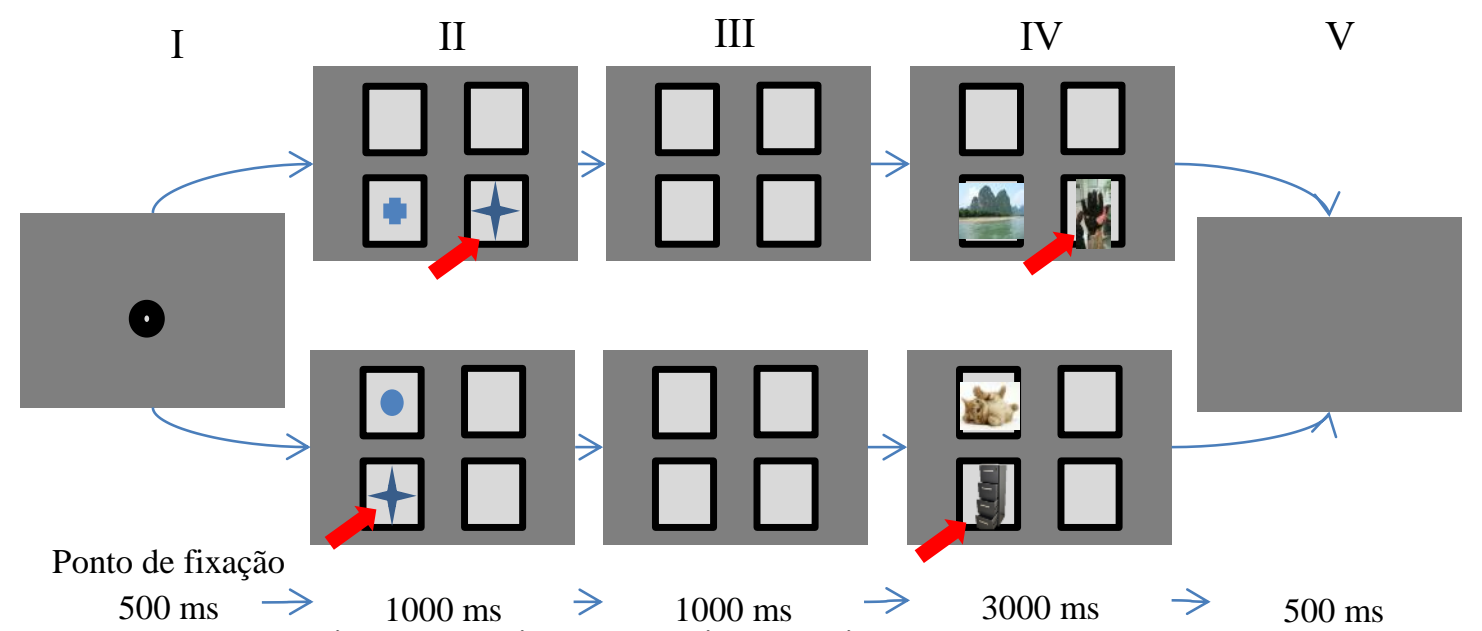

Figura 5. Características do estímulo arbitrário aleatório. Adicionalmente aos estímulos arbitrários que antecedem de forma consistente às fotografias de cada categoria, um sétimo estímulo arbitrário (assinalado pela seta na figura) antecederá com a mesma probabilidade imagens de todas elas, estabelecendo assim uma condição na qual o estímulo não teria função discriminativa programada.

Um total de 96 tentativas foram programadas para esta fase. A fim de manter constante a densidade de apresentação das diferentes categorias assim como a distribuição das localizações aleatorizadas ao longo do treino (e não só considerando o conjunto do total de tentativas), a ordem de apresentação foi organizada em quatro blocos de 24 tentativas de características tão semelhantes entre si quanto possível. De ser executado com mais participantes, o procedimento permite a apresentação das tentativas de forma variada quando rearranjados esses blocos.

Outro controle metodológico está na possibilidade de fazer com que as Figuras geométricas possam ser pareadas com as diferentes categorias variando entre diferentes participantes, facilitando o reconhecimento de algum padrão de observação que não dependa do pareamento experimental, mas sim de, por exemplo, alguma característica desses estímulos arbitrários. A possibilidade de configurar essas características permite ao experimentador fazer com que todos seus participantes recebam exatamente o mesmo treino ou randomizar a ordem de apresentação e o tipo de pareamentos à conveniência.

A Fase I foi programada para terminar uma vez atingido um critério de estabilidade que hierarquiza os pareamentos Figura-Fotografia a partir do tempo de fixação. O participante entrava na segunda fase no momento em que as três categorias mais observadas guardavam o mesmo ranqueamento, tanto na Figura geométrica quanto 
na Fotografia, durante nove de doze tentativas em que fosse apresentada. Em outras palavras, a Figura geométrica mais observada devia ser aquela correspondente à Fotografia mais observada, e igualmente devia acontecer com a segunda e a terceira posição. A probabilidade de esse critério ser atingido ao acaso é de $0,48 \%{ }^{9}$. A mudança de fase não foi sinalizada para o participante.

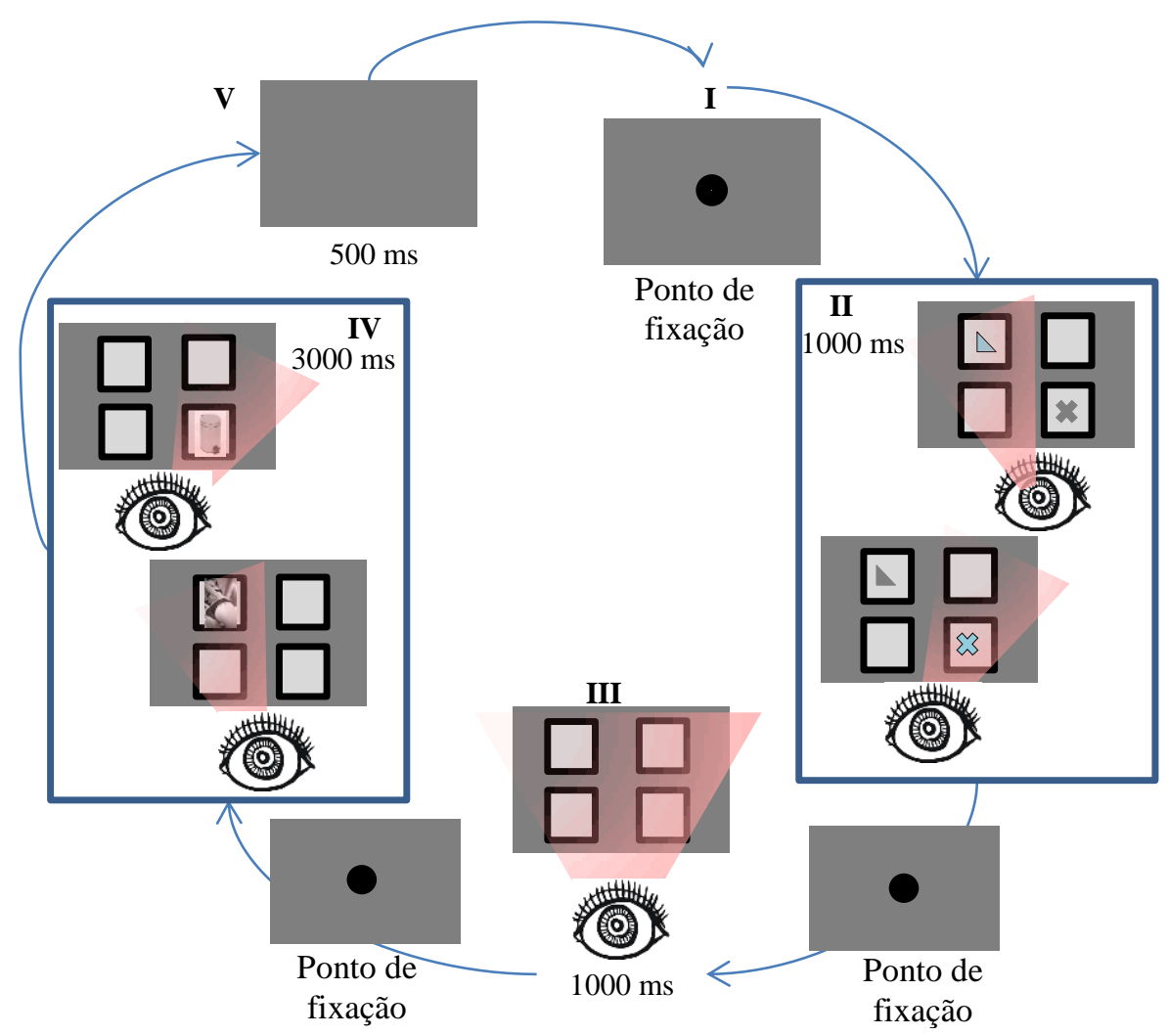

Figura 6. Disponibilidade e aparição das imagens. Em II, as figuras geométricas são "iluminadas" quando o participante realiza uma fixação no quadrante correspondente e "apagadas" quando ele não o faz. Com as fotografias, o participante deve realizar uma fixação na área do quadrante para elas aparecerem na tela.

\section{Fase II: Irregularidade no pareamento mais observado}

Logo depois de atingir o critério de estabilidade, o programa mudava em tempo real as contingencias da categoria mais observada. A nova condição consistiu em que a Figura geométrica continuava sendo apresentada, mas a fotografia era substituída por aquela correspondente à categoria ranqueada no terceiro lugar segundo os tempos de

\footnotetext{
${ }^{9}$ Probabilidade condicionada. $1 / 7 \times 1 / 6 \times 1 / 5=1 / 210$.
} 
fixação do participante. Tanto a estrutura das tentativas quanto as contingências de apresentação das imagens das outras categorias continuaram vigentes (ver Figura 7).

A categoria ranqueada no terceiro lugar é observada o suficiente para evitar algum efeito de chão que impossibilite analisar as respostas obtidas (o que poderia acontecer com as categorias menos observadas), e da mesma maneira, as probabilidades de a substituição resultar em indiferença são menores do que se fosse feito com a segunda categoria mais observada.

O objetivo dessa fase é alterar a regularidade nos pareamentos apresentada na fase anterior e registrar as mudanças que ocorrem nas respostas oculares, tanto nas categorias modificadas quanto nas imagens que não estiveram envolvidas.

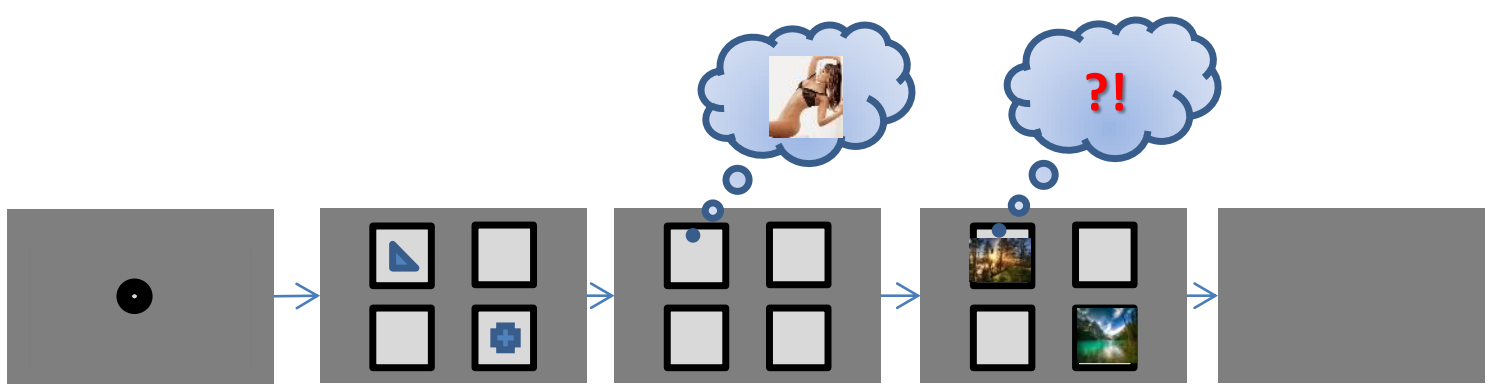

Figura 7. Manipulação experimental. $O$ estímulo arbitrário que nas tentativas passadas antecedeu a categoria de fotografias mais observadas, nessa segunda fase do experimento será seguido por fotografias da categoria colocada na terceira posição.

\section{Resultados}

\section{Descrições iniciais}

A Tabela 2 mostra o ranqueamento a partir do qual foi estabelecido o critério de aprendizagem proposto para este experimento. A categoria com maior tempo de fixação foi Violência, seguida de Erótica e Filhotes. A diferença entre as Figuras geométricas nas três primeiras posições esteve ao redor do 1,5\%, enquanto das Fotografias foi menor do que $0,5 \%$ entre a primeira e a segunda posição, enquanto da terceira esteve ao redor do $13 \%$. Por conseguinte, a Figura contrastada foi a correspondente à categoria Violência, que na segunda fase esteve acompanhada de Fotografias de Filhotes; em 
consequência, durante a Fase II foram apresentadas Fotografias de bebés antecedidos por uma Figura geométrica pareada anteriormente com esse conteúdo (esperados), e também Fotografias de bebés antecedidos pela Figura geométrica associada à conteúdo violento (contrastados).

Tabela 2 . Ranqueamento obtido no momento de atingir o critério de aprendizagem

\begin{tabular}{lcll}
\hline \multicolumn{2}{c}{ Figuras / Milissegundos } & \multicolumn{2}{c}{ Fotografias / Milissegundos } \\
\hline 1o. E - violência & 579487 & 1o. - violência & 1608107 \\
2o. A - erótica & 572747 & 2o. A - erótica & 1604745 \\
3o. B - filhotes & 567729 & 3o. B - filhotes & 1387654 \\
4o. G - aleatória & 546064 & 4o. C - paisagem aberta & 1354253 \\
5o. C - paisagem aberta & 515996 & 5o. - doenças & 1274195 \\
6o. - doenças & 489252 & 6o. D - paisagem fechada & 1161524 \\
7o. D - paisagem fechada & 471468 & 7o. G - aleatória & 985222 \\
\hline
\end{tabular}

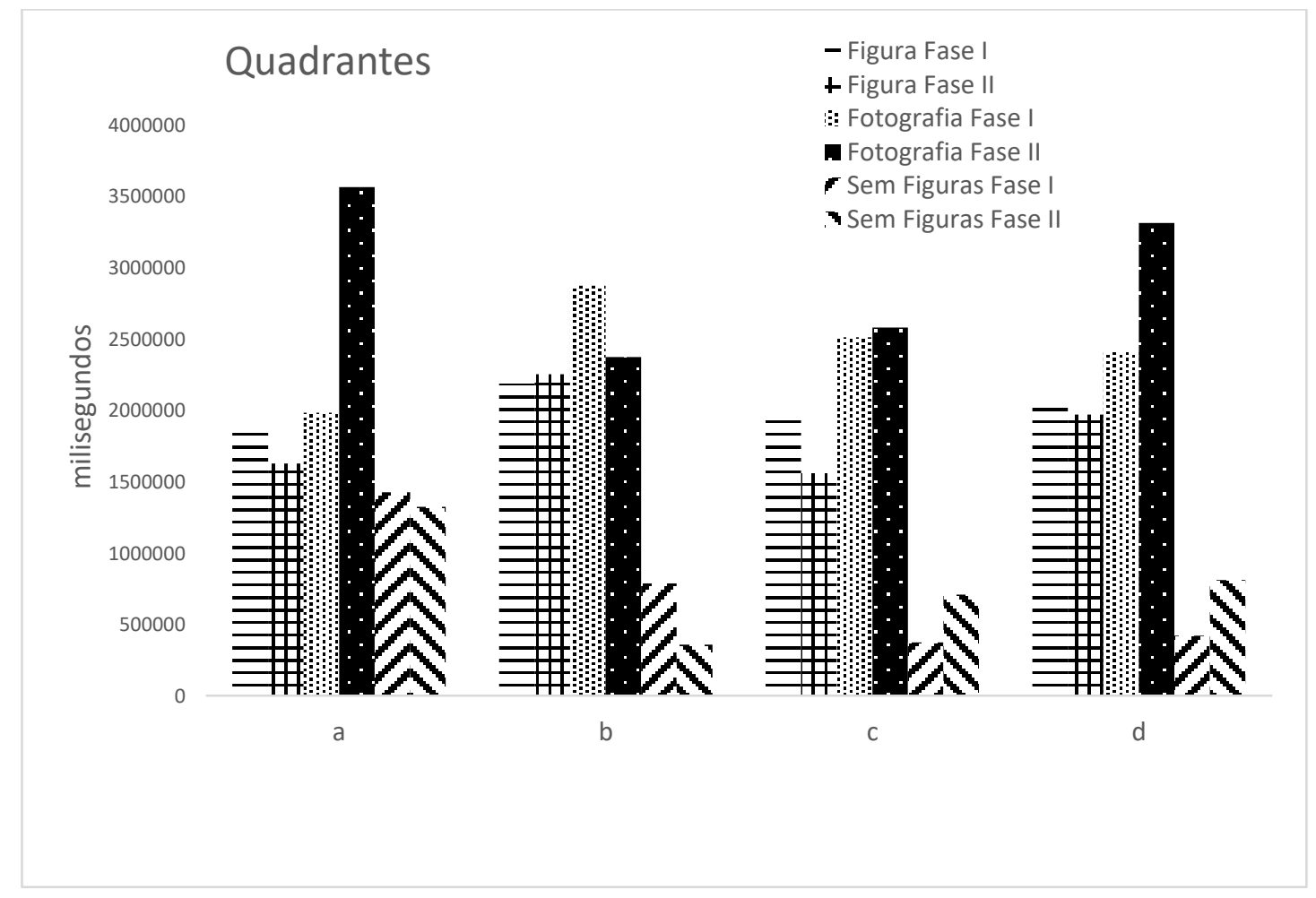

Figura 8. Tempo de observação dos quadrantes em diferentes momentos.

A Figura 8 Mostra os tempos de fixação acumulados em cada um dos quadrantes em que apareciam os estímulos (a-b-c-d). Em princípio, se o tempo de fixação depende do conteúdo apresentado, e dado que a distribuição de categorias e combinações possíveis entre duplas de estímulos foi aleatorizada (Anexo 3) cuidando de não favorecer nenhum viés, se esperaria indiferença entre os quadrantes. No entanto, o 
quadrante "a" (esquina superior esquerda da tela) foi mais observado do que os outros, sobretudo nos momentos em que não aparecia nenhum conteúdo neles (i.e., Sem figuras Fase I e Fase II). Considerando que nossa escritura tem uma direção que vai de esquerda para direta, e de cima para baixo, e possível que em indivíduos alfabetizados a exploração visual seja afetada por esse fato (ver Starr e Inhoff, 2004).

Esse viés é menos evidente quando os quadrantes contem alguma imagem, sugerindo que o conteúdo de fato foi uma variável importante na distribuição dos tempos de fixação e, adicionalmente, indica que a randomização das tentativas foi satisfatória. Os tempos e fixação nos quadrantes durante a apresentação das Figuras geométricas se mantêm constantes durante as duas fases do experimento, entanto que quando apresentadas as Fotografias aparece um aumento durante a Fase II para o quadrante "a".

\section{Durações e frequências}

Analisando o comportamento das categorias, foi possível identificar diferenças nos tempos de fixação dependentes do conteúdo dos estímulos. Na Figura 9 está representada a frequência com que as diferentes Imagens (tanto Figuras geométricas quanto Fotografias) foram preferidas. Isto é, do total de tentativas em que apareceu cada imagem (aproximadamente 20 vezes em cada Fase), foram contabilizadas as ocasiões em que dita imagem foi preferida sobre a outra (p.e. 10/20). Desta maneira, uma taxa de preferência de 50\% significa que a escolha desse tipo de imagem foi indiferente. Neste índice não foi levado em consideração o tamanho da diferencia entre ambas as imagens apresentadas, pois mesmo que dita diferença fosse de um segundo ou de 0,1 segundo, a contaria mais um na frequência de preferência para a categoria.

Nas Figuras geométricas é observada certa indiferença entre as categorias, especialmente durante a Fase I, e só a Figura associada a Violência atinge níveis maiores do que $70 \%$. No caso das Fotografias, somente a categoria de filhotes atinge essa porcentagem. Já durante a Fase II, a Figura geométrica Doença teve um aumento importante, chegando quase a um $80 \%$ de preferência sobre as outras figuras apresentadas, no entanto a Fotografia desta categoria no foi mais observada durante a 
Fase II. As Fotografias das categorias Eros e Bebês chegaram a atingir taxas de mais de 90\%. A Figura geométrica contrastada (Violência), foi menos observada do que quando apresentada na Fase I. Também, as Fotografias de Bebés não sinalizados (contrastados) foram menos preferidas do que as Fotografias de Bebés sinalizadas pela Figura geométrica pareada durante a Fase I.

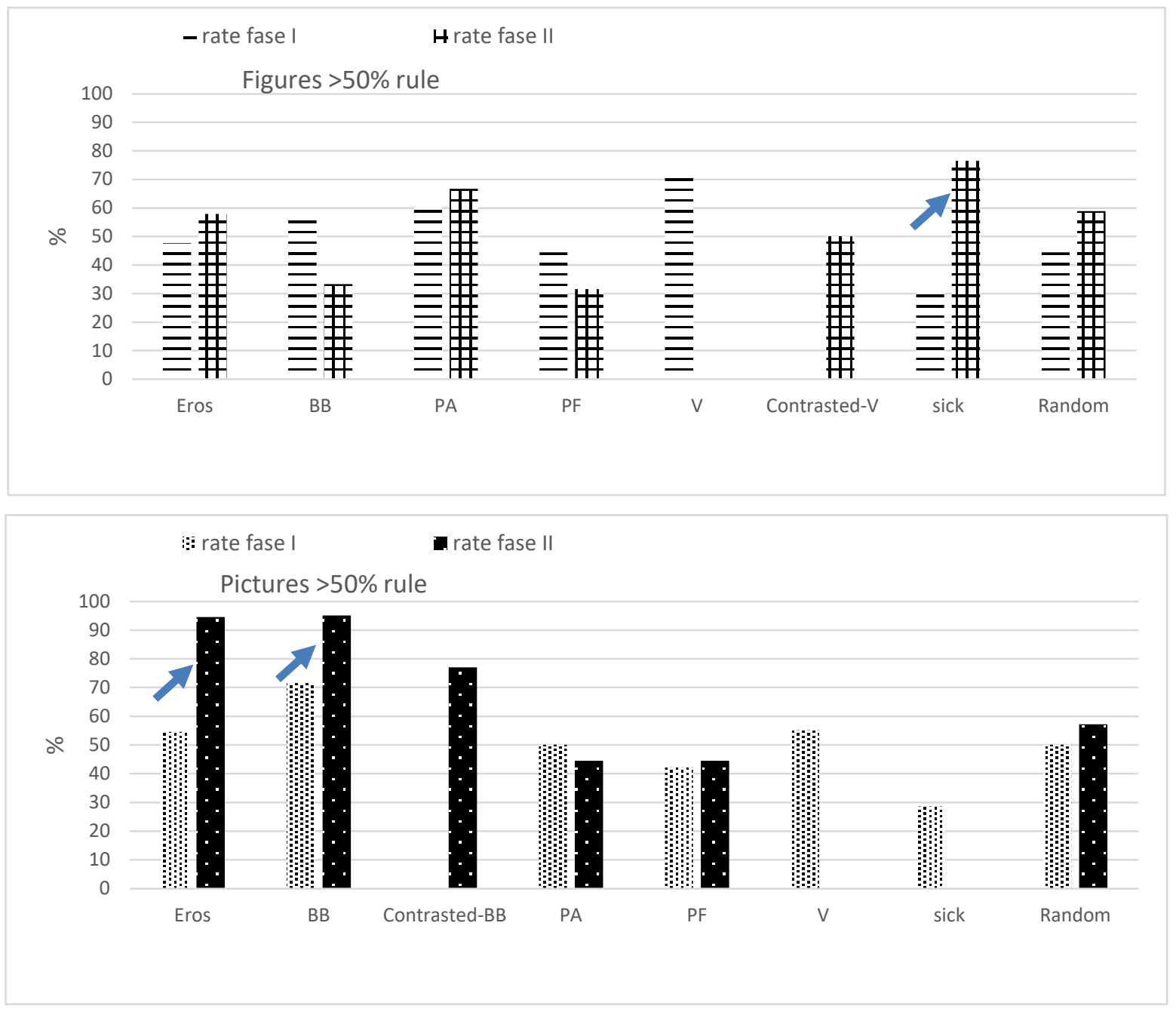

Figura 9. Frequência relativa de preferência Figuras geometricas e Fotografias

Quando o tempo de fixação é usado para identificar as tentativas em que a observação foi indiferente entre os estímulos apresentados numa determinada tentativa, outras características da resposta ocular são evidenciadas. A Figura 10 representa a taxa com que as diferentes Imagens superaram o $60 \%$ de tempo efetivo de fixação durante cada tentativa. Independentemente do tempo disponível para as diferentes Imagens (1000 ms para as Figuras geométricas e $3000 \mathrm{~ms}$ para as Fotografias), foi considerado o 
tempo que a participante fixou o olhar nos quadrantes com algum conteúdo. Por exemplo, se dos três segundos em que as fotografias estavam disponíveis, o tempo efetivo de observação foi de 1 segundo distribuído em $700 \mathrm{~ms}$ para a fotografia X e 300 ms para a fotografia $\mathrm{Y}$, a fotografia $\mathrm{X}$ seria classificada como preferida e a fotografia $\mathrm{Y}$ como não-preferida. Posteriormente, as Imagens classificadas como preferidas (que superaram o 60\% de tempo efetivo de observação), são contabilizadas em relação ao total de vezes em que foi apresentada (aprox. 20 vezes em cada Fase). No caso em que, por exemplo, 5 das 20 vezes em que uma categoria foi apresentada atingisse o critério, a taxa de preferência dessa categoria sobre as outras seria de $25 \%$. As tentativas restantes foram classificadas como indiferentes $(40<x<60)$ ou não preferidas $(x<40)$.

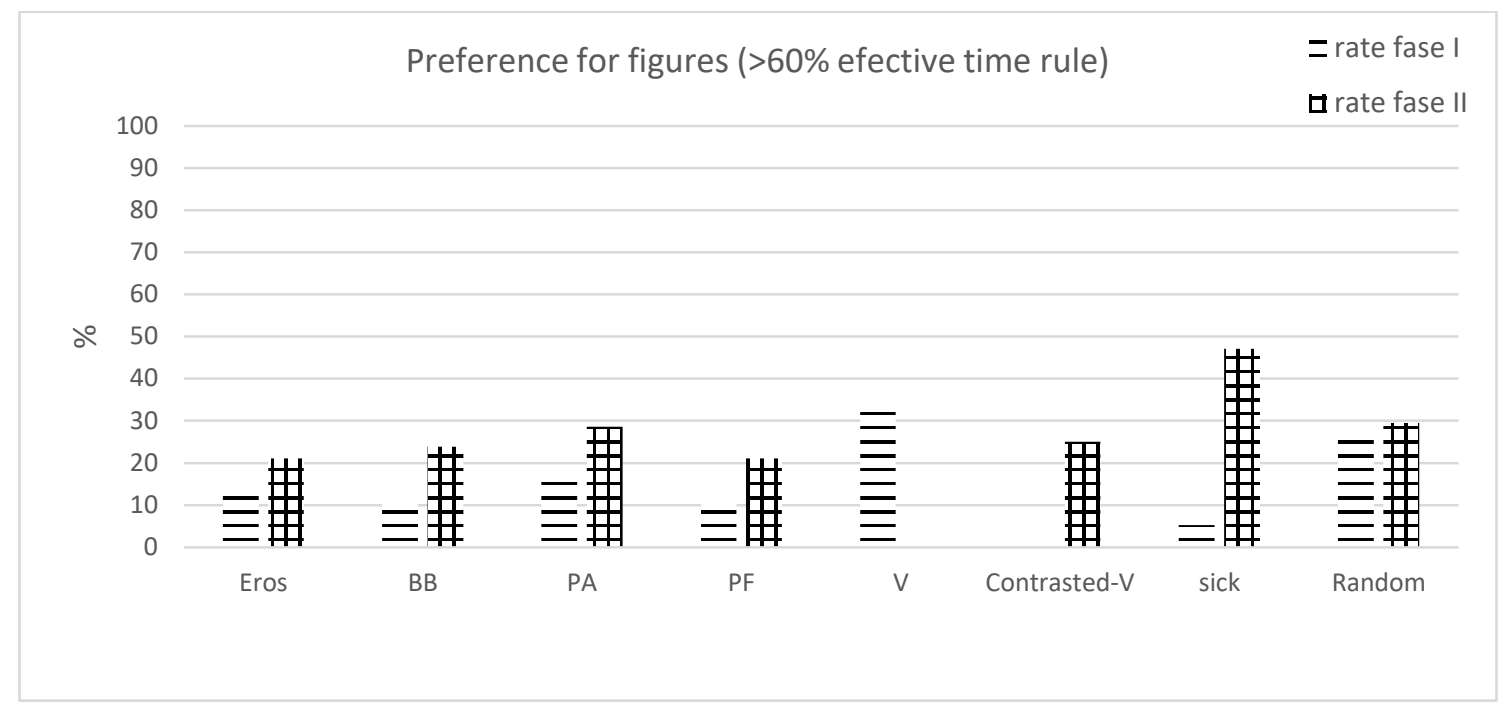

Figura 10. Frequência relativa de preferência das Figuras geometricas que atingem o criterio de $60 \%$.

Com a aplicação desse critério de preferência superior ao 60\% do tempo efetivo de observação (Imagens "realmente preferidas") aparecem as mesmas tendências da análise anterior (que incluía as Imagens “indiferentes”). No entanto, se faz evidente que durante a Fase I só de um 10\% a um 15\% das Figuras geométricas apresentadas atinge esse critério, e que durante a Fase II essas porcentagens se mantêm ao redor do 25\% para a maioria das categorias, exceto para a Figura geométrica correspondente a Doença, que aumentou de menos de $10 \%$ de preferência na Fase I até quase um 50\% das tentativas na Fase II.

Já nas Fotografias (Figura 11) as categorias Eros, Filhotes e Violência atingiram o critério de preferência em até um $40 \%$ das tentativas da primeira Fase. Mesmo que não seja possível identificar uma tendência clara, é observado que as categorias de 
Paisagem Aberta, Paisagem Fechada e Doença foram pouco preferidas durante essa Fase. Quando as contingências da Fase II entraram em vigor, é observada uma hierarquização organizada das categorias, ranqueando as Fotografias de valência emocional positiva no topo da preferência (Eróticas e Filhotes), as categorias neutras no meio, e evidenciando que a categoria de Doença parou de ser observada (e por tanto, preferida). A categoria Random teve um aumento de $10 \%$ de preferência durante a segunda Fase em comparação com a primeira. Adicionalmente, as Fotografias de Filhotes antecedidas pela Figura geométrica correspondente a Violência foram $20 \%$ menos preferidos do que as Fotografias de Bebés que sempre foram antecedidas pela mesma Figura geométrica.

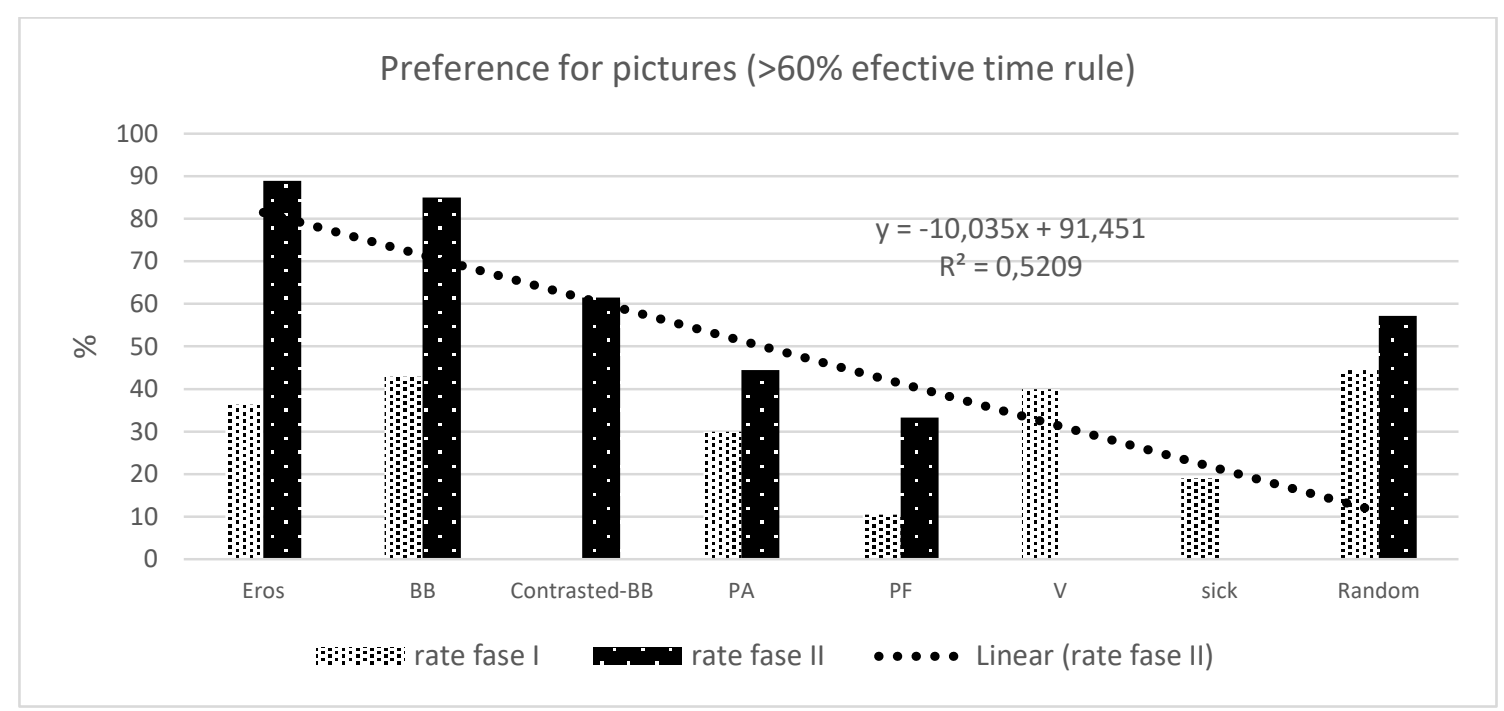

Figura 11. Frequência relativa de preferência das Fotografias que atingem o critério de $60 \%$

Tabela 3 Frequência de tentativas que atingiram os critérios de preferência

\begin{tabular}{c|cccccccc|cccccccc} 
& \multicolumn{8}{|c|}{ FIGURAS GEOMÉTRICAS } & \multicolumn{7}{c}{ FOTOGRAFÍAS } \\
& $\mathbf{E}$ & $\mathbf{B B}$ & $\mathbf{P A}$ & $\mathbf{P F}$ & $\mathbf{V}$ & $\mathbf{C}-$ & $\mathbf{S}$ & $\mathbf{R}$ & $\mathbf{E}$ & $\mathbf{B B}$ & $\begin{array}{c}\text { C- } \\
\text { BB }\end{array}$ & $\mathbf{P A}$ & $\mathbf{P F}$ & $\mathbf{V}$ & $\mathbf{S}$ & $\mathbf{R}$ \\
\hline Total Fase I & 21 & 19 & 18 & 18 & 21 & 0 & 19 & 18 & 22 & 21 & 0 & 20 & 19 & 20 & 21 & 18 \\
Preferidos $>50$ & 10 & 11 & 11 & 8 & 15 & 0 & 6 & 8 & 12 & 15 & 0 & 10 & 8 & 11 & 6 & 9 \\
Preferidos $>60$ & 3 & 2 & 3 & 2 & 7 & 0 & 1 & 17 & 8 & 9 & 0 & 6 & 2 & 8 & 4 & 8 \\
Total Fase II & 19 & 21 & 21 & 19 & 0 & 16 & 17 & 10 & 18 & 20 & 13 & 18 & 18 & 0 & 0 & 14 \\
Preferidos $>50$ & 11 & 7 & 14 & 6 & 0 & 8 & 13 & 5 & 17 & 19 & 10 & 8 & 8 & 0 & 0 & 8 \\
Preferidos $>60$ & 4 & 5 & 6 & 4 & 0 & 4 & 8 & 5 & 16 & 17 & 8 & 8 & 6 & 0 & 0 & 8
\end{tabular}


A Figura 12 mostra o tempo médio de fixação das Figuras geométricas nas duas fases. Não são observadas diferenças evidentes entre as categorias, e dos $1000 \mathrm{~ms}$ disponíveis, o tempo efetivo de fixação está ao redor dos $300 \mathrm{~ms}$. O tempo médio de fixação das Fotografias durante a primeira Fase foi só duas vezes maior do que aquele das Figuras geométricas (600 ms aproximadamente) mesmo quando ficava disponível na tela três vezes mais (3000 ms). Um destaque deste gráfico é a diferença de $20 \%$ entre a Figura geométrica de Violência entre as fases do experimento, sugerindo um efeito do procedimento de contraste nestes estímulos arbitrários.

Replicando as análises de frequências, o tempo de fixação das Fotografias durante a Fase II exibe uma hierarquia organizada que corresponde com a valência emocional das categorias propostas (Figura 13). Essa hierarquia é obtida pelo aumento de tempo de fixação em categorias de valência emocional positiva (Eros e Filhotes), e uma diminuição na categoria Doença. A observação das Fotografias Neutras (Paisagem Aberta e Paisagem Fechada) não sofreram mudanças importantes na passagem de uma fase para a outra. As Fotografias da categoria Random foram observadas o dobro do tempo durante a Fase II em comparação com o observado durante a primeira fase.

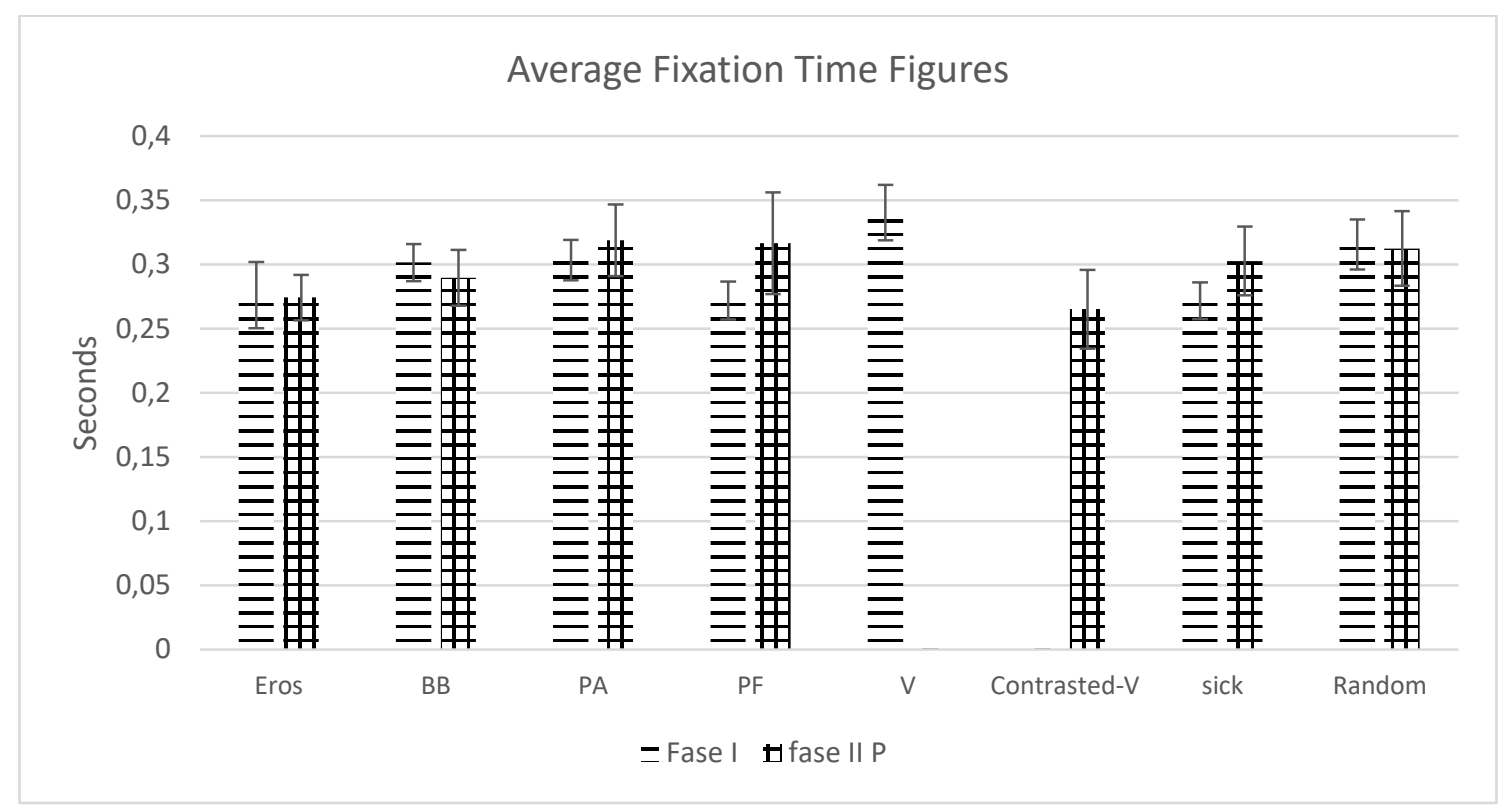

Figura 12. Duração da fixação das Figuras geométricas. 


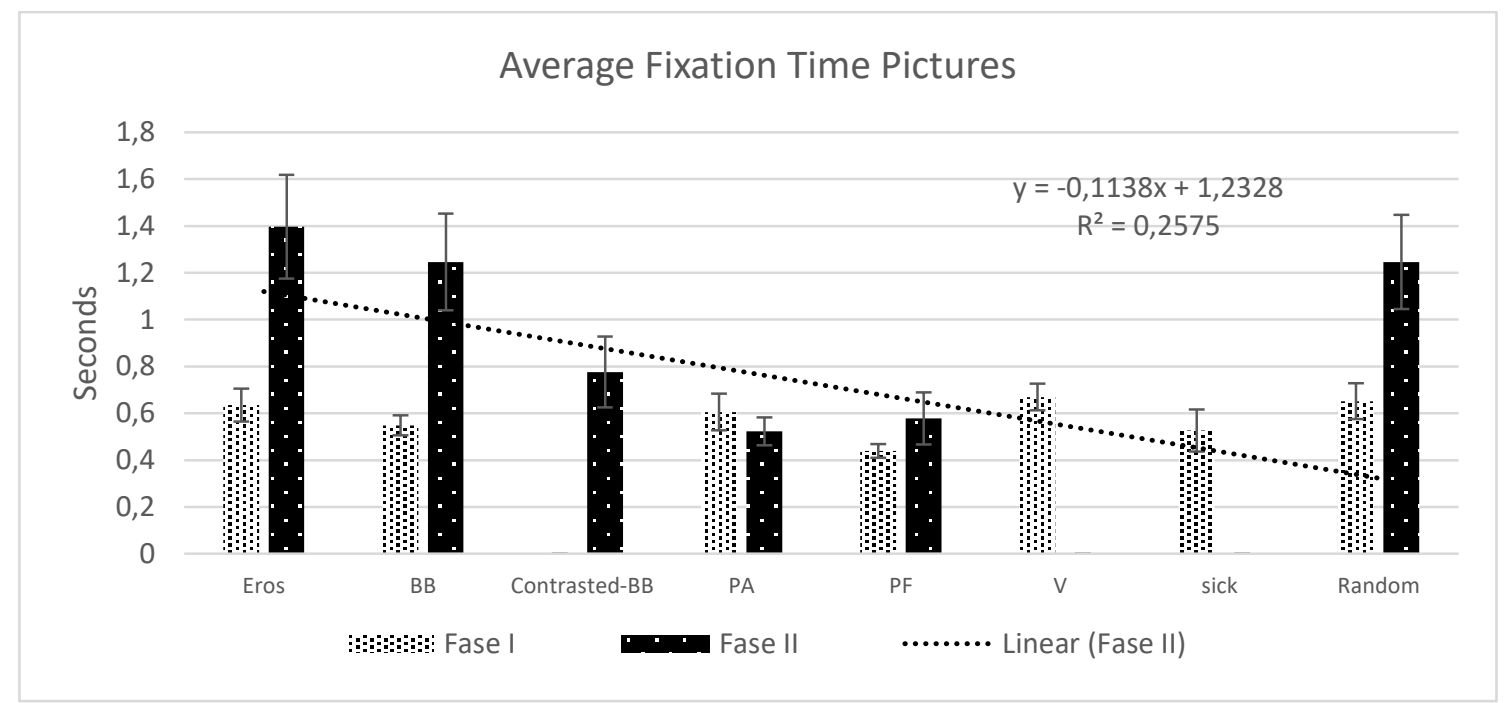

Figura 13. Duração da fixação das Fotografias.

Considerando que a margem de variação entre as medidas depende do tempo de apresentação, a indiferença observada entre as Figuras geométricas pode ser resultado do curto tempo de exposição (1 segundo) em comparação ao tempo disponível para observar as Fotografias (3 segundos). Evidentemente, o fato de se tratar de estímulos arbitrários (figuras geométricas) sem nenhum valor emotivo também poderia dar conta da distribuição obtida. No entanto, as medidas que consideram o tempo relativo de fixação (em porcentagens), e não o tempo absoluto em segundos, parecem mais sensíveis às diferenças entre estímulos de estas características.

Nesta taxa relativa é levada em consideração o tempo em que o participante de fato efetuou uma fixação nas Imagens apresentadas. Por exemplo, se dos três segundos em que as fotografias estavam disponíveis, o tempo efetivo de observação foi de 1 segundo, distribuído em 700 ms para a fotografia A e 300 ms para a fotografia B, será representado como $70 \%$ do tempo para a categoria A e $30 \%$ para a categoria B. $50 \%$ representaria indiferença entre as imagens disponíveis.

A Figura 14 mostra que as Figuras geométricas das categorias localizadas nos extremos emocionais (Eros e Doença) foram sim mais observadas durante a Fase II quando considerado o tempo efetivo de observação. As outras categorias não se mostraram afetadas. Quando analisadas as Fotografias com essas considerações (Figura 15), a diferença entre as imagens de Bebês contrastados (antecedidos pela figura geométrica correspondente a Violência) e os Bebês antecedidos pela mesma Figura geométrica durante todo o treino se faz menos evidente. 


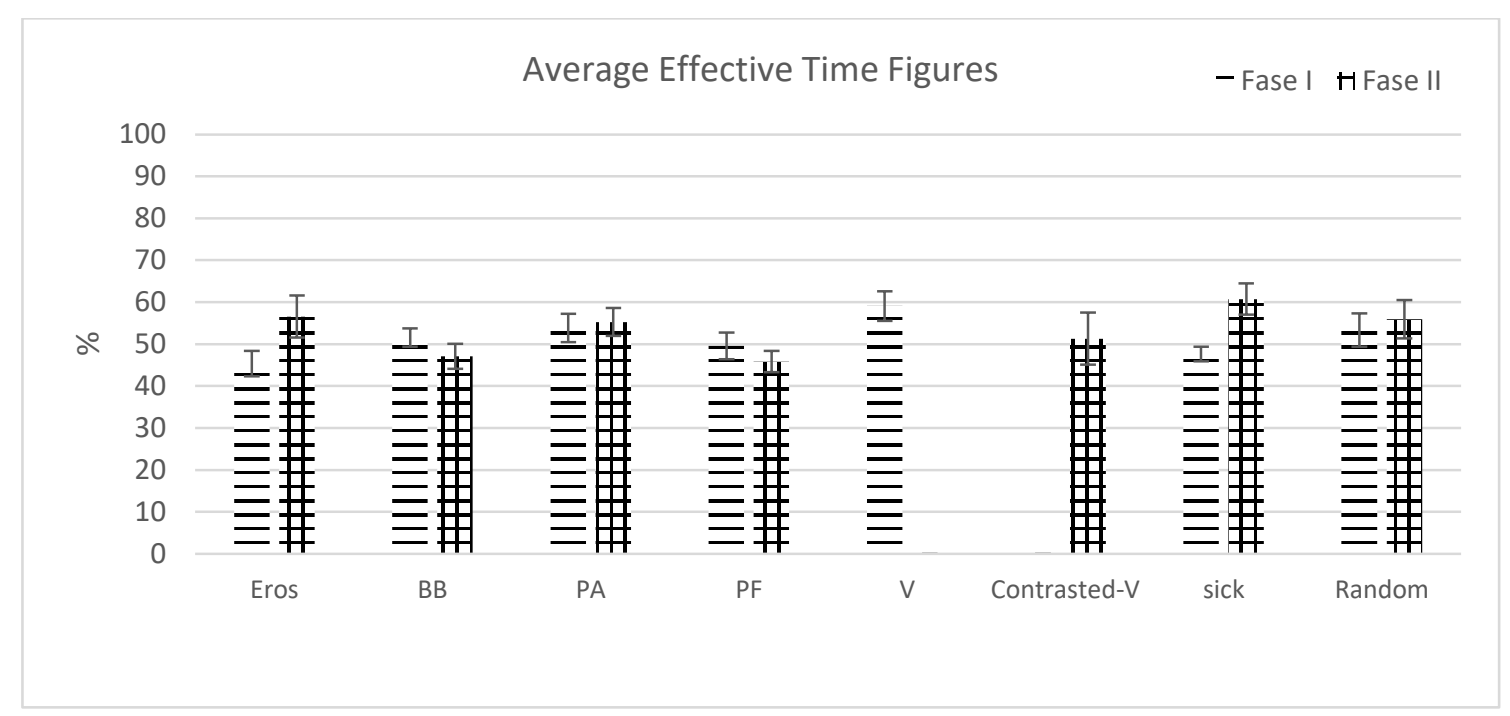

Figura 14. Tempo efetivo de observação das Figuras geométricas

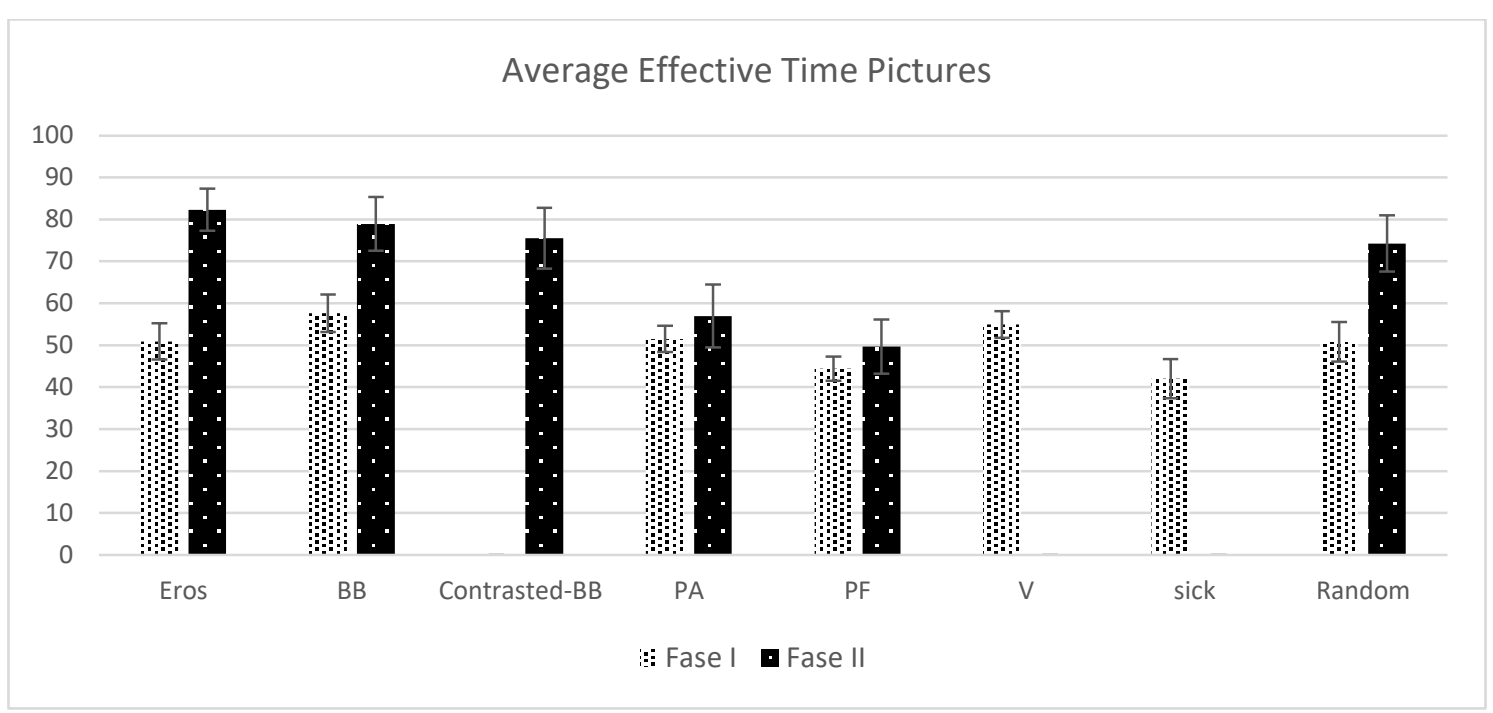

Figura 15. Tempo efetivo de observação das Fotografias

Quando considerado o tempo de fixação das Imagens só no caso de atingir algum dos critérios de preferência ( $>50$ ou $>60 \%$ ), são observadas as mesmas tendências gerais do que quando consideradas todas as apresentações. No entanto, vale a pena notar algumas das diferenças mais dramáticas para analisar o comportamento daqueles estímulos que superam o limiar da indiferença. Na Figura 16 é observado que durante a segunda fase houve um aumento de mais do $40 \%$ no tempo de fixação para a Figura geométrica da categoria Paisagem Fechada respeito a Fase I. As Fotografias (Figura 17) não estão mostrando distribuições tão organizadas e hierarquizadas como as 
obtidas com as frequências (Figura 11) ou durações (Figura 13) durante a Fase II. Contudo, o aumento do tempo de fixação nas categorias Eros, Filhotes e Random é evidente neste gráfico. A categoria Paisagem fechada também aumenta de valor com este índice, sugerindo que o obtido para sua Figura geométrica correspondente não é simplesmente um viés na medição. A diferença entre as fotografias de Filhotes contrastados respeito as fotografias de Filhotes que sempre foram precedidos pela mesma Figura geométrica aparece mais óbvia aqui do que a observada com os outros indicadores. Em termos gerais, essas mesmas conclusões podem ser levantadas quando o critério para escolher as imagens preferidas é mais exigente (Figura 18 e Figura 19).

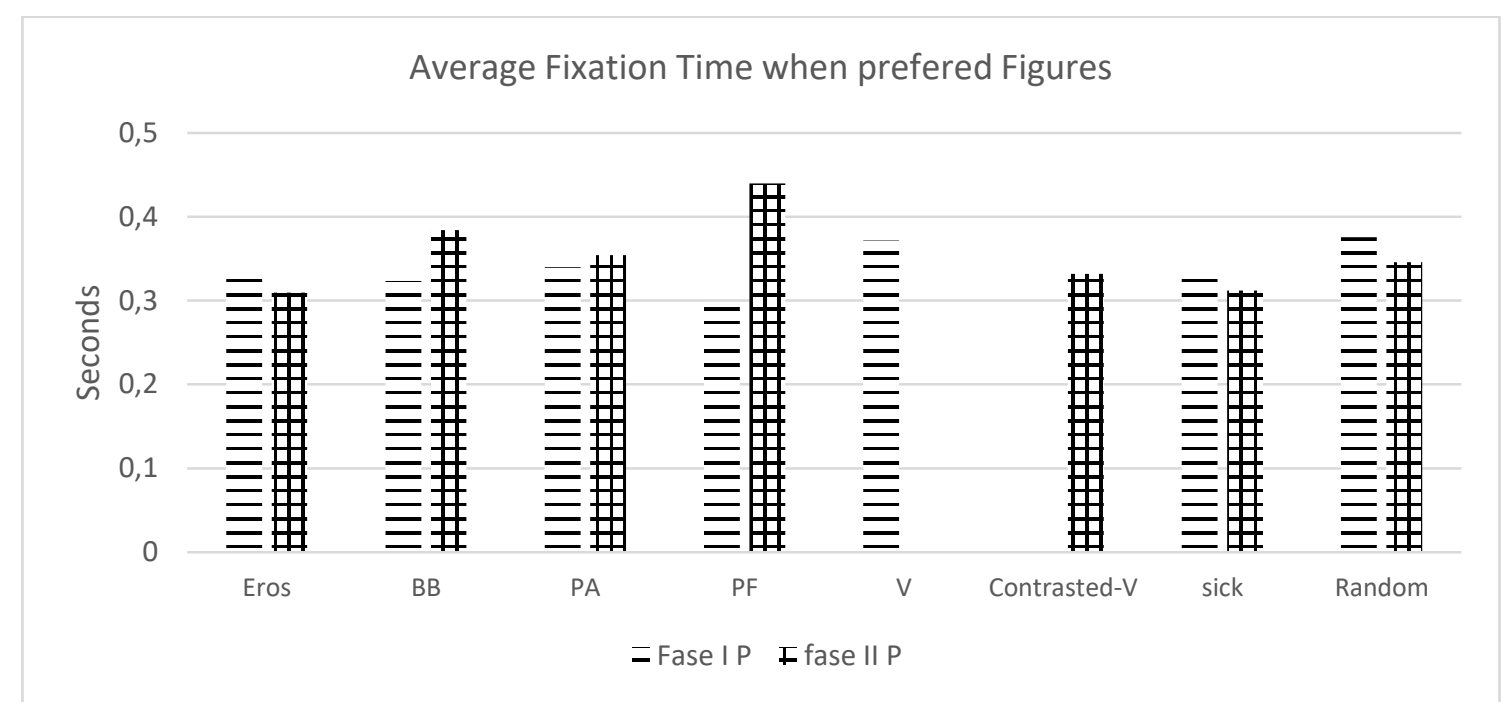

Figura 16. Tempo meio de fixação das Figuras geométricas preferidas

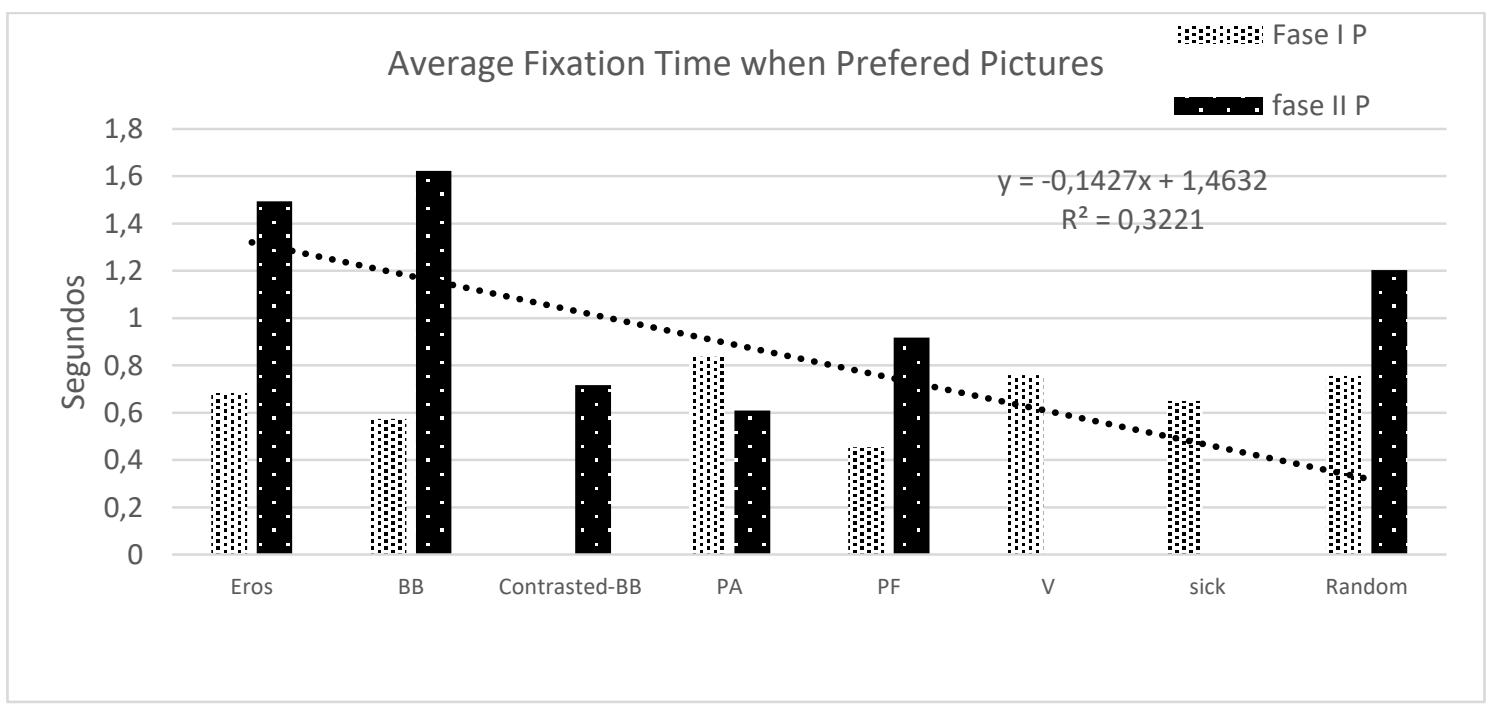

Figura 17. Tempo meio de fixação das Fotografias preferidas 
Average Fixation Time 60-40\% Rule Figures

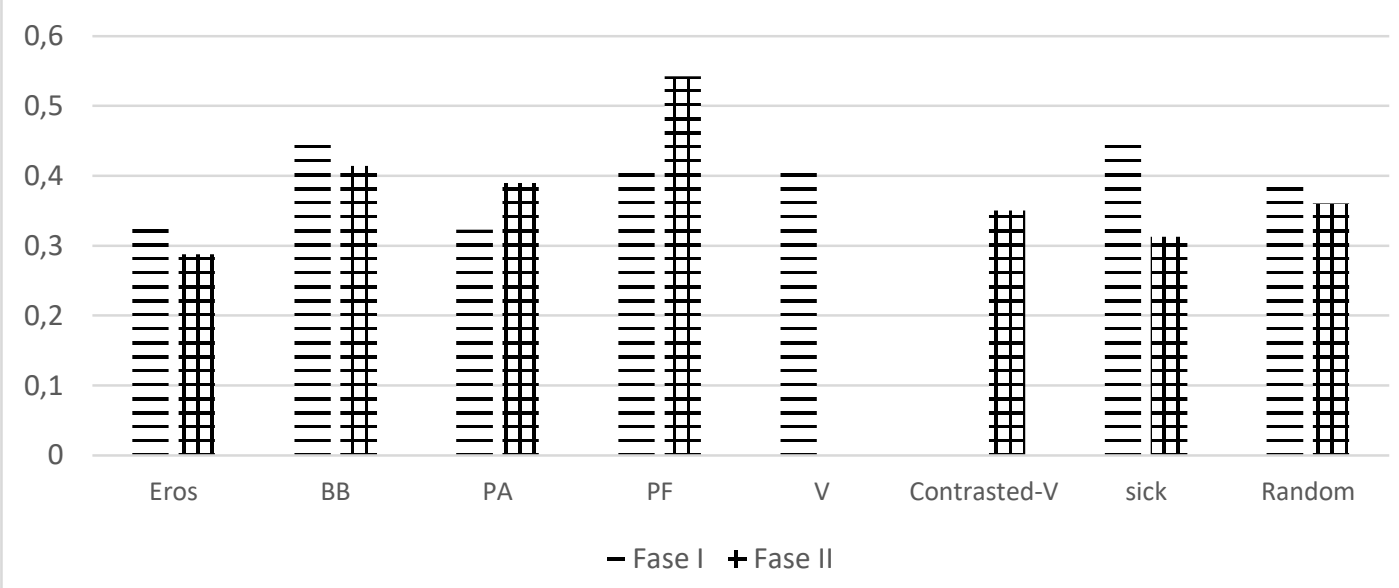

Figura 18. Tempo meio de fixação das Figuras geométricas preferidas com o critério de $60 \%$

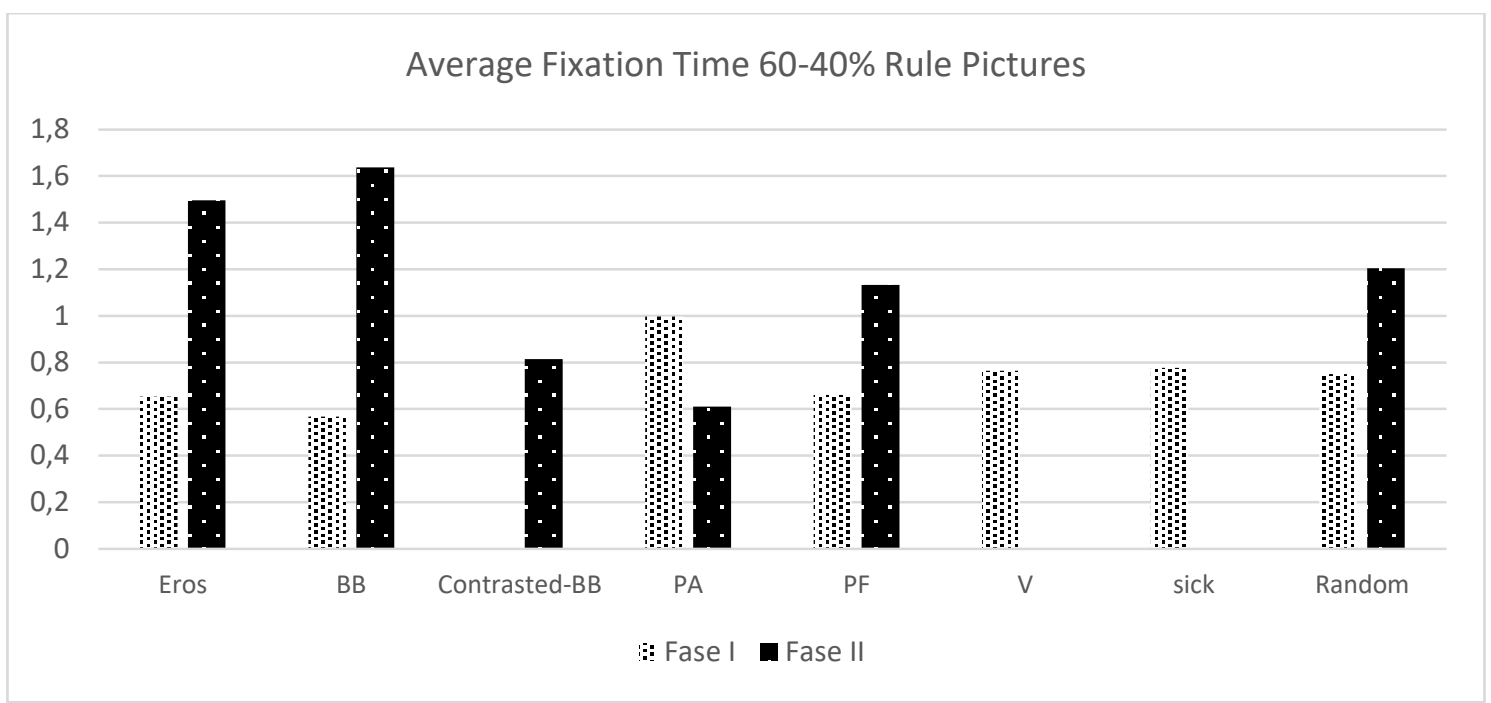

Figura 19. Tempo meio de fixação das Fotografias preferidas com o critério de $60 \%$

\section{Rejeição e Exclusividade}

Adicional às durações e frequências, que representam a informação de maneira aglomerada e discreta, outro indicador que pode dar esclarecimentos sobre o comportamento de preferência está na análise dos valores de rejeição (neste caso, $0 \mathrm{~ms}$ de fixação) e exclusividade (100\% do tempo efetivo de observação) entre as opções disponíveis. Assim, é obtida uma distribuição dos valores observados experimentalmente num campo das dimensões mais convenientes para a análise. Para este experimento, esse campo pode estar conformado pela diferença entre os tempos de 
fixação das duas imagens apresentadas e pela proporção que essa diferença representa na observação total de cada tentativa. Isto é importante porque um mesmo valor nessa diferença pode representar um $10 \%$ do tempo total de observação de uma tentativa, e em outra corresponder ao $100 \%$ do tempo total de observação.

Por exemplo, se a Imagem $\mathrm{X}$ foi observada durante $700 \mathrm{~ms}$ e a Imagem $\mathrm{Y}$ durante $300 \mathrm{~ms}$, a diferença entre elas (400 ms) será plotada em relação aos $1000 \mathrm{~ms}$ que conformaram o tempo efetivo de observação para as duas categorias dessa tentativa particular. No entanto, $400 \mathrm{~ms}$ pode ser também a diferença entre uma imagem que foi observada exclusivamente durante esse tempo (por conseguinte seu par teria sido fixado durante $0 \mathrm{~ms}$ ), e por tanto expressar um $100 \%$ do tempo efetivo de observação.

Na Figura 20 aparece a distribuição obtida para as Figuras geométricas de todas as categorias. Cada ponto corresponde a uma tentativa, no eixo $x$ aparece a diferença de tempo de observação entre as Figuras das tentativas em que aparece a categoria, e no eixo $y$ aparece a porcentagem que essa diferença representa no total de tempo de fixação. Uma distribuição alinhada $\operatorname{aos} 45^{\circ}$ a partir do ponto 0 indica diferenças pequenas e proporcionais entre a Figura de uma categoria particular e aquela com que foi apresentada (a maior tempo de observação desse estímulo, maior a proporção do tempo total da tentativa). Esse é o caso das Categorias Paisagem Fechada, Doença e Random, as quais tiveram ao redor de um $40 \%$ de diferença no tempo total de observação com as figuras geométricas das outras categorias com que foram apresentadas. 


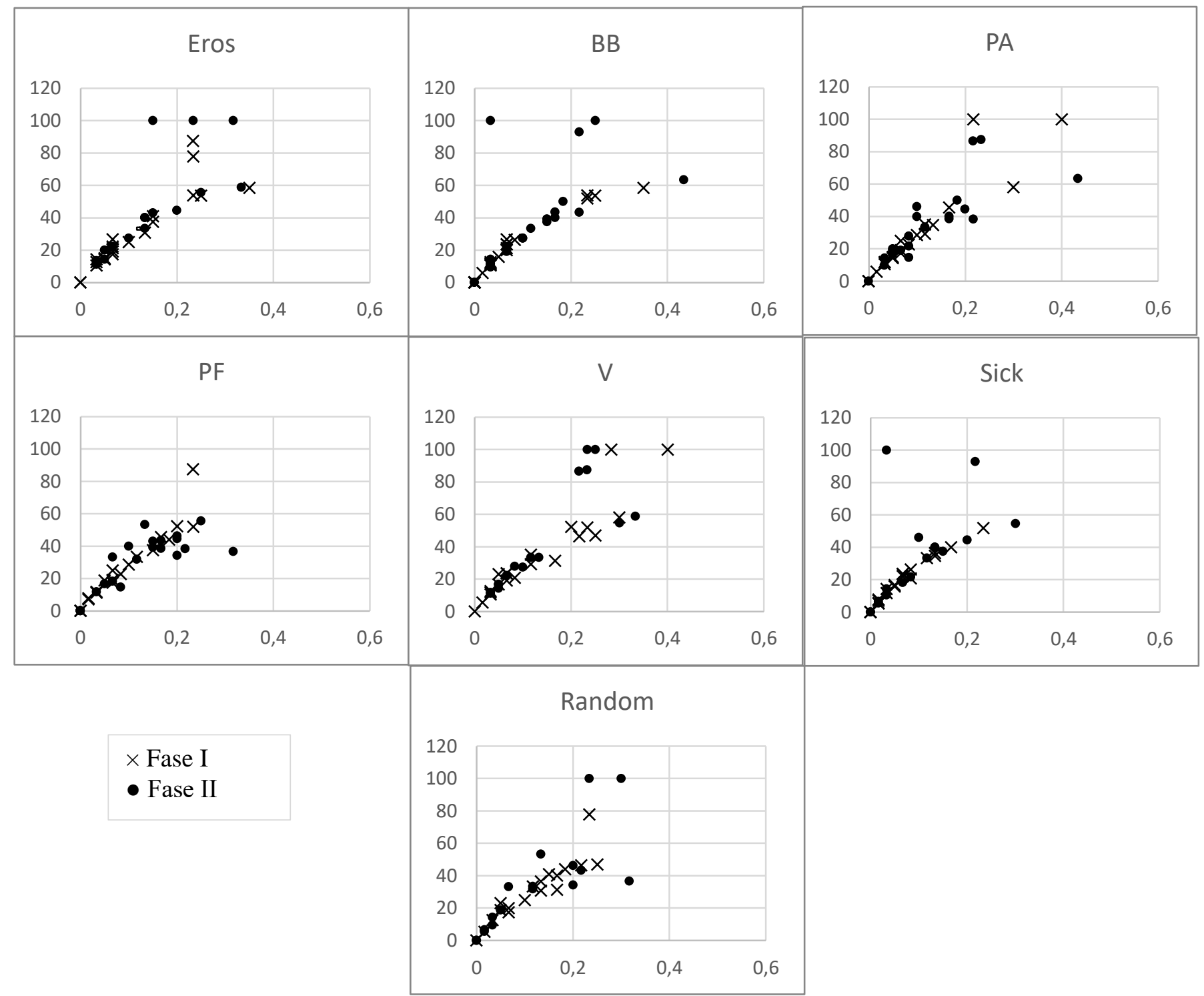

Figura 20. Distribuição dos tempos de fixação em relação ao tempo efetivo de observação das Figuras geométricas.

As distribuições observadas nas Fotografias são mais variadas do que das obtidas nas Figuras geométricas, com diferenças ao redor do $80 \%$ do tempo total de observação no caso de Eros, Filhotes e Random em uma parte importante das tentativas, sobretudo durante a Fase II (Figura 21). Tanto nas Figuras geométricas quanto nas Fotografias, é observado que algumas categorias nunca atingem o $100 \%$, isto é, nunca são preferidas com exclusividade. 


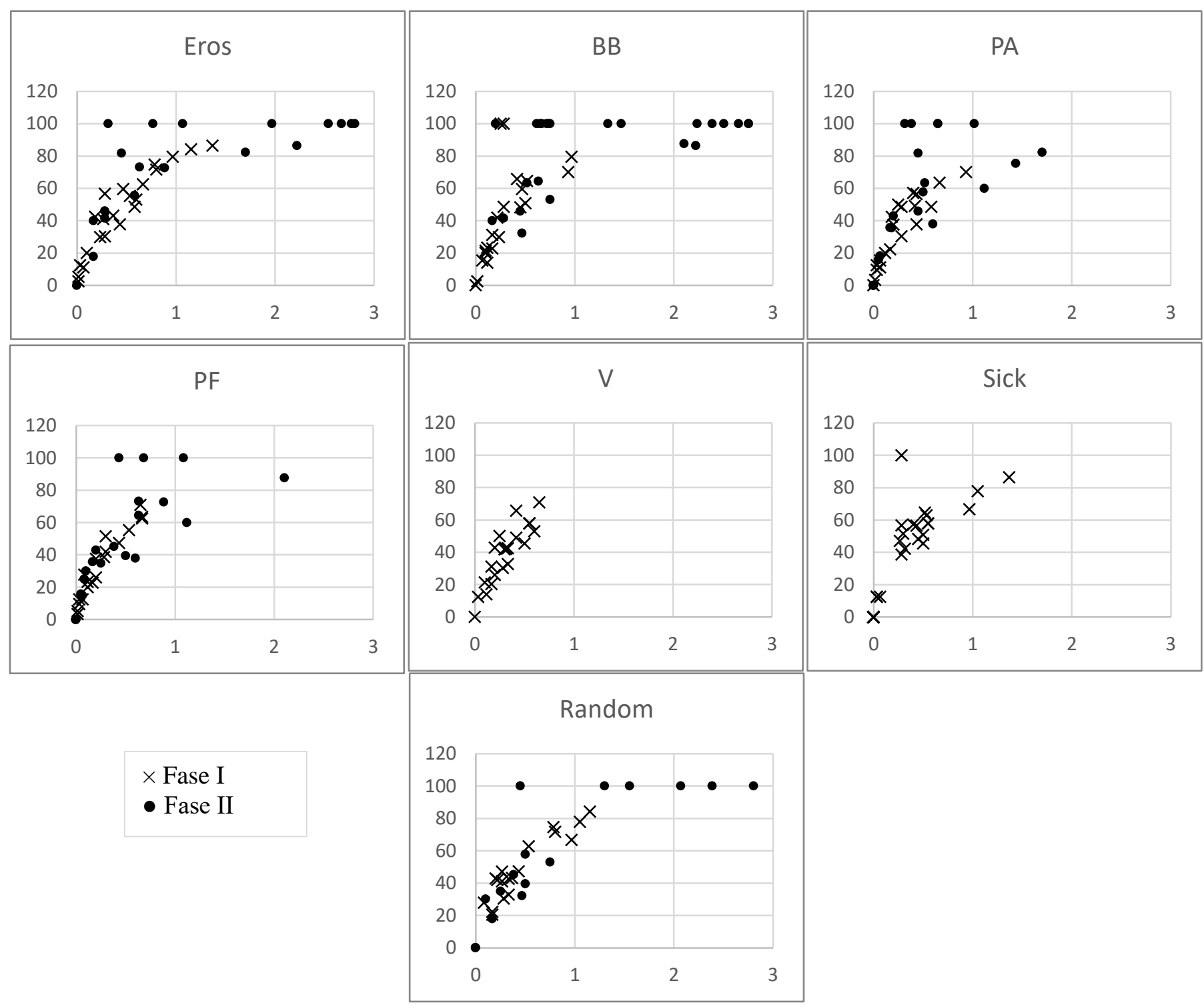

Figura 21. Distribuição dos tempos de fixação em relação ao tempo efetivo de observação.

\section{Temporalidade (sequencias temporais)}


A distribuição dos tempos de observação de forma comparativa entre as categorias permite visualizar diferenças na tendência de atingir o valor máximo em termos das diferenças entre valores máximos e mínimos. No entanto, para saber como acontece essa distribuição em função do treino é necessário visualiza-la ao longo das tentativas. Nas seguintes figuras, são mostradas as tentativas no eixo $x$, com uma quebra que assinala a mudança de fase (ao redor da apresentação 20).

A Figura 22 mostra uma correspondência entre os tempos de observação relativos entre Figuras geométricas e Fotografias dentro da mesma Categoria. É observado que no começo do treino, quando a Figura geométrica é observada pouco tempo, a Fotografia também é. Já na Fase II começam a aparecer as tentativas nos extremos $0 \%$ e $100 \%$. No geral, não é observada uma estabilidade acumulativa na qual os valores se mantem constantes de uma tentativa para outra, no entanto, é possível observar que para algumas categorias a linha que representa as Fotografias passa a estar acima da linha que representa as Figuras geométricas. Em quanto as Figuras geométricas se mantem ao redor do 50\%, o comportamento das Fotografias começa a se diferenciar. No caso das categorias Eros e Filhotes, a linha das Fotografias começa a aparecer acima da linha das figuras geométricas de forma mais consistente. Nas outras categorias, essa tendência não é clara. No caso da categoria Doença, é dramática a queda da observação das Fotografias no começo da Fase II, enquanto a figura geométrica correspondente continua sendo observada.

Em outras palavras, mesmo quando o tempo absoluto de exposição entre Figuras geométricas e Fotografias é diferente (1 segundo e 3 segundos respectivamente), existe uma correspondência entre elas no começo do treino, que está ao redor do 50\% do tempo total de observação, mas que varia entre categorias. Conforme o treino avança, o valor das Fotografias vem superar - em diferentes graus- o das Figuras em alguns casos (Eros, Filhotes e Random), enquanto para outras categorias acontece o contrário (Doença). 
Eros

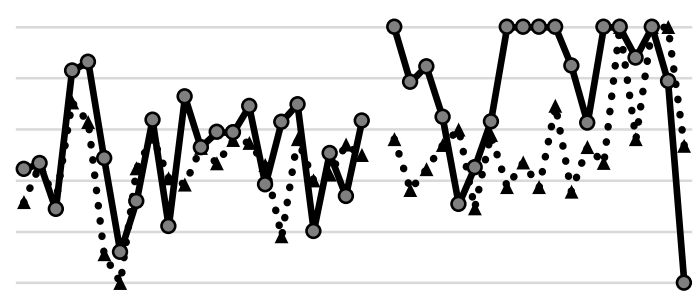

1357911131517192123252729313335373941

PF

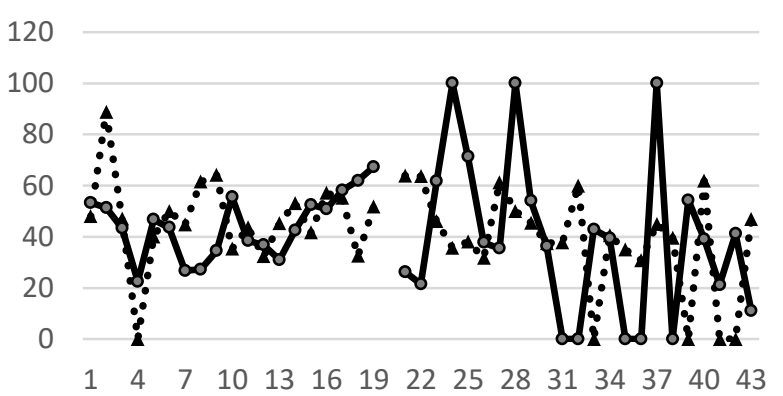

BB

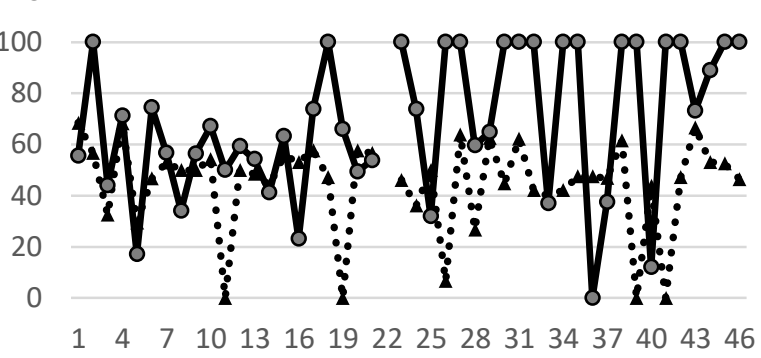

V

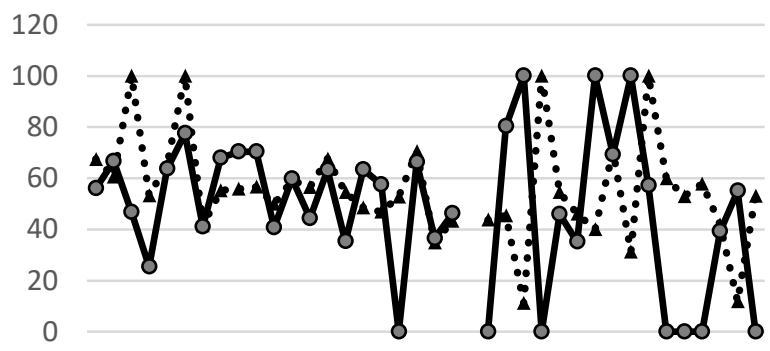

135791113151719212325272931333537

Random

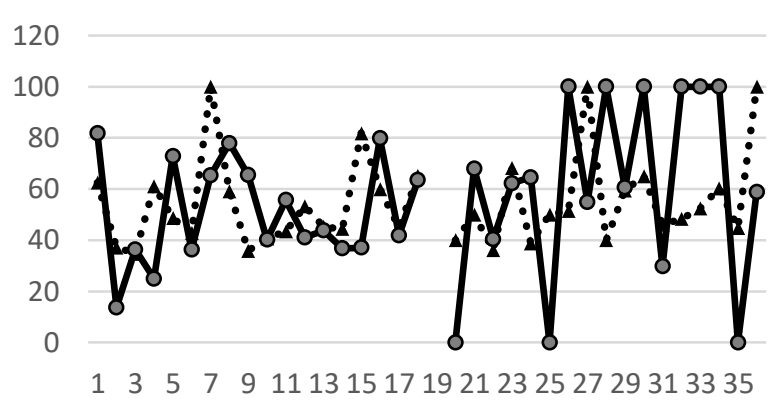

PA

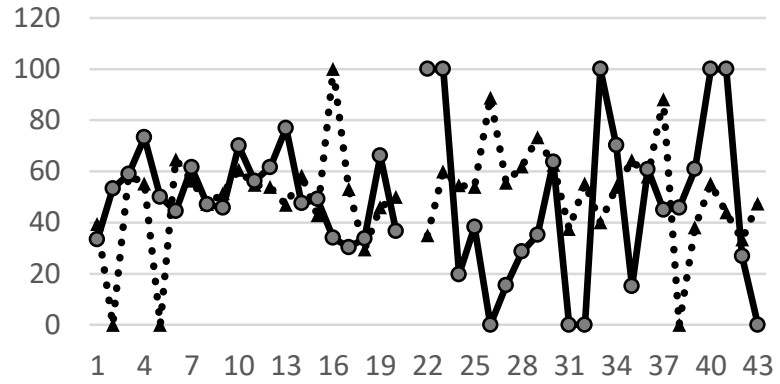

Sick

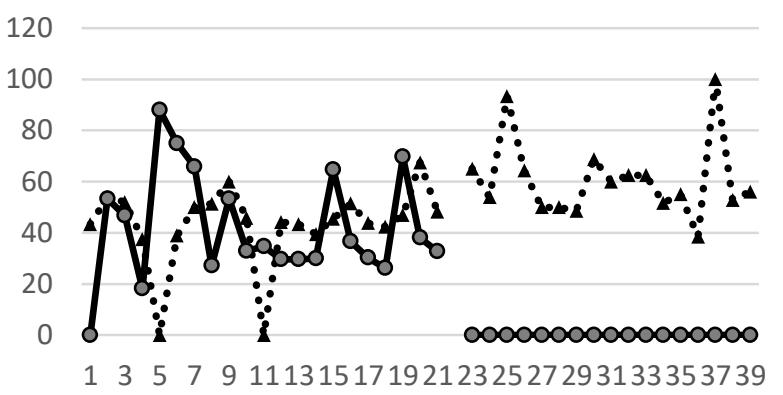

Figura geométrica

Fotografía

Figura 22. Tempo de observação das Figuras geométricas e das Fotografias de cada categoria ao longo das tentativas 


\section{Comparações entre categorias}

Adicionalmente a correspondência entre Figuras geométricas e Fotografias dentro de uma mesma categoria, é possível analisar o comportamento das imagens de uma categoria particular com seu análogo da outra categoria com que foi apresentada. Figura 23 e a Figura 24 permitem visualizar se alguma categoria se comportou de forma particular, independentemente da outra imagem com que foi pareada, ou se os pares de imagens apresentados co-variaram seguindo algum padrão. No caso das Figuras geométricas é difícil reconhecer alguma regularidade, exceto na categoria Doença, que durante a segunda Fase passa a estar de forma constante por encima das outras Figuras geométricas com que é apresentada (independente do seu conteúdo). No caso das Fotografias é observado um aumento nos tempos de observação no final do treino, claro indicador de preferência sobre as outras categorias.

Logo no final da sessão experimental, a participante não conseguiu reportar verbalmente quais tinham sido os pares de estímulos apresentados. 


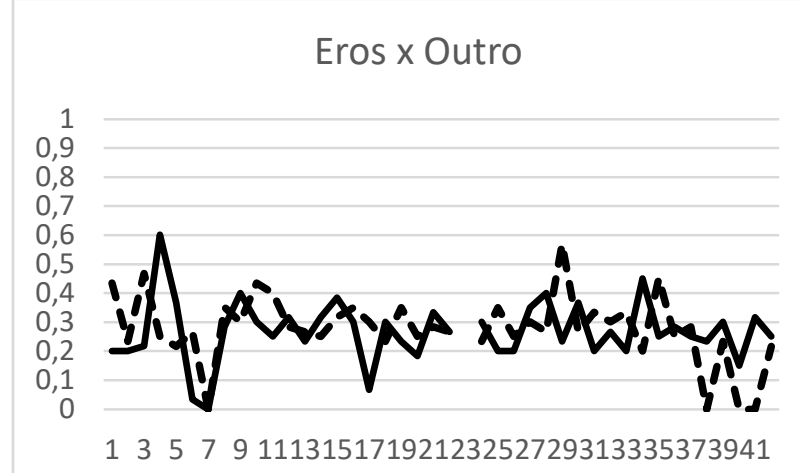

$$
\begin{array}{r} 
\\
1 \\
0,9 \\
0,8 \\
0,7 \\
0,6 \\
0,5 \\
0,4 \\
0,3 \\
0,2 \\
0,1 \\
0
\end{array}
$$

BB $\times$ Outro

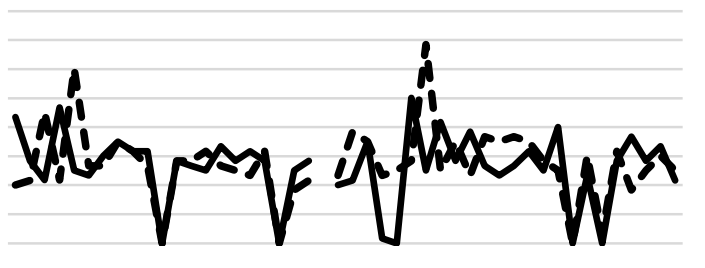

$144 \quad 7 \quad 10131619222528313437404346$

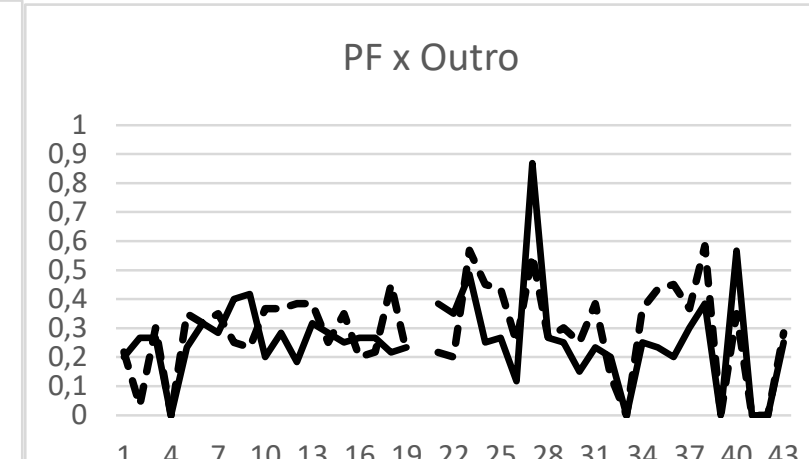

$\begin{array}{lllllllllllllll}1 & 4 & 7 & 10 & 13 & 16 & 19 & 22 & 25 & 28 & 31 & 34 & 37 & 40 & 43\end{array}$

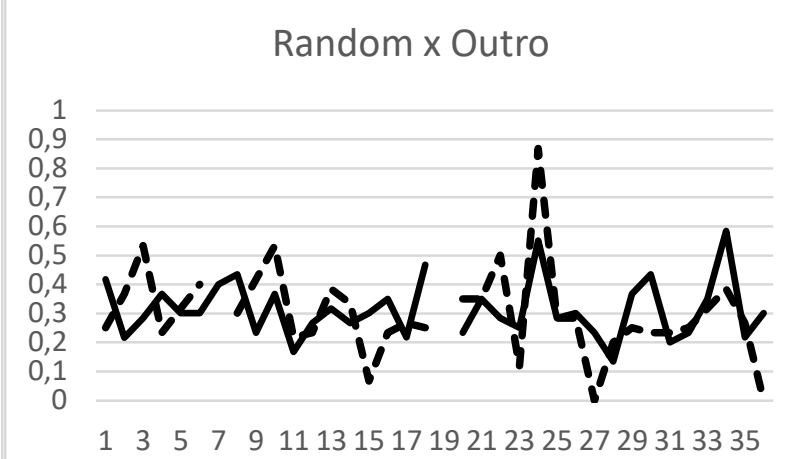

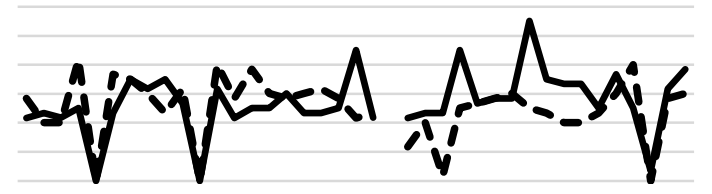

13579111315171921232527293133353739

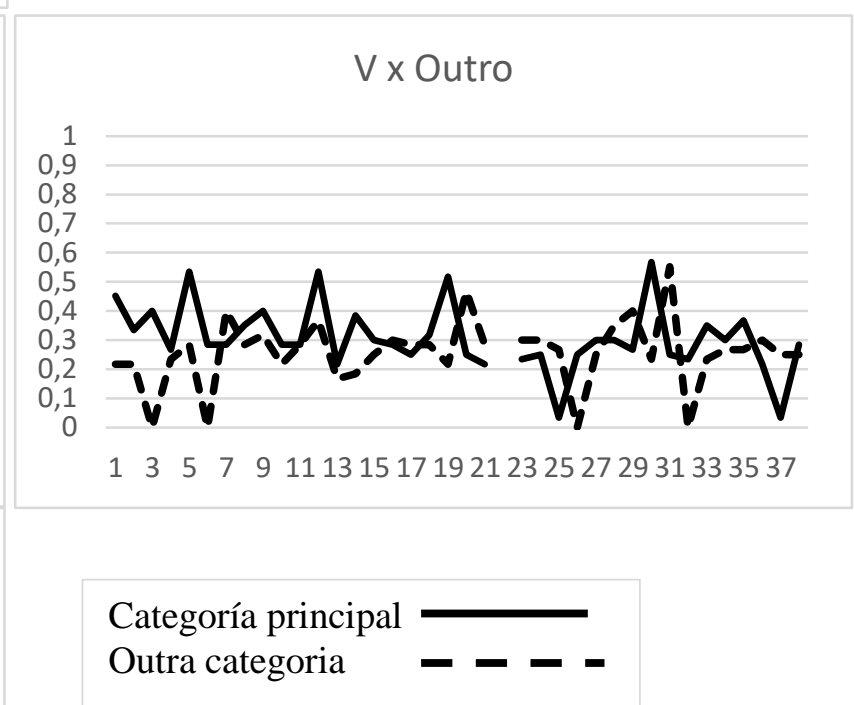

1357911131517192123252729313335

Figura 23. Observação das Figuras geométricas ao longo das tentativas 


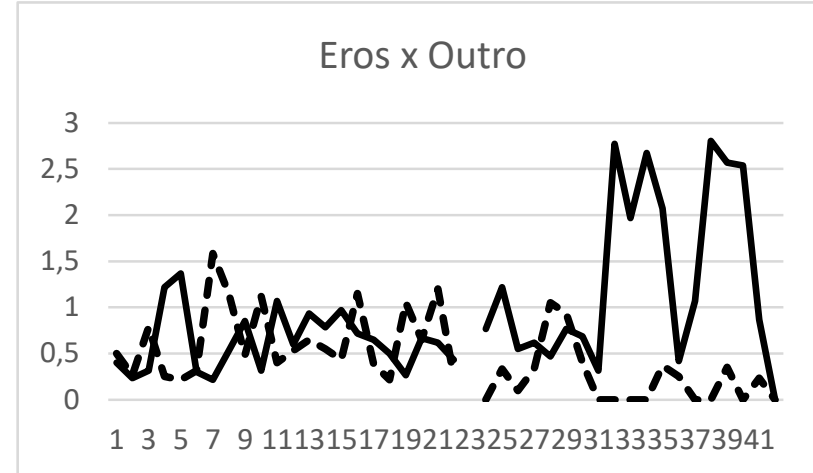

PA x Outro

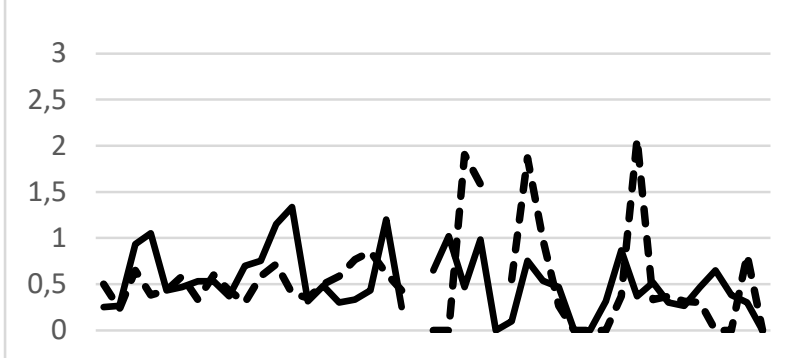

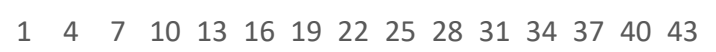

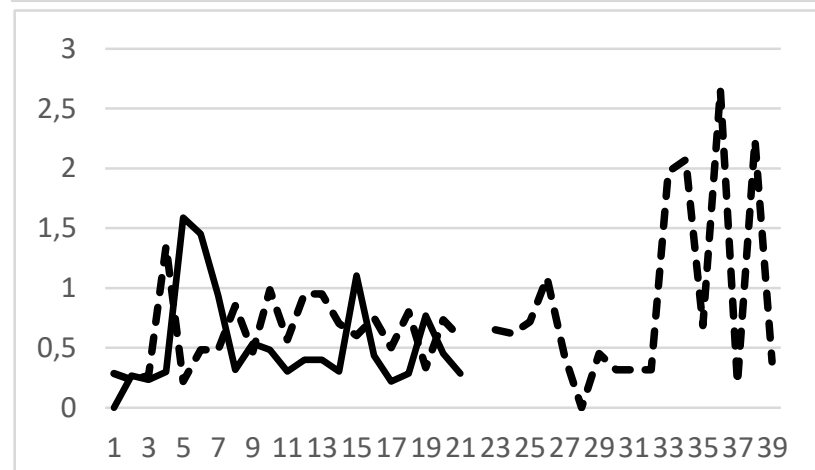

BB $\times$ Outro

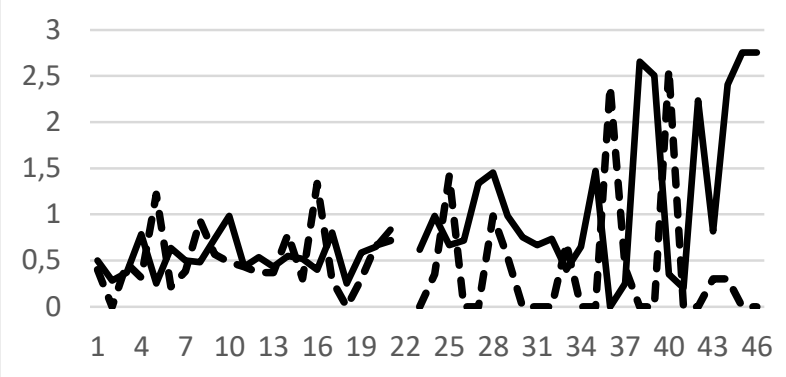

PF x Outro

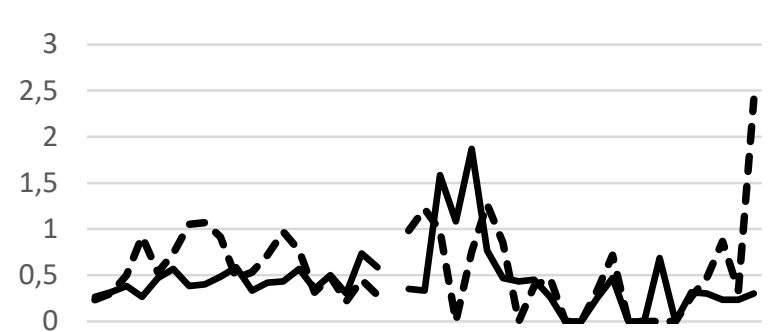

$\begin{array}{lllllllllllllll}1 & 4 & 7 & 10 & 13 & 16 & 19 & 22 & 25 & 28 & 31 & 34 & 37 & 40 & 43\end{array}$

Random x Outro

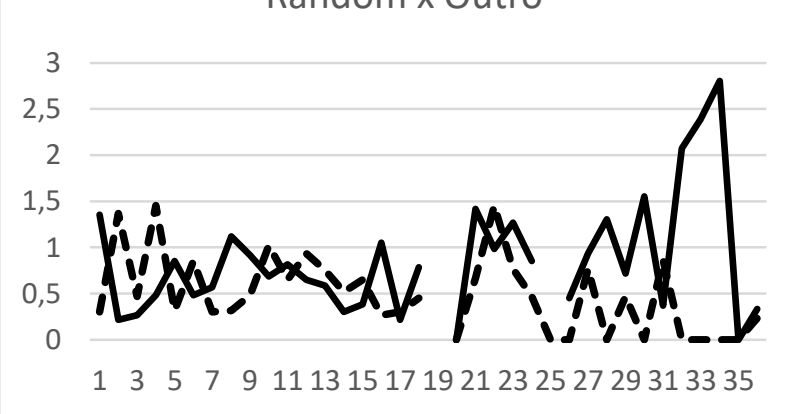

V x Outro

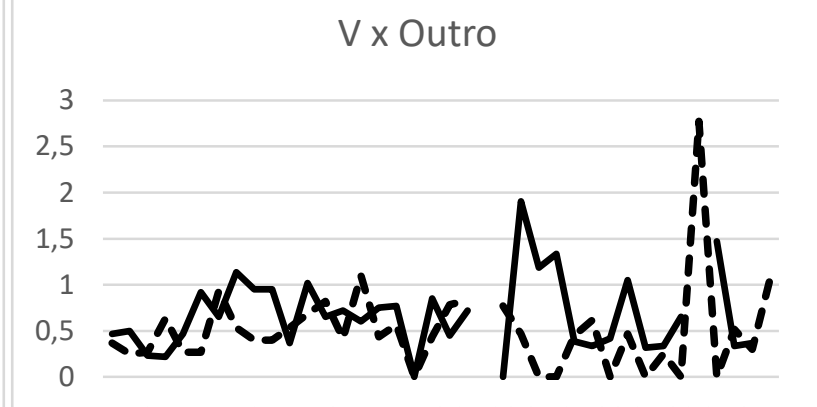

135791113151719212325272931333537 


\section{Discussão}

"I shut my eyes and all the world drops dead; I lift my lids and all is born again. (I think I made you up inside my head)." Mad Girl's Love Song - Sylvia Plath - 1953

Neste projeto foi proposto um procedimento que empregasse a resposta ocular em humanos de forma análoga àqueles utilizados tradicionalmente no fenômeno de Contraste Sucessivo (com outras respostas e outras espécies). Para isso foram apresentados pareamentos entre fotografias classificadas a partir do seu conteúdo emocional e figuras geométricas arbitrárias que às antecediam de maneira contingente e regular, até atingir algum tipo de estabilidade no comportamento. Nesse momento foi introduzida a manipulação característica do Contraste Sucessivo que consiste em apresentar um estímulo de menor valor do que o esperado e avaliou-se o impacto dessa perturbação na distribuição das respostas oculares dedicadas às categorias treinadas (incluindo aquelas que não foram diretamente alteradas). Esta foi uma proposta arriscada pois foram muitos os parâmetros envolvidos na tarefa experimental, sem antecedentes específicos que pudessem guiar a tomada de decisões. Contudo, os resultados obtidos são quando menos provocadores, e permitem examinar as características do procedimento tanto no técnico quanto no teórico.

\section{Avaliação Técnica e Metodológica.}

Uma das principais características deste procedimento é que reconhece diferenças individuais a partir do desempenho dos participantes ao longo do treino. Como as preferências estão definidas a partir da distribuição comportamental entre as opções disponíveis (hierarquização), a ordem obtida (da mais à menos preferida/observada) pode ser usada como uma linha de base múltipla que aprimorará a caracterização do comportamento após a execução das mudanças programadas. Mesmo quando teoricamente é esperado que estímulos "agradáveis" ou "apetitivos" sejam preferidos frente a estímulos “desagradáveis", são muitas as variáveis que podem afetar esse perfil de preferências. No 
caso da nossa participante, foi a categoria Violência que ocupou o primeiro lugar na hierarquia.

Armstrong e Olatunji (2012) fazem uma meta-análise de estudos que utilizam rastreador ocular para caracterizar vieses atencionais para estímulos emocionais em participantes com desordenes afetivos. Os autores mostram que, em relação aos participantes controle, os indivíduos ansiosos mostram maiores níveis de vigilância às ameaças em situações de observação livre e em tarefas de procura, e também apresentam dificuldades desengajando a atenção de imagens ameaçantes em tarefas de procura visual, mas não durante a observação livre. De outro lado, os indivíduos depressivos não mostraram particular vigilância aos estímulos ameaçantes, mas uma redução na orientação à estímulos positivos, e maior manutenção do olhar em estímulos disfóricos. Entendendo que não é possível garantir a disposição com que os sujeitos (humanos e não-humanos) participam da sessão experimental, um procedimento capaz de medir e identificar esse tipo de variações representa claras vantagens na hora de analisar e interpretar os dados obtidos.

Contudo, dois aspectos gerais devem ser levados em consideração para desenvolver futuras pesquisas com esse procedimento, pois os resultados mostram que o critério utilizado poderia ser aprimorado para incluir mais instancias de estabilidade e ser ainda mais abrangente. Em primeiro lugar, o comportamento observado na Categoria Doença, em que a participante mostra uma diminuição dos tempos de observação das Fotografias junto com maiores tempos dedicados às Figuras geométricas, indicam que estava acontecendo um ajuste comportamental de não-observação que foi completamente desconsiderado pelo algoritmo, programado só para identificar regularidades com a lógica de controle de estímulos apetitivo e desconhecendo as estratégias frente a situações aversivas. Para solucionar esse imprevisto poder-se-ia, por exemplo, contabilizar as tentativas em que as fotografias de algum tipo de categoria deixaram de ser observadas de forma consecutiva (p.e. sete tentativas com fixação de 0 segundos, ou fixação nula em 9 de 12 tentativas em que a Fotografia foi apresentada), e incluir esta categoria no ranqueamento, não como uma categoria preferida, mas como uma categoria estável. 
Como o critério de estabilidade estava definido pela relação de correspondência entre os estímulos arbitrários (Figuras geométricas) e os estímulos com valência emocional (Fotografias), deve ser pensado se isso aplica para as categorias aversivas, pois o tempo dedicado à Figura geométrica pode aumentar (como foi o caso neste experimento) o que sugere que foi "informativo" para a participante, mas também poderia diminuir, caso se torne um estímulo aversivo via condicionamento, caso em que seria observado um participante evitando tanto a fotografia como a figura geométrica associada a ela. $\mathrm{O}$ fato da resposta aprendida (condicionada, aos estímulos arbitrários) conservar ou não a topografia da resposta espontânea (incondicionada), depende parcialmente dos intervalos entre o estímulo arbitrário e o estímulo aversivo (Kehoe, Graham-Clarke e Schreurs, 1989. Ver também Akins, 2000, para um exemplo com a resposta sexual dependente do intervalo CSUS).

Embora a negligência dirigida às fotografias de Doença tenha aparecido só na Fase II, e por isso pudesse ser considerada um efeito da manipulação experimental, incluir no critério de estabilidade parâmetros relativos à evitação seria importante porque alguns sujeitos poderiam ser particularmente sensíveis a esse tipo de pareamentos e desconsideralo faria com que eles estivessem expostos a um sobre treino e dificultando a comparação com outros participantes. Identificar um padrão de evitação é importante também porque, mesmo apresentando exclusivamente estímulos "apetitivos", diversas experiências ou disposições do participante podem fazer com que se emitam esse tipo de respostas. Uma pessoa com fortes restrições ideológicas pode evitar olhar (consciente e ativamente) para fotografias que um adolescente irrefletido fixaria com exclusividade, por exemplo.

Uma segunda consideração sobre o critério de estabilidade levantada a partir dos resultados está relacionada com o tipo de medição que seria mais adequada. A fim de aproveitar o fato de algumas medições serem mais sensíveis às pequenas diferenças entre as categorias (como as observadas durante a Fase I), seria importante considerá-las dentro do critério de estabilidade a conta de fazer a tarefa mais curta e eficiente. A frequência relativa de escolha tem sido uma medida tradicional de preferência muito conveniente em paradigmas experimentais que usam respostas discretas, como a pressão da barra na caixa 
de Skinner ou na hora de escolher um reforçador para crianças com problemas de aprendizagem (p.e. Kodak., Fisher, Kelley, e Kisamore, 2009). No entanto, quando a resposta analisada é continua, vários índices obtidos a partir das durações das respostas podem auxiliar a caracterização dos fenômenos comportamentais estudados. A precisão fornecida por equipamentos tão sofisticados e potentes como o EyeLink deve ser explorada nesse sentido.

Considerações adicionais podem ser feitas ao redor do aprimoramento do critério e da seleção de medições. Por exemplo, a Figura 14 mostra que a proporção de tempo efetivo de observação é uma medida que poderia ser considerada no critério, pois consegue mostrar diferenças entre as Figuras geométricas que outras medições não deixaram tão evidente. Para ter então um critério de estabilidade mais coerente com os resultados obtidos, tal vez fosse conveniente ranquear as figuras geométricas a partir de medidas relativas, enquanto as Fotografias continuam sendo ranqueadas a partir das durações. De outro lado, os resultados que mostram o comportamento das Categorias quando satisfeito o critério de preferência de 60-40\%, quer dizer, quando a imagem apresentada era fixada durante mais do que o $60 \%$ do tempo efetivo de observação, apontam que essa medição foi sensível à mudança da primeira a segunda fase, tanto em durações (Figura 18 e Figura 19) quanto em frequências (Figura 10 e Figura 11) e pode ser de grade utilidade quando seja necessária uma hierarquização (ou outro tipo de classificação) que discrimine entre o "realmente preferido", o indiferente e o não-preferido.

Outro aspecto a ser considerado na avaliação técnica do procedimento são os estímulos utilizados. Ainda que o IAPS é um banco de dados que pretende atingir uma padronização e validação no estudo da emoção e atenção, os esforços feitos para mantê-lo atualizado e vigente devem ser aproveitados em pesquisas cujo delineamento experimental não permita realizar analises comparativos ou obter alguma linha de base para medir os efeitos das manipulações a partir dela. Estudos que utilizam imagens tomadas da internet têm obtido resultados satisfatórios comparando grupos (p.e. Rupp e Wallen, 2007). Tal vez o critério de estabilidade neste experimento poderia ter sido atingido mais rapidamente e a 
distribuição do olhar poderia ter sido mais discriminada de ter usado fotografias validadas de outra forma, o que deve ser levado em consideração em futuras aplicações deste procedimento ou na criação e uso deste tipo de tarefas experimentais.

Por último, mesmo que a apresentação por pares foi efetiva para conseguir um ranqueamento das categorias e uma discriminação entre as Figuras geométricas e as Fotografias, vale a pena mencionar que existem diferentes possibilidades de arranjar os estímulos na hora de apresentar eles para os participantes. Nas avaliações de preferências os estímulos podem ser apresentados individualmente, em pares ou num arranjo com vários itens. O objetivo geral de qualquer tipo de avaliação é construir uma hierarquia com a qual possa ser afirmado que $\mathrm{A}>\mathrm{B}>\mathrm{C}>\mathrm{D}>\mathrm{n}$, e parte do sucesso de cada método consiste precisamente em discriminar da maneira mais detalhada possível essa hierarquia. O possível viés de leitura que explicaria os maiores tempos de observação no quadrante "a" durante alguns momentos específicos do procedimento (Figura 8) poderia ser amortecido se a apresentação dos estímulos fosse feita num formato circular, como num Labirinto de Barnes-Holmes. Outra modificação possível consistiria em apresentar as sete categorias simultaneamente a cada tentativa, em analogia com o labirinto radial, e registrar como se distribui o olhar nessa situação. A exploração dessas opções fica em aberto.

É importante entender todas essas considerações (sobre o critério, as medições, o tipo de estímulos e do arranjo em geral) como parte da calibragem de um procedimento que busca maior sensibilidade e eficiência na hora de estudar algum fenômeno comportamental, e cuidar dos vieses que podem surgir comprometendo sua confiabilidade ou validez. Isto inclui permanecer atentos à instancias em que possa estar sendo suprimida alguma evidência (cherry picking) para favorecer algum tipo de resultado. Uma estratégia para aumentar o cuidado nesse sentido é manter comparações entre as diferentes medidas e coerência no seu uso, sem excluir ou incluir a conveniência. 
Avaliação Teórica e Conceitual. 
Contraste Sucessivo e Resposta Ocular - 51 
Contraste Sucessivo e Resposta Ocular - 53 
Contraste Sucessivo e Resposta Ocular - 54 
Contraste Sucessivo e Resposta Ocular - 55 
Contraste Sucessivo e Resposta Ocular - 56 


\section{Considerações Finais.}

Existem uma variedade de medidas que podem ser obtidas com um rastreador ocular como o EyeLink (Holmqvist, Nyström, Andersson, Dewhurst, Jarodzka, e Van de Weijer, 2011). Existem as medidas dos movimentos dos olhos (sacadas), de posição (onde o participante olha, ou não), de latência e de numerosidade (frequências, durações). Neste documento foram analisadas essas últimas por serem as medidas clássicas no paradigma experimental de Contraste, mas é claro que a caracterização do comportamento registrado poderia ser muito mais completa. As principais dificuldades para atingir esse objetivo correspondem à capacidade de processamento da enorme quantidade de dados gerados por um equipamento como o EyeLink.

O Eyelink 1000 ® deve seu nome ao fato dele funcionar numa velocidade de 1000hz. Mil coordenadas por segundo num procedimento como àquele aqui apresentado, que pode demorar ao redor de 40 minutos, é muita informação em relação a experimentos comparáveis metodologicamente. No entanto, se trata de um nível de informação semelhante com àquele gerado em outras atividades fora do laboratório, como o tráfico de usabilidade de qualquer site da internet, ou em diferentes jogos ou aplicativos moveis. Em outras palavras, existem as ferramentas informáticas e estatísticas para dar conta desse volume de dados. De fato, existem bibliotecas de programação inteiras disponíveis para fazer quase qualquer análise. Contudo, a avaliação de um procedimento como o apresentado aqui passa por várias dificuldades. Em primeiro lugar, deve ser mencionada a dificuldade técnica, pois é preciso pelo menos alguma familiaridade com as linguagens de programação e com os métodos de processamento e análise de dados para conseguir se comunicar com o experto dessas áreas e para conseguir adaptar essas ferramentas às particularidades de cada experimento. Esse não deveria ser um assunto preocupante numa instituição bem organizada que capacite seus pesquisadores e facilite os vínculos interdisciplinares.

Mas um segundo tipo de complicação mais fundamental aparece quando um equipamento sofisticado inibe mais do que encoraja à criação de novos procedimentos. Na 
Psicologia, como em outras áreas predominantemente analítico-indutivas, o favorecimento dos experimentos graduais e acumulativos faz parte do processo de "decomposição" e "localização" necessário para o desenvolvimento da pesquisa. Em palavras de Rheinberger (1997), os “sistemas experimentais" são maquinas feitas para reduzir a complexidade, mas para não cair na trivialidade é preciso se manterem vinculados com outros sistemas; é assim que se reconhece a coerência e coesão das práticas cientificas. Algumas vezes, esse tipo de práticas parece impedir o desenvolvimento de observações mais complexas, como se a validez experimental ficasse necessariamente comprometida quando existe complexidade metodológica. É claro que a manipulação e medição de muitas variáveis implica maior número de comparações e controles, mas a capacidade de atender essas demandas é mais um assunto técnico do que metodológico.

Para ilustrar como esse suposto conflito entre controle e complexidade não procede necessariamente em todos os casos, podemos pensar no Large Hadron Collider (LHC), o maior instrumento experimental do mundo. Com uma circunferência de $27 \mathrm{~km}$, o colisionador de partículas é a ferramenta com que são estudadas propriedades fundamentais da matéria e da energia. Cada tentativa e ensaio experimental rodado no LHC gera uma quantidade enorme de dados que demoram semanas para serem processados e analisados por cientistas ao redor do mundo. A colisão de partículas continua sendo a mesma estratégia metodológica desde a criação dos primeiros aceleradores a finais dos anos 20 do século passado, mas os cálculos e teorias que vem sendo desenvolvidos vão precisar de maiores níveis de energia, o que vem acompanhado de maior sensibilidade nas medições e a geração de Terabytes de informação por segundo. Em certo sentido, o LHC é o mais simples arranjo experimental de maior complexidade.

Tal vez a analogia não pode ir muito longe, mas tenta abrir a questão de qual é o máximo de informação que pode ser obtida num experimento psicológico. Neste caso particular, é claro que um experimento mais simples poderia ter sido programado: comparar duas e não sete categorias, não incluir um controle de pareamento aleatório, utilizar só um ou dois sistemas motivacionais. Mas se é pertinente para responder à pergunta de pesquisa, porque construir um labirinto de dois braços quando é possível construir um de 8 ou de 20 , 
sobretudo quando isso não implica grandes diferenças em termos de programação, nem exigências de material ou de espaço.

Os movimentos oculares permitem obter muitas respostas a cada tentativa, o que por sua vez possibilita maior aleatorização de condições experimentais. Ainda procedimentos comportamentais mais simples, como a habituação, se beneficiariam de ser estudados com múltiplas variáveis sendo medidas. Por que medir só a frequência de respostas na barra de Skinner quando posso medir adicionalmente a pressão com que é executado o movimento? Será que essa outra medida se comporta igual a medida tradicional? Se é o caso, deve ser explicado, e se não acontece, deve ser investigado. Além de mostrar-se conveniente para estudar situações de Contraste, com algumas modificações este poderia ser um procedimento utilizado na exploração e estudo de outros fenômenos comportamentais que envolvam interações clássico-operantes, discriminações condicionadas, evitação, entre outras. Da mesma maneira, é um procedimento que permite fazer comparações entre vários sistemas motivacionais (p.e. sexual, social, auto- preservação) com uma mesma topologia de resposta (i.e., observar). Nenhuma destas características compromete a validez interna do experimento e pelo contrário é uma característica que pode vir a aumentar a validez externa, ao mesmo tempo que direciona decisões metodológicas baseado nos dados obtidos. Os resultados apresentados podem ser considerados prometedores nesse sentido.

A Ciência pode ser comparada com explorar um labirinto, tem entradas que contém algum tesouro, outras têm algum outro agrado, e tem outras que "não levam a nada", mas essas entradas também são importantes porque estão oferecendo informação sobre aquilo que estudamos. É difícil ter certeza do conteúdo de cada braço desse labirinto que seria a "realidade", pois isso depende de quão exaustiva é nossa exploração. Parafraseando a Cham (2008), nosso trabalho como cientistas experimentais é puxar os limites das condições em que podemos afirmar com confiança o que está e o que não está acontecendo. É hora de fazer os esforços políticos e administrativos pertinentes para aproveitar ao máximo os recursos disponíveis, é impostergável o contato multidisciplinar com programadores e estatísticos que participem no desenvolvimento de melhores experimentos, aprimorando os modelos de análise e aumentando a capacidade de processamento da riqueza de dados 
possibilitada por um equipamento como o EyeLink. A complexidade do nosso objeto de estudo, o comportamento e suas motivações, exige de nós delineamentos experimentais tão ambiciosos e criativos quanto possível tecnicamente. 


\section{Referências}

Abler, B., Walter, H., \& Erk, S. (2005). Neural correlates of frustration. Neuroreport, 16(7), 669672

Akins CK. 2000. Effects of species-specific cues and the CS-US interval on the topography of the sexually conditioned response. Learn. Motiv. 31:211-35

Amsel A. (1992). Frustration theory: an analysis of dispositional learning and memory. Cambridge, UK: Cambridge University Press;.

Antonitis, J. J. (1951). Response variability in the white rat during conditioning, extinction, and reconditioning. Journal of Experimental Psychology, 42, 273-281.

Belke, T. W. (1992). Stimulus preference and the transitivity of preference. Animal Learning \& Behavior, 20, 401-406.

Bouton, M. \& Peck, C. (1992). Spontaneous recovery in cross-motivational transfer (counterconditioning). Animal Learning \& Behavior. 20 (4), 313-321

Brooks, Hale, Nelson, Bouton (1995).

Catania, C. (1999). Aprendizagem.

Crespi LP. (1942) Quantitative variation of incentive and performance in the white rat. Am J Psychol;40:467-517.

Cuenya, L., Kamenetzky, G., Fosacheca, S., \& Mustaca, A. E. (2013). Efecto de contraste sucesivo negativo en la valoración emocional de imágenes. Anales de psicología, 29(3), 944-952.

Domjan, M. (2016). JEAB.

Flaherty CF, Greenwood A, Martin J, Leszczuk M. (1998). Relationship of negative con-trast to animal models of fear and anxiety. Anim Learn Behav;26:397-407.

Guttman, A. (1977). Positive contrast, negative induction, and inhibitory stimulus control in the rat. Journal of the Experimental Analysis of Behavior, 27, 219-233.

Hall M, Irwin M (2001) Physiological indices of functioning in bereavement. In: Handbook of Bereavement Research (Stroebe MS, Hansson RO, Stroebe W, Schut H, eds), pp 473-492. Washington, DC: American Psychological Association

Halpern, J., Schwartz, J. A., \& Chapman, R. (1968). Simultaneous and successive contrast effects in human-probability learning. Journal of experimental psychology, 77(4), 581.

Herrnstein, R. J. (1970). On the law of effect. Journal of the Experimental Analysis of Behavior. 13, 243-266.

Holmqvist, K., Nyström, M., Andersson, R., Dewhurst, R., Jarodzka, H., \& Van de Weijer, J. (2011). Eye tracking: A comprehensive guide to methods and measures. OUP Oxford.

Jimenez-Garcia, A. M., Ruiz-Leyva, L., Cendan, C. M., Torres, C., Papini, M. R., \& Moron, I. (2016). Hypoalgesia induced by reward devaluation in rats. PLoS One, 10, 1-15.

Kodak, T., Fisher, W., Kelley, M. \& Kisamore, A. (2009). Comparing preference assessments: Selection- versus duration-based preference assessment procedures. Research in Developmental Disabilities. 30, 1068-1077.

Kehoe EJ, Graham-Clarke P, Schreurs BG. 1989. Temporal patterns of the rabbit's nictitating membrane response to compound and component stimuli under mixed CS-US intervals. Behav. Neurosci. 103:283-95

LeDoux J.( 2012). Rethinking the emotional brain. Neuron;73:653-76.

Mackintosh, N. J. (1974) The Psychology of Animal Learning. New York: Academic Press

Madelain, L., Champrenaut, L., \& Chauvin, A. (2007). Control of Sensorimotor Variability by Consequences, J Neurophysiol 98: 2255-2265

Madelain, L., Harwood, M. R., Herman, J. P., \& Wallman, J. (2010). Saccade adaptation is unhampered by distractors. Journal of Vision, 10(12):29, 1-14

Madelain, L, Paeye, C \& Wallman, J. (2011). Modification of saccadic gain by reinforcement, $J$ Neurophysiol 106: 219-232. 
Nevin, J. A. (1967). Effects of reinforcement scheduling on simultaneous discrimination performance. Journal of the Experimental Analysis of Behavior, 10, 251-260.

Papini MR. (2002) Pattern and process in the evolution of learning. Psychol Rev;109:186-201.

Papini MR. (2003) Comparative psychology of surprising nonreward. Brain Behav Evol;62:83-95.

Papini MR. (2006) Role of surprising nonreward in associative learning. Jpn J AnimPsychol;56:35-

54.

Papini MR, Wood M, Daniel AM, Norris JN. (2006). Reward loss as psychological pain.Int J Psychol Psychologic Ther;6:189-213.

Papini MR, (2014) Diversity of Adjustments to Reward Downshifts in Vertebrates International Journal of Comparative Psychology. 27(3), 420-445

Pessôa, C. V. B. B., Huziwara, E. M., Perez, W. F., Endemann, P., \& Tomanari, G. Y. (2009). Eye fixation to figures in a four-choice situation with luminance balanced areas. Journal of Eye Movement Research, 2, 1-6.

Rheinberger, H. (1997). Experimental Complexity in Biology: Some Epistemological and Historical Remarks. Philosophy of Science, 64, S245-S254. Retrieved from http://www.jstor.org/stable/188407

Repp, A. C., Barton, L. E., \& Brulle, A. R. (1983). A comparison of two procedures for programming the differential reinforcement of other behaviors. Journal of Applied Behavior Analysis, 16, 435-445.

Rupp, H. A., \& Wallen, K. (2007). Sex differences in viewing sexual stimuli: An eye-tracking study in men and women. Hormones and behavior, 51(4), 524-533.

Salamone, J. D., \& Correa, M. (2012). The mysterious motivational functions of mesolimbic dopamine. Neuron, 76(3), 470-485.

Scully J, Tosi H, Banning K (2000) Life event checklists: Revisiting the Social Readjustment Rating Scale after 30 years. Educ Psychol Measur 60:864-876.

Schmid, P. C., Mast, M. S., Bombari, D., Mast, F. W., \& Lobmaier, J. S. (2011). How mood states affect information processing during facial emotion recognition: an eye tracking study. Swiss Journal of Psychology.

Spence, K. W. (1956). Behavior theory and conditioning. New Haven, CT: Yale UniversityPress;

Tinklepaugh, O. L. (1928). An experimental study of representative factors in monkeys. J Comp Psychol;8:197-236.

Tomanari, G.Y. (2009). Resposta de observação: Uma reavaliação. Acta Comportamentalia, 17, 259-277.

Tomanari, G.Y., Balsamo, L.M., Fowler, T.R., Lombard, K.M., Farren, K.M., \& Dube, W.V. (2007). Manual and ocular observing behavior in human subjects. European Journal of Behavior Analysis, 8, 29-40.

Wangelin, B. C., Löw, A., McTeague, L. M., Bradley, M. M., \& Lang, P. J. (2011). Aversive picture processing: Effects of a concurrent task on sustained defensive system engagement. Psychophysiology, 48(1), 112-116.

Weinstein, L. (1972). Negative incentive contrast in humans with partial versus continuous reinforcement and repeated reductions in reward. Journal of Experimental Psychology, 94(2), 210.

Wyckoff, L.B.J. (1969). The role of observing responses in discrimination learning. In D.P. Hendry (Ed.). Conditioned Reinforcement (pp. 237-260). Homewood, Illinois: The Dorsey Press. 


\section{ANEXOS}

Anexo 1 Número das imagens do IAPS utilizadas no experimento, agrupadas por categoria, e acompanhada dos valores da escala de valência afetiva reportados por Lang, Bradley e Cuthbert (2008)

\begin{tabular}{|c|c|c|c|}
\hline Categoria & $\begin{array}{l}\text { Descrição das } \\
\text { imagens }\end{array}$ & $\mathbf{N}^{\circ}$ das imagens & $\begin{array}{c}\text { Media na } \\
\text { escala de } \\
\text { valência afetiva }\end{array}$ \\
\hline \multirow{6}{*}{ Erótica } & \multirow{6}{*}{$\begin{array}{l}\text { Mulheres } \\
\text { seminuas, nuas } \\
\text { ou casais } \\
\text { heterossexuais } \\
\text { em interação } \\
\text { erótica. }\end{array}$} & 400240044005400740084071 & \multirow[t]{2}{*}{7,40} \\
\hline & & 408540904141414241804225 & \\
\hline & & 423242354240429043004647 & Min: 6,28 \\
\hline & & 465146524658465946644668 & \multirow[t]{3}{*}{ Max: 8,21} \\
\hline & & 466946704672467746804681 & \\
\hline & & 468346904692469346954697 & \\
\hline \multirow{6}{*}{ Filhotes } & \multirow{6}{*}{$\begin{array}{l}\text { Bebés humanos } \\
\text { sozinhos ou } \\
\text { com adultos, e } \\
\text { filhotes de } \\
\text { outras espécies. }\end{array}$} & 141014401441146014631595 & \multirow[t]{2}{*}{7,01} \\
\hline & & 161016301710172117221750 & \\
\hline & & 181220402045205020572058 & \multirow{4}{*}{$\begin{array}{l}\text { Min: 5,08 } \\
\text { Max: 8,02 }\end{array}$} \\
\hline & & 206020702071207520802091 & \\
\hline & & 215121522153224022502260 & \\
\hline & & 233223442347265026552660 & \\
\hline \multirow{6}{*}{$\begin{array}{l}\text { Paisagens } \\
\text { naturais }\end{array}$} & \multirow{6}{*}{$\begin{array}{l}\text { Praias, } \\
\text { montanhas, } \\
\text { parques, flores. }\end{array}$} & 500050305199520052015210 & \multirow[t]{2}{*}{6,81} \\
\hline & & 521552205250526052705390 & \\
\hline & & 559456005611563156355660 & Min: 5,13 \\
\hline & & 570057115720572557265760 & Max: 8,05 \\
\hline & & $576457795780578158115814 \mathrm{j}$ & \\
\hline & & 58255900749274957580 & \\
\hline \multirow{6}{*}{$\begin{array}{l}\text { Locais } \\
\text { fechados }\end{array}$} & \multirow{6}{*}{$\begin{array}{l}\text { Prédios, } \\
\text { escritórios, } \\
\text { objetos } \\
\text { cotidianos. }\end{array}$} & 615070027003700470067009 & \multirow[t]{2}{*}{5,16} \\
\hline & & 701370147016701970207021 & \\
\hline & & 702370257032703470357042 & Min: 4,31 \\
\hline & & 704370457052705670577059 & Max: 7,4 \\
\hline & & 706270807090716571807217 & \\
\hline & & 723472357240750477007710 & \\
\hline \multirow{6}{*}{ Violência } & \multirow{6}{*}{$\begin{array}{l}\text { Cenas de } \\
\text { guerras, } \\
\text { assaltos, } \\
\text { espancamentos. }\end{array}$} & 301030153030306330683069 & \multirow[t]{2}{*}{2,71} \\
\hline & & 318131853190322535003530 & \\
\hline & & 602160226211621262136230 & \multirow{4}{*}{$\begin{array}{l}\text { Min: } 1,96 \\
\text { Max: } 4,25\end{array}$} \\
\hline & & 624263126313635065206560 & \\
\hline & & 682168319163925292539265 & \\
\hline & & 940094109413941494209428 & \\
\hline \multirow{6}{*}{ Doença } & \multirow{6}{*}{$\begin{array}{l}\text { Pessoas } \\
\text { exibindo dano } \\
\text { tissular (p.e. } \\
\text { queimaduras, } \\
\text { infecções). }\end{array}$} & 205320552095220527162718 & \multirow[t]{2}{*}{2,48} \\
\hline & & 273027502800300030163053 & \\
\hline & & 306230803100310131023103 & \multirow{4}{*}{$\begin{array}{l}\text { Min: } 1,5 \\
\text { Max: } 4,21\end{array}$} \\
\hline & & 313031313150316031683170 & \\
\hline & & 319532133220323032613266 & \\
\hline & & 330133509005904393259405 & \\
\hline
\end{tabular}




\author{
Universidade de São Paulo \\ Instituto de Psicologia \\ Departamento de Psicologia Experimental \\ TERMO DE CONSENTIMENTO LIVRE E ESCLARECIDO \\ (Obrigatório para Pesquisas em Seres Humanos - Resolução CNS nº 466/2012)
}

\title{
INFORMAÇÕES GERAIS DO ESTUDO
}

Você está sendo convidado como voluntário a participar da pesquisa: Movimentos oculares $\boldsymbol{e}$ aprendizagem: avaliação de um novo procedimento, coordenada por Adriana Saavedra Moreno, psicóloga e mestranda em psicologia experimental, sob a supervisão do Prof. Dr. Gerson Tomanari. Trata-se de uma pesquisa que visa estabelecer se as respostas oculares, que colocam aos organismos predominantemente visuais em contato com seu meio ambiente (como no caso dos humanos) seguem os mesmos padrões de aprendizagem que respostas periféricas (p.e. deslocamento), ou se existem diferenças por tratar-se de um órgão sensorial. Restrições técnicas fizeram com que, no passado, as respostas a essas perguntas fossem difíceis de obter, mas os equipamentos atuais de rastreamento ocular permitem superar essas limitantes e conseguem um maior grau de precisão e refinamento nas medições obtidas.

O estudo envolve a apresentação de imagens na tela de um computador enquanto a localização do olho é registrada. As imagens utilizadas foram tomadas do IAPS (International Afecttive Picture System), um banco internacional de imagens para a pesquisa experimental desenvolvido pelo Centro para o Estudo da Emoção e da Atenção (CSEA - pela sua sigla em inglês) da Universidade de Flórida. São muitas as publicações científicas que já usaram esse conjunto de imagens em pesquisas psicológicas ao redor do mundo, inclusive no Brasil.

Vale a pena aclarar que essa pesquisa não está propondo avaliar memoria, inteligência, raciocínio ou qualquer outra habilidade cognitiva. Também não pretende ser uma pesquisa sobre transtornos emocionais ou da personalidade, nem tenta ser usada no estudo, diagnóstico ou tratamento de qualquer condição psicológica ou psiquiátrica. No entanto, algumas dessas condições podem comprometer os resultados ou sua interpretação. Sem precisar dar nenhum detalhe adicional solicitarmos, por gentileza, informar ao pesquisador em caso de suspeita, diagnóstico ou de estar recebendo tratamento farmacológico e/ou terapêutico. É importante lembrar que não se trata de uma tarefa com erros ou acertos, pois a pesquisa pretende descrever o funcionamento normal dos movimentos oculares, e por isso o único desempenho correto é aquele que seja espontâneo.

\section{RISCOS E BENEFÍCIOS DA PARTICIPAÇÃO NESSA PESQUISA}

A atividade está programada para ser realizada durante uma única sessão com duração aproximada de 15 minutos no Laboratório F.S. Keller de Estudos do Comportamento Operante no Instituto de Psicologia da USP. Nesse intervalo é possível sofrer algum desconforto, pois deverá permanecer com a cabeça na mesma posição ao longo de todo o procedimento com ajuda de um suporte. Adicionalmente, de maneira semelhante ao que pode acontecer assistindo à televisão ou navegando pela internet, algumas das imagens utilizadas recriam situações com diversos graus de erotismo, violência ou náusea, o que pode ser desencadeador de alguma reação desagradável. No caso de 
desconforto decorrente do procedimento experimental existe a possibilidade de encaminhamento ao Centro de Atendimento Psicológico do nosso instituto.

Sua participação é essencialmente altruísta, quer dizer, não existe um benefício direto específico ou imediato para nenhum dos participantes da pesquisa. Mesmo quando não será disponibilizada nenhuma compensação financeira, caso você tenha qualquer despesa decorrente da participação na pesquisa (incluindo, mas não limitado a gastos com transporte ou alimentação), haverá ressarcimento dos valores gastos depois de concluir a atividade. Existe também a possibilidade de receber mais informações, aclarar suas dúvidas e de receber um relatório com os resultados gerais da pesquisa, caso você esteja interessado.

Contudo, sua participação é muito importante, pois se espera que a realização de estudos sobre o movimento ocular permita esclarecer mecanismos psicológicos básicos, e com isso, contribuir no desenvolvimento de novas e melhores intervenções para indivíduos com dificuldades no aprendizado. Como voluntário você poderá desistir de participar e/ou retirar o seu consentimento a qualquer momento durante ou depois da realização do procedimento, sua recusa não trará nenhum prejuízo ou penalidade em sua relação com o pesquisador ou com a instituição, pois sua participação não é obrigatória de forma alguma.

\section{GARANTIA DE ESCLARECIMENTO, SIGILO E LIBERDADE DE RECUSA.}

Os pesquisadores irão tratar a sua identidade com padrões profissionais de sigilo e confidencialidade. Seu nome ou o material que indique a sua participação não será liberado sem a sua permissão. Você não será identificado em nenhuma publicação que possa resultar deste estudo. Uma das vias deste consentimento informado será arquivada no Laboratório F.S. Keller de Estudos do Comportamento Operante do Instituto de Psicologia da Universidade de São Paulo e outra será fornecida a você.

\section{CONTATOS E ESCLARECIMENTOS}

Qualquer dúvida entre em contato com a pesquisadora responsável Adriana Saavedra Moreno através do telefone (+57 11) 3091-1902 ou pelo e-mail asaavedram@usp.br. Se você tiver alguma consideração ou dúvida sobre a ética dessa pesquisa, pode entrar em contato com o Comitê de Ética em Pesquisa (CEP) do Instituto de Psicologia da Universidade de São Paulo, pelo Av. Prof. Mello Moraes, 1721, Bloco G, sala 27- Cidade Universitária - São Paulo/SP - CEP: 05508-030. Telefone (11) 3091-4182, e-mail ceph.ip@usp.br.

Caso você concorde em participar desse estudo, por favor, leia as seguintes afirmações e indique seu consentimento.

$\mathrm{Eu}$, identificado com o $\mathrm{N}^{\circ}$ declaro que:

Sou maior de 18 anos

Não omiti informações importantes sobre minha saúde visual.

Entendi os objetivos gerais do estudo, conheço os riscos e benefícios de minha participação, entendi o procedimento e o que posso esperar dele. 
Compreendo que minha participação nesse estudo é voluntaria e que posso me retirar a qualquer momento e por qualquer motivo sem ter que dar explicações ao pesquisador.

Compreendo que minha participação nesse estudo é com propósitos de pesquisa, e que não constitui de forma nenhuma uma avaliação de mim como indivíduo.

Consinto que os dados gerados pelo equipamento de rastreamento ocular sejam armazenados como parte do estudo.

Compreendo que qualquer informação armazenada nessa pesquisa permanecerá anônima e confidencial, e que nenhuma informação que me identifique será disponível.

Compreendo que posso entrar em contato com os pesquisadores, a mestranda ADRIANA SAAVEDRA MORENO, e/ou o professor orientador GERSON TOMANARI no telefone (+57 11) 3091-1902, ou pelo correio electrónico asaavedram@usp.br para receber mais informações e/ou um resumo dos resultados gerais obtidos.

Compreendo que posso entrar em contato com o Comitê de Ética em Pesquisa (CEP) do Instituto de Psicologia da Universidade de São Paulo se tiver alguma consideração ou dúvida a respeito dos aspectos éticos dessa pesquisa.

Recebi uma via assinada e datada deste documento e é do meu conhecimento que outra via assinada e datada será arquivada no Laboratório F.S. Keller de Estudos do Comportamento Operante do Instituto de Psicologia da Universidade de São Paulo.

São Paulo, dia do de 201

Participante

email

Nome
Pesquisadora

Adriana Saavedra Moreno 
Anexo 3. Combinatória e controle das Tentativas de Treino, tentando manter a simetria para evitar vieses. Para cada quadrante (A-B-C-D) têm oito Fotografias de cada categoria. Em Negrito aparecem as Fotografias antecedidas pela Figura geométrica Random (seis de cada categoria, nove em cada quadrante). Cada combinação possível entre as categorias (Eros-PA; Eros-PF; Eros-Sick; Eros-V: BB- PA...) aparece seis vezes, e aquelas com a mesma valência emotiva (Positivas: Eros-BB; PA-PF; Sick-V) aparecem oito vezes. (Técnica estatística: cubo de Einstein). As tentativas foram aleatorizadas durante o experimento.

\begin{tabular}{|c|c|c|c|c|}
\hline Trial & A & B & C & D \\
\hline 1 & $x$ & $x$ & Eros & BB \\
\hline 2 & $x$ & Eros & BB & $x$ \\
\hline 3 & BB & $x$ & $x$ & Eros \\
\hline 4 & $x$ & BB & $x$ & Eros \\
\hline 5 & Eros & $x$ & BB & $x$ \\
\hline 6 & Eros & BB & $x$ & $x$ \\
\hline 7 & $x$ & Eros & $x$ & BB \\
\hline 8 & BB & $x$ & Eros & $x$ \\
\hline 9 & PA & Eros & $x$ & $x$ \\
\hline 10 & Eros & $x$ & PA & $x$ \\
\hline 11 & PA & $x$ & $x$ & Eros \\
\hline 12 & $x$ & PA & Eros & $x$ \\
\hline 13 & $x$ & Eros & $x$ & PA \\
\hline 14 & $x$ & $x$ & Eros & PA \\
\hline 15 & PF & Eros & $x$ & $x$ \\
\hline 16 & Eros & $x$ & PF & $x$ \\
\hline 17 & $\mathrm{PF}$ & $x$ & $x$ & Eros \\
\hline 18 & $x$ & PF & Eros & $x$ \\
\hline 19 & $x$ & Eros & $x$ & PF \\
\hline 20 & $x$ & $x$ & Eros & PF \\
\hline 21 & Eros & Sick & $x$ & $x$ \\
\hline 22 & Sick & $x$ & Eros & $x$ \\
\hline 23 & Eros & $x$ & $x$ & Sick \\
\hline 24 & $x$ & Eros & Sick & $x$ \\
\hline 25 & $x$ & Sick & $x$ & Eros \\
\hline 26 & $x$ & $x$ & Sick & Eros \\
\hline 27 & Eros & V & $x$ & $x$ \\
\hline 28 & V & $x$ & Eros & $x$ \\
\hline 29 & Eros & $x$ & $x$ & V \\
\hline 30 & $x$ & Eros & V & $x$ \\
\hline 31 & $x$ & V & $x$ & Eros \\
\hline 32 & $x$ & $x$ & V & Eros \\
\hline
\end{tabular}

\begin{tabular}{|c|c|c|c|c|}
\hline Trial & A & B & C & D \\
\hline 33 & PA & BB & $x$ & $x$ \\
\hline 34 & BB & $x$ & PA & $x$ \\
\hline 35 & PA & $x$ & $x$ & BB \\
\hline 36 & $x$ & PA & BB & $x$ \\
\hline 37 & $x$ & BB & $x$ & PA \\
\hline 38 & $x$ & $x$ & BB & PA \\
\hline 39 & PF & BB & $x$ & $x$ \\
\hline 40 & BB & $x$ & PF & $x$ \\
\hline 41 & PF & $x$ & $x$ & BB \\
\hline 42 & $x$ & PF & BB & $x$ \\
\hline 43 & $x$ & BB & $x$ & PF \\
\hline 44 & $x$ & $x$ & BB & PF \\
\hline 45 & BB & Sick & $x$ & $x$ \\
\hline 46 & Sick & $x$ & BB & $x$ \\
\hline 47 & BB & $x$ & $x$ & Sick \\
\hline 48 & $x$ & BB & Sick & $x$ \\
\hline 49 & $x$ & Sick & $x$ & BB \\
\hline 50 & $x$ & $x$ & Sick & BB \\
\hline 51 & BB & $\mathrm{V}$ & $x$ & $x$ \\
\hline 52 & $\mathbf{v}$ & $x$ & BB & $x$ \\
\hline 53 & BB & $x$ & $x$ & $\mathrm{~V}$ \\
\hline 54 & $x$ & BB & V & $x$ \\
\hline 55 & $x$ & V & $x$ & BB \\
\hline 56 & $x$ & $x$ & V & BB \\
\hline 57 & PF & PA & $x$ & $x$ \\
\hline 58 & $x$ & PF & PA & $x$ \\
\hline 59 & PA & $x$ & $x$ & PF \\
\hline 60 & $x$ & PF & $x$ & PA \\
\hline 61 & PA & $x$ & PF & $x$ \\
\hline 62 & $x$ & $x$ & PF & PA \\
\hline 63 & $x$ & PA & $x$ & PF \\
\hline 64 & PF & $x$ & PA & $x$ \\
\hline
\end{tabular}

\begin{tabular}{|l|l|l|l|l|}
\hline Trial & \multicolumn{1}{|c|}{ A } & \multicolumn{1}{|c|}{ B } & \multicolumn{1}{|c|}{ C } \\
\hline 65 & Sick & PA & x & x \\
\hline 66 & PA & x & Sick & x \\
\hline 67 & Sick & x & x & PA \\
\hline 68 & x & Sick & PA & x \\
\hline 69 & x & PA & x & Sick \\
\hline 70 & x & x & PA & Sick \\
\hline 71 & V & PA & x & x \\
\hline 72 & PA & x & V & x \\
\hline 73 & V & x & x & PA \\
\hline 74 & x & V & PA & x \\
\hline 75 & x & PA & x & V \\
\hline 76 & x & x & PA & V \\
\hline 77 & Sick & PF & x & x \\
\hline 78 & PF & x & Sick & x \\
\hline 79 & Sick & x & x & PF \\
\hline 80 & x & Sick & PF & x \\
\hline 81 & x & PF & x & Sick \\
\hline 82 & x & x & PF & Sick \\
\hline 83 & V & PF & x & x \\
\hline 84 & PF & x & V & x \\
\hline 85 & V & x & x & PF \\
\hline 86 & x & V & PF & x \\
\hline 87 & x & PF & x & V \\
\hline 88 & x & x & PF & V \\
\hline 89 & V & Sick & x & x \\
\hline 90 & x & x & Sick & V \\
\hline 91 & x & Sick & V & x \\
\hline 92 & x & V & Sick & x \\
\hline 93 & Sick & x & x & V \\
\hline 95 & X & Xick \\
\hline
\end{tabular}


SÃO PAULO, BRASIL

2017 